\title{
Does Architecture Dream of Upheaval?
}

\author{
by
}

Lu Yao Ji

A thesis submitted to the Faculty of Graduate and Postdoctoral

Affairs in partial fulfillment of the requirementsfor the degree of

Master of Architecture

Carleton University

Ottawa, Ontario

(C) 2015

Lu Yao Ji 


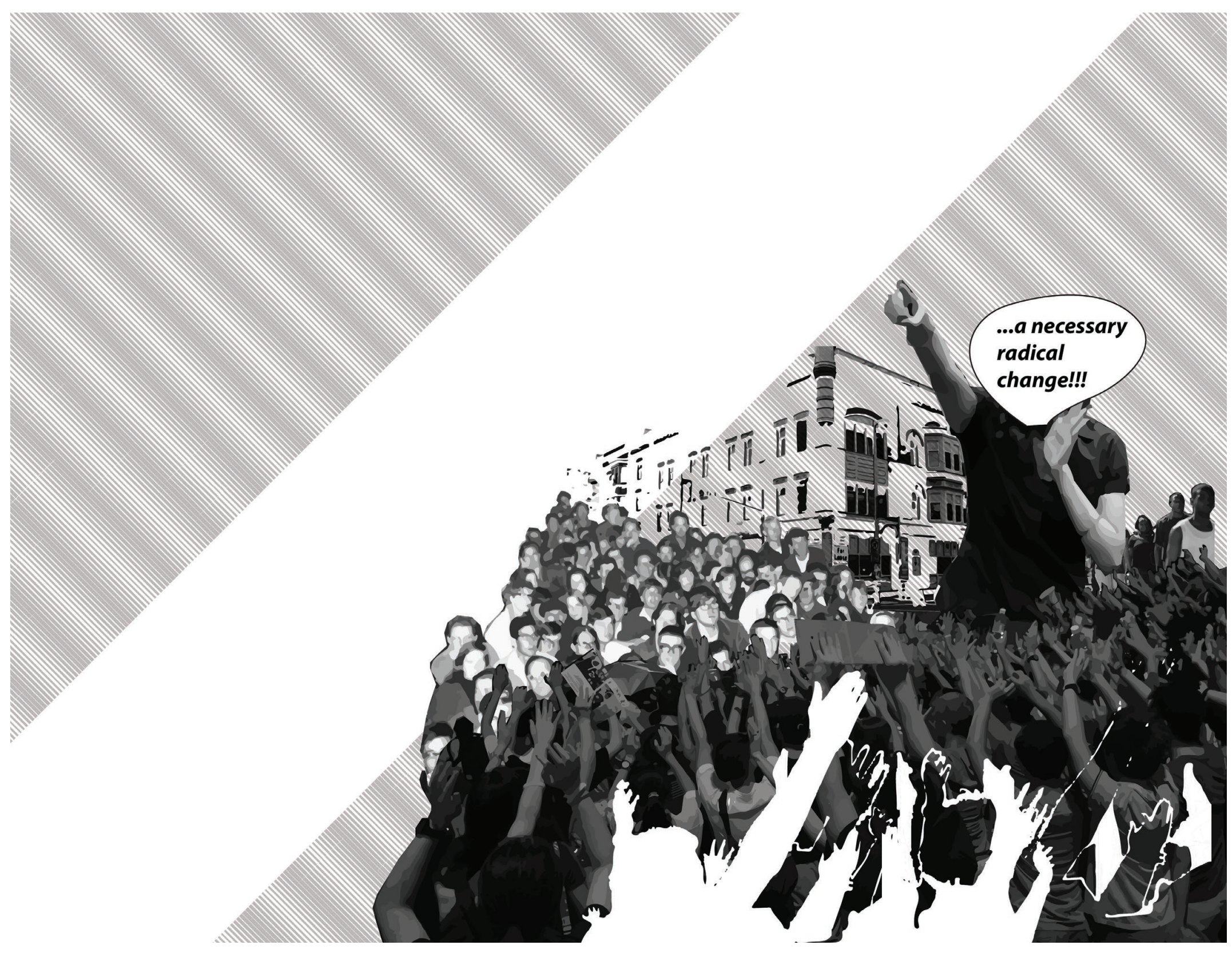




\section{TABLE OF CONTENT}

$\begin{array}{lc}\text { Acknowledgment } & \text { i } \\ \text { Reader's Guide } & \text { ii } \\ \text { Map of Words } & \text { iii }\end{array}$

Abstract

PART ONE

words from editor:

Does Architecture Dream of Upheaval?

PART TWO

Observations:

How Far is Kashgar from Shenzhen? 12

Rest Not in Peace: WTC

Common Ground: $\quad$ Side A 32

Side B $\quad 38$ 


\section{PART THREE}

Performance:

The Site of Upheaval

$\begin{array}{cc}\text { Introduction } & 46 \\ \text { Origin: Location } & 48 \\ \text { Story } & 51\end{array}$

Future: A Speculative Alternative

On Stage

“Does Architecture Dream of Upheaval?”

Act I

scene $0 \quad$ What Is in the Shell?

scene $1 \quad$ An Exploded History

scene 2 A House Mix

71

72

Act II

scene $1 \quad$ Turning the Gear

scene 2

Robotics to Rebuild

77

scene 3

Welcoming the $1 / 4$ Offices 
Act III

scene $1 \quad$ A Day in the Big Box Office

scene 2 Powernap! 82

scene $3 \quad$ Overtime (1) 83

scene $4 \quad$ Overtime (2)

Act IV

$\begin{array}{lll}\text { scene } 1 & \text { Cinema on a Hill }\end{array}$

$\begin{array}{lll}\text { scene } 2 \text { Generator: Buoyancy } & 87\end{array}$

$\begin{array}{lll}\text { scene2.5 Generator: Regenerator } & 89\end{array}$

$\begin{array}{lll}\text { scene } 3 & \text { Underwater }\end{array}$

Act V

scene $0 \quad$ Everyone Wants a Piece of the Cake 93

$\begin{array}{lll}\text { scene } \infty & \text { The Uplift } & 98\end{array}$

Keeping the City Afloat $\quad 102$ 


\section{Acknowledgment}

Thanks to Roger Connah, my thesis advisor, for being extremely supportive and inspiring throughout the entire time of producing this piece of work

Thanks to mom and dad for their unconditional love half way across the World.

Thanks to LMP, an amazing friend that fixes my grammar errors.

Thanks to my little cactus for sitting quietly in front of my computer when I work

Thanks to all my friends. 

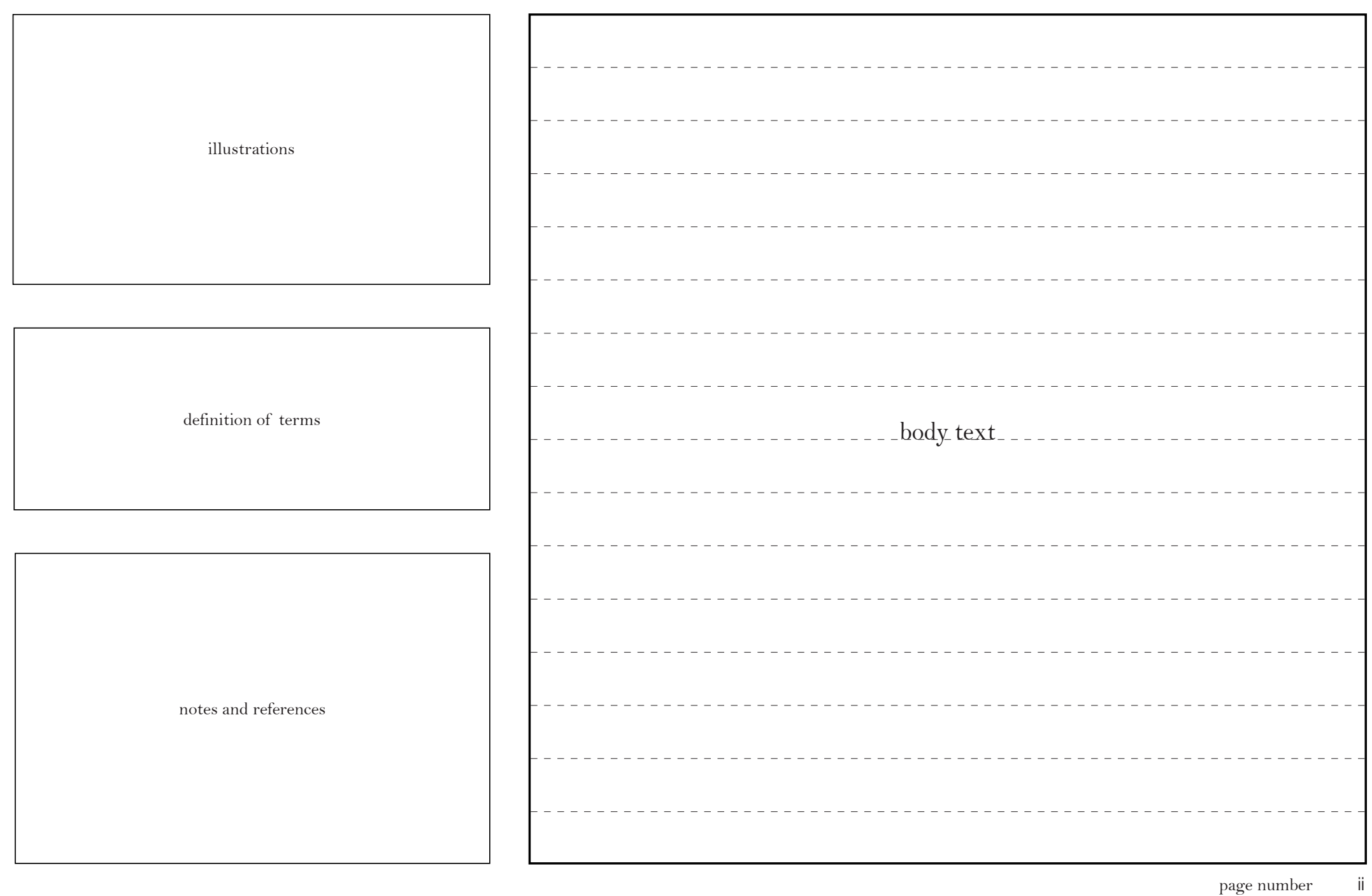


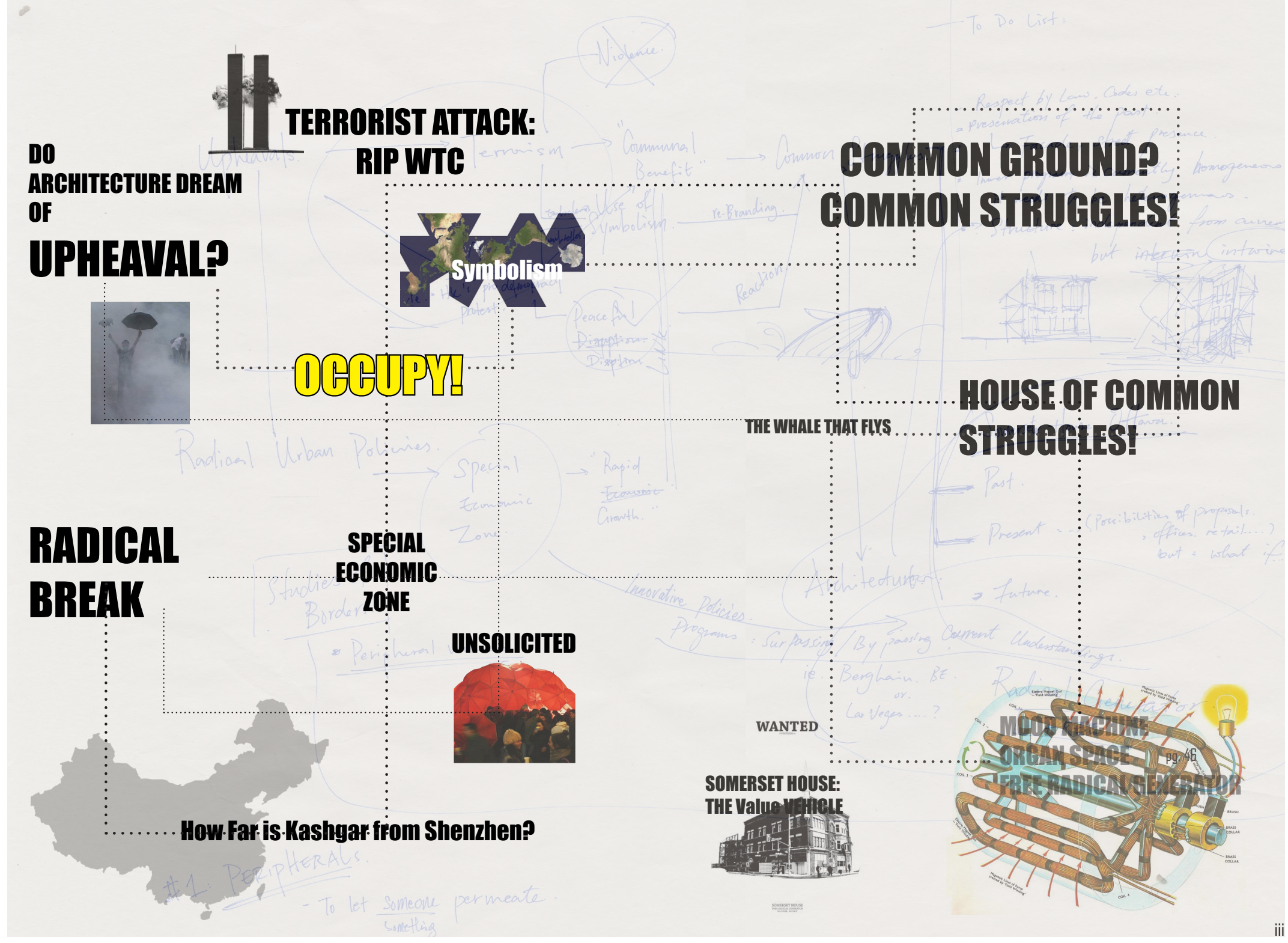




\section{UPHEAVAL}

1. SEZ: Special Economic Zone

Chinese (Pinyin) jingji tequ or (Wade-Giles romanization) chingchi t'e-chü, any of several localities in which foreign and domestic trade and investment are conducted without the authorization of the Chinese central government in Beijing. Special economic zones are intended to function as zones of rapid economic growth by using tax and business incentives to attract foreign investment and technology.

"Special economic zone (SEZ)", accessed October 27, 2014, last modified April 20, 2009,http://www.britannica.com/EBchecked/ topic/558530/special-economic-zone-SEZ

\section{Kashgar}

In 2011, the city of Kashgar is appointed a SEZ using Shenzhen as its development model hence started the on-going friction between the newly introduced Han culture and the local Uyghur culture.

3. Shenzhen

A city bordering Hong Kong, designated in 1979 under the Deng Xia Ping regime as one of China's first SEZs. Under priviliged policie and convinient access to Hong Kong, a free port, Shenzhen has become the fastest growing city in China.

4. Upheaval

Noun, Definition:

1: the action or an instance of upheaving especially of part of the earth's crust

2: extreme agitation or disorder : radical change

"Upheaval" accessed October,27,2014, http://www.merriam-

webster.com/dictionary/upheaval.
This document is written as a journal. The passage begins by drawing connections between the advancement of China's Special Economic Zones ${ }^{1}$ (SEZ) and the implementation of SEZ in Kashgar ${ }^{2}$ in 2010 using a pre-existing model succeeded in Shenzhen ${ }^{3}$. The observation of the change in urban conditions through rapid development is heightened with the outbreak of the upheaval in Kashgar four years into its transformation from the historic silk-road trading hub to the newly destined economic frontier of China. The sudden disturbance brings the previously unspoken dilemma of SEZ under the spotlight: an interesting phenomenon of violent disruption brought by the frictions between the old and new.

An upheaval ${ }^{4}$, where unsolicited violence has bloomed is a child to the social, political, and economic condition. It is neither a leader nor a follower.

Upheaval expresses a different scenario that coexists within the larger cultural context; it re-examines the context it is situated in and generates new conditions. Upheaval demonstrates a collective behavior that is attempting to grab onto an alternative way towards the future. Considering the leading 
culture of architecture today, instead of preserving the loss, embracing the cycle of degeneration and regeneration as continuous events can result in an alternative strategy for architectural conservation. In the process of introducing such a concept, can architecture take the form of an upheaval, a radical break that resonates enough to generate shared emotions?

Wolf D. Prix's of the Austrian studio Coop Himmelb(1)au was once fascinated by a leaping whale which exemplified an amazement brought on by disruption: "I was in a boat and the water is very calm but I could feel that there was something moving under the surface. All of a sudden the animal emerged and jumped 15 meters high. You have to imagine it: a 30-tonne, floating, flying object". ${ }^{5}$ The figure of heaviness transitions from one medium to another. As from water to air through its power to defeat the confinement of gravity, the leaping whale disrupts the tranquility of both water and air as it flies.

Can architecture become an upheaval disrupting the clearly defined social values in this example of the leaping whale? In the search for a speculative architecture 
the rhizome ${ }^{6}$, re-appropriating not only on a map, but through a network that suggests an alternative set of parameters influencing architecture and urbanism.

This rhizome does not offer a solution to existing architectural difficulties, rather it aims to generate a radical uplift of possibilities: an upheaval, in this senses an architectural performance. The architectural upheaval resembles the great leap of a thirty-ton whale in the ocean: in struggle, it jumps for survival.

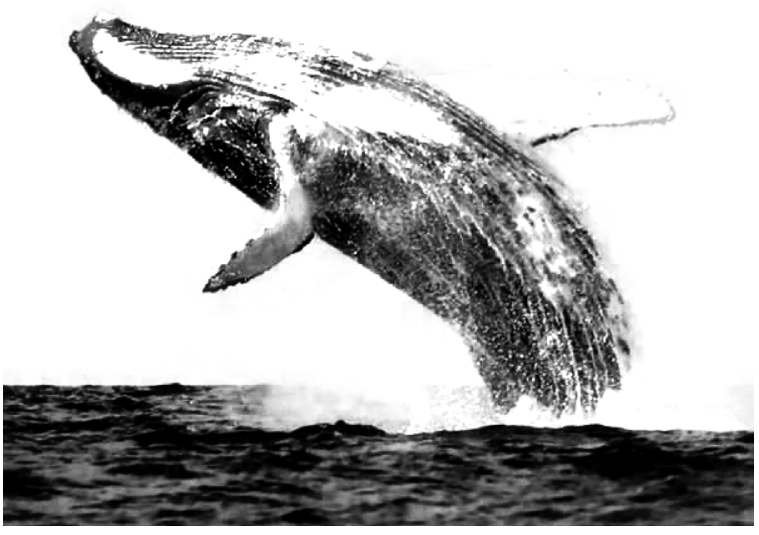


PART I

INTRODUCTION 


\section{DOES ARCHITECTURE}

DREAM

OF UPHEAVAL?

Constantly switching my mind between a rather conservative Canadian context and the aggressive boom of Chinese mega-cities, I began to contemplate what the act of constructing architecture has to offer to a city in its progression into a "metropolis". To the Chinese mega-cities, it is a race, a competition to transform the image of a once "developing country" into one of the most impressive performances under the spotlight of the global economy. The transformation of Chinese megacities bears the pain and the struggle of endless debate. From this progression, the seemingly ruthless competition of "producing architecture" in Chinese megacities has projected a certain power, brilliance and an unlimited possibility carried out under confinement and constraint.

The thought of transplanting nuances from different social issues into architectural scenarios was sharpened after visiting a newly developed 
7. Other Spaces Michel Foucault discussed the term "heterotopia" in his 1984 journal "Des Epaces Autres", translated to English as Other Spaces. Briefly described with six principles, the Other Spaces elaborates the multiplicity and its denial of singularity. A space is always a collective space of zones, enclaves, separations, and interconnections

Foucault, Michel,"Des Espace Autres," March 1967, Architecture / Movement/ Continuité October, 1984, Translated from the French by Jay Miskowiec, accessed February 27 2015, http://web.mit.edu/

allanmc/www/foucault1.pd
Special Economic Zone (SEZ), in Xinjiang, China. Bordering Tajikistan and Kyrgyzstan, the city of Kashgar is deemed an ideal gateway to Central Asia. Kashgar was listed as an SEZ in 2010, hence starting the massive construction of a "new metropolis". Unlike the Shenzhen SEZ, which has seen enormous success since its inception in 1979, Kashgar appears extremely vulnerable. Through a series of radical events, the coexistence of governmental power and vernacular habitat in the new Kashgar SEZ unfolds interesting phenomena that further exemplify intricate connections between the urban and its "other spaces” A heterotopia, as described by Michel Foucault as a space of coexistence. ${ }^{7}$

My first visit to the city of Kashgar was in 2012. Underneath the hypermodernized skyline, donkeys and cars shared lanes, portable shops occupied sidewalks selling dry produce, spices, and lamb, and hanging balconies became vegetable gardens. It appeared that life continued undisrupted by the massive construction. In harmony with the new constructions, the old vernacular dwellings stand quietly with the Mu-shih-t'a-ko Mountain Range, the landmark of the Kashgar Region, afar as its backdrop. However, this harmony would not last long. 
New implementation in Kashgar: a generic development copying and pasting the SEZ model from Shenzhn /Image: Lu Yao Ji

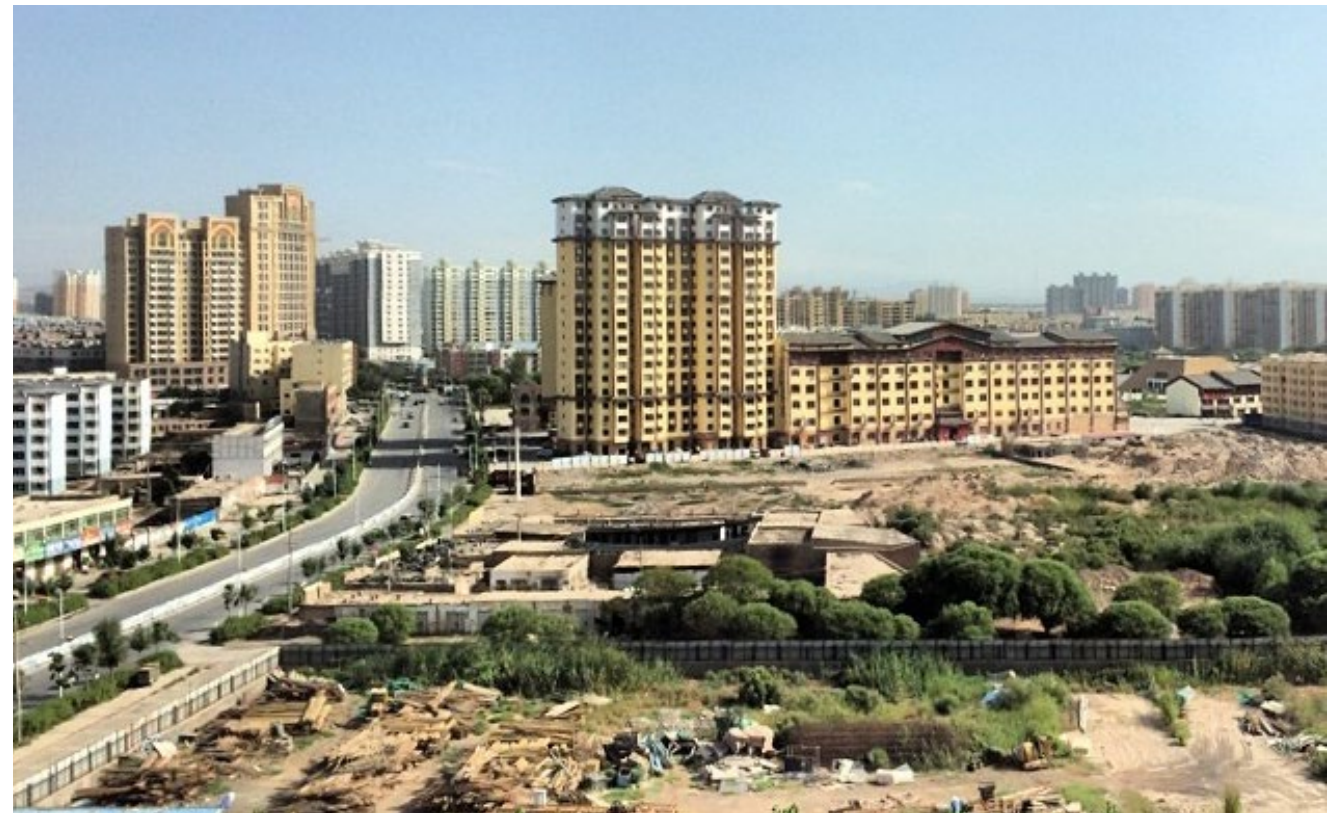

Soldiers stand guard outside the Id Kah mosque in Kashgar, Chin after the assassination of the Chief Imam /Image: Kevin Frayer

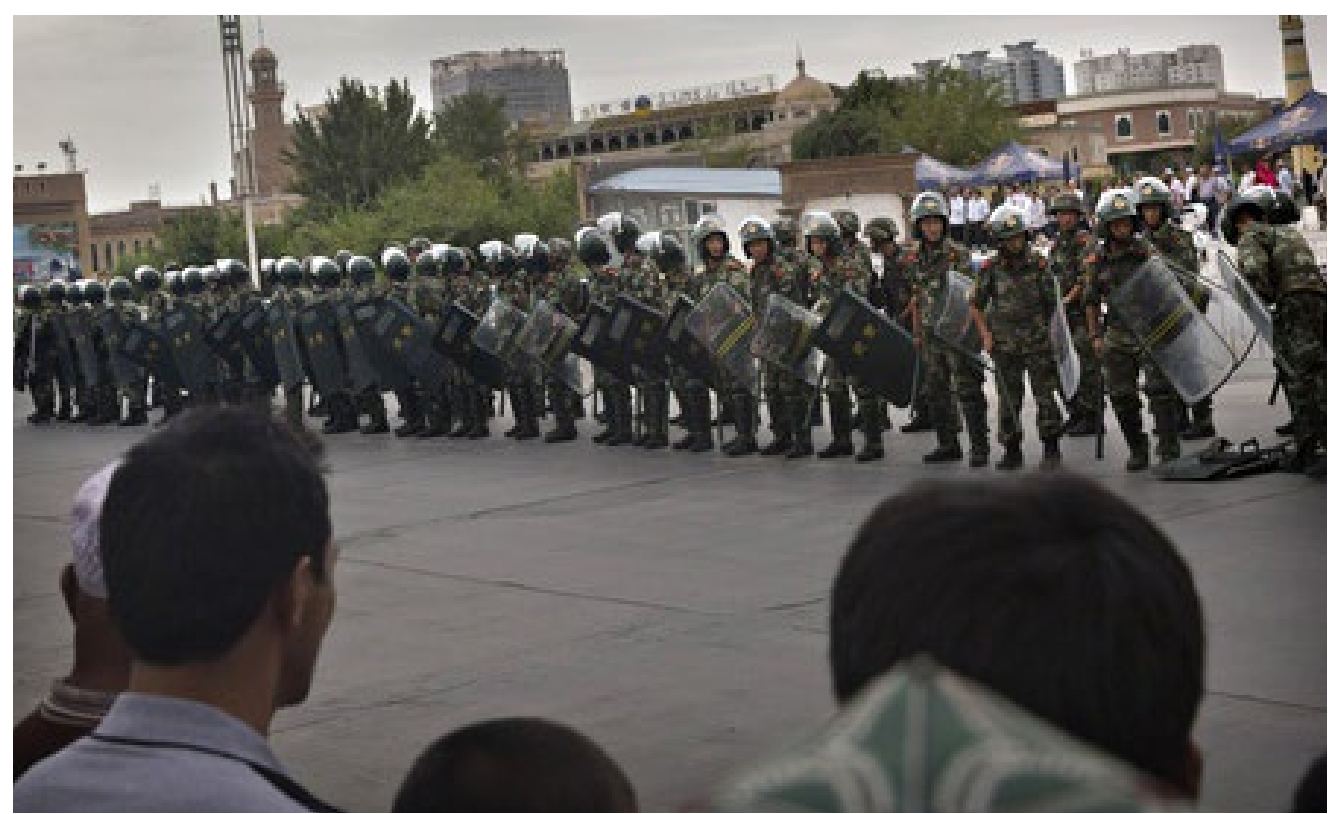


8. "Chief imam at Kashgar mosque stabbed to death as violence surges in Xinjiang" The Guardian, accessed October 272014 http://www.theguardian.com/world/2014/jul/31/china-jume-tahirimam-kashgar-xinjiang-mosque-stabbed-death-violence 9. Eid al-Fitr A Muslim celebration at the end of fasting 10. The Guardian referenced an Editorial on Tianshan, the government run website of Xinjiang

"Chinese authorities tighten security in Xinjiang region after surge in violence" The Guardian, date published July 30, 2014 accessed October 27 2014, http://www.theguardian.com/world/2014/ $\mathrm{jul} / 30 /$ chinese-tighten-security-xinjiang-violence-uighur-muslimminority

11. Id Kah Mosque the largest mosque in China, also a known tourism destination in Kashgar

On July 30th, the city suddenly became a site of fear, anger, and confusion within a few hours of a violent outbreak in a peripheral township of Kashgar Region, followed by the assassination of the chief Imam. ${ }^{8}$ The effects continued to reverberate within the community and disrupted the "society in harmony" which the government has been trying to construct. These actions, along with the upheaval suddenly turned the "special economic miracle" into a site of perfectly choreographed murder. An editorial on Tianshan, the Xinjiang government-run website, read: "The terrorists chose the day before Eid al-Fitr ${ }^{9}$ to carry out this attack, showing that they wanted to create an atmosphere of fear among the Muslim public and rampantly incite troubles. They deliberately tried to link the terror attack to religion, hoping to create a greater trouble." ${ }^{10}$ Unlike usual gatherings for prayer at the Id Kah Mosque ${ }^{11}$ during Eid al-Fitr, after the incident thousands of Uyghur's gathered at the Mosque, mourning and questioning whether the mainland's implementation of a SEZ would actually improve their living conditions. The tension between the gathering crowds and the soldiers intensified drastically, but the Id Kah Mosque stood there unmoved. However, now while it was once the site of celebrations, it will be forever linked to the fear and 


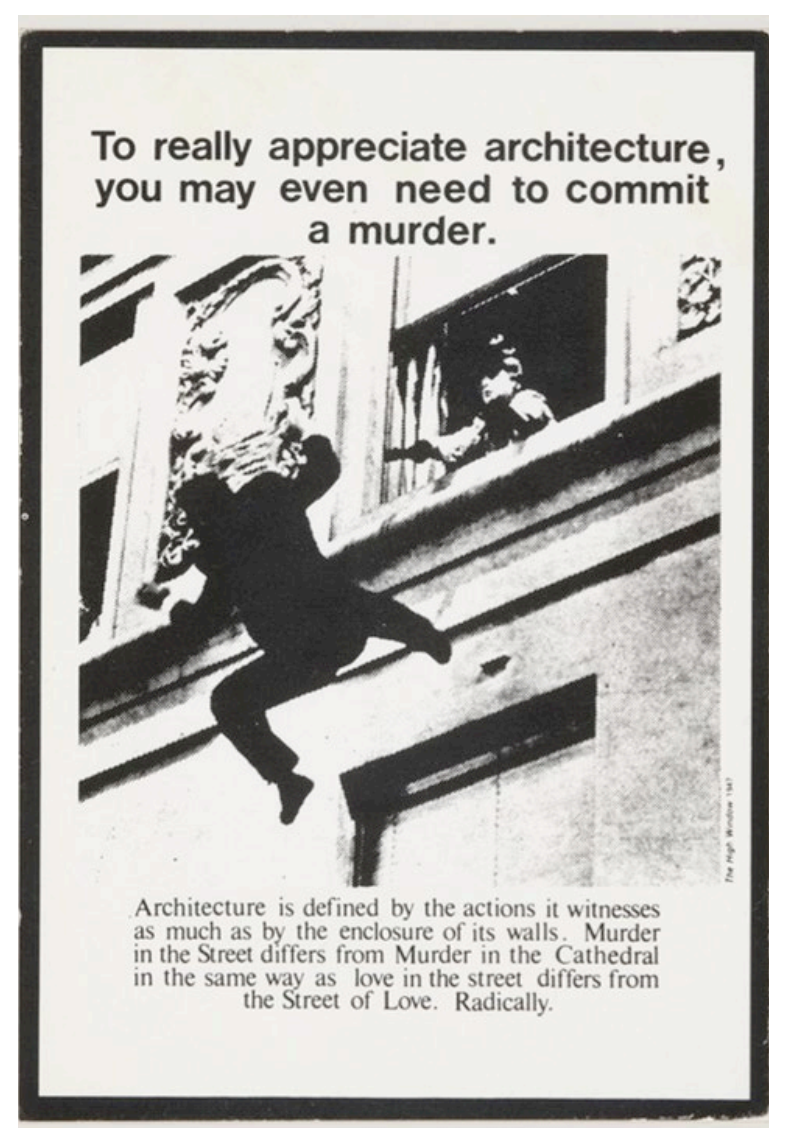

Bernard Tschumi,

Advertisement for Architecture 1966-1967

12. Cairns,Stephen, Jacobs,M. Jane. Buildings Must Die: A Perverse View of Architecture. pg43 .MIT Press. May 2014 confusion heightened by the assassination. For the Uyghurs, the mosque will always be their shelter, but for the tourists, the once respectful sight-seeing destination has become a place that speaks of tension, murder, and violence.

Architecture never changes. What changes is the events that it witnesses and participates. By observing the upheavals and how such unsolicited events became effective in gaining social awareness and public interest rapidly and powerfully we might ask, why architecture remains a spectator in silence? Regardless what the public desires, architecture itself will always participate and be part of the world we conceive. As Architect Bernard Tschumi stated in his Advertisement for Architecture, "Architecture, from this perspective, is defined less by the materiality of its built form, and more by its interaction - in this case as 'witness' of and collaborator in a murder - with the event world that unfolds in and around it." ${ }^{12}$ His series of postcardsized juxtapositions of words and images suggested that the repetitive reproduction of "advertisements of the products of architecture" vastly contrasts from any singular architecture that is communicating beyond the imagery on paper. Through Advertisement for Architecture, architecture as means of production is reproduced via publicity. Analogically "witness 
of a murder", when advertisements and other devices are associated with architecture, the inherent plurality of architecture is immediately revealed.

If architecture witnesses struggles, does it amplify the agony of that struggle and make it common?

If architecture is like an advertisement seen by the world, does it use publicity to promote values? In what way can the aesthetics of political movements influence an architectural opinion emerging from the nonhierarchical formation of an upheaval? Suddenly the line of evolution of one discipline detaches and appropriates in complete disregard to the preconceived boundaries of other disciplines. The rhizomatic nature exemplified through globalization does not imply more rules and limits on how one should approach architecture, but a new set of parameters to evaluate architecture's situation in this rhizome of an unimaginable number of systems.

Architecture, in opposition to being a spectator of events and a mediator of publicity, now needs to participate proactively not passively. Tracing back 
to the upheavals in Kashgar, collapsing the dream of a "special economic miracle" with such speed and impact, why can we not let architecture become an upheaval? In other words, the collapse of an idealized imagery could reveal the early opportunities for a radical change. It is not the upheaval that causes destruction: in fact it is the act of non-action that destroys the present with a harmless and silent aesthetic. Wolf Prix of Coop Himmelb(L)au stresses the expressiveness of the architectural forms in his early works, suggesting not only a balance of form and function but a coexistence of physical plasticity, the language of communication, and the multiplicity of functions. Architecture by his definition is neither a spectator nor an observer. It should be a performer in action engaging the observers in an almost disruptive way. His narrative for his 1984 installation "Blazing Wing" is self-destructing. However, through the struggle of the steel structure coexisting with the flame and heat, the radiation of heat impacts on its surrounding environment as its own struggle continues. 


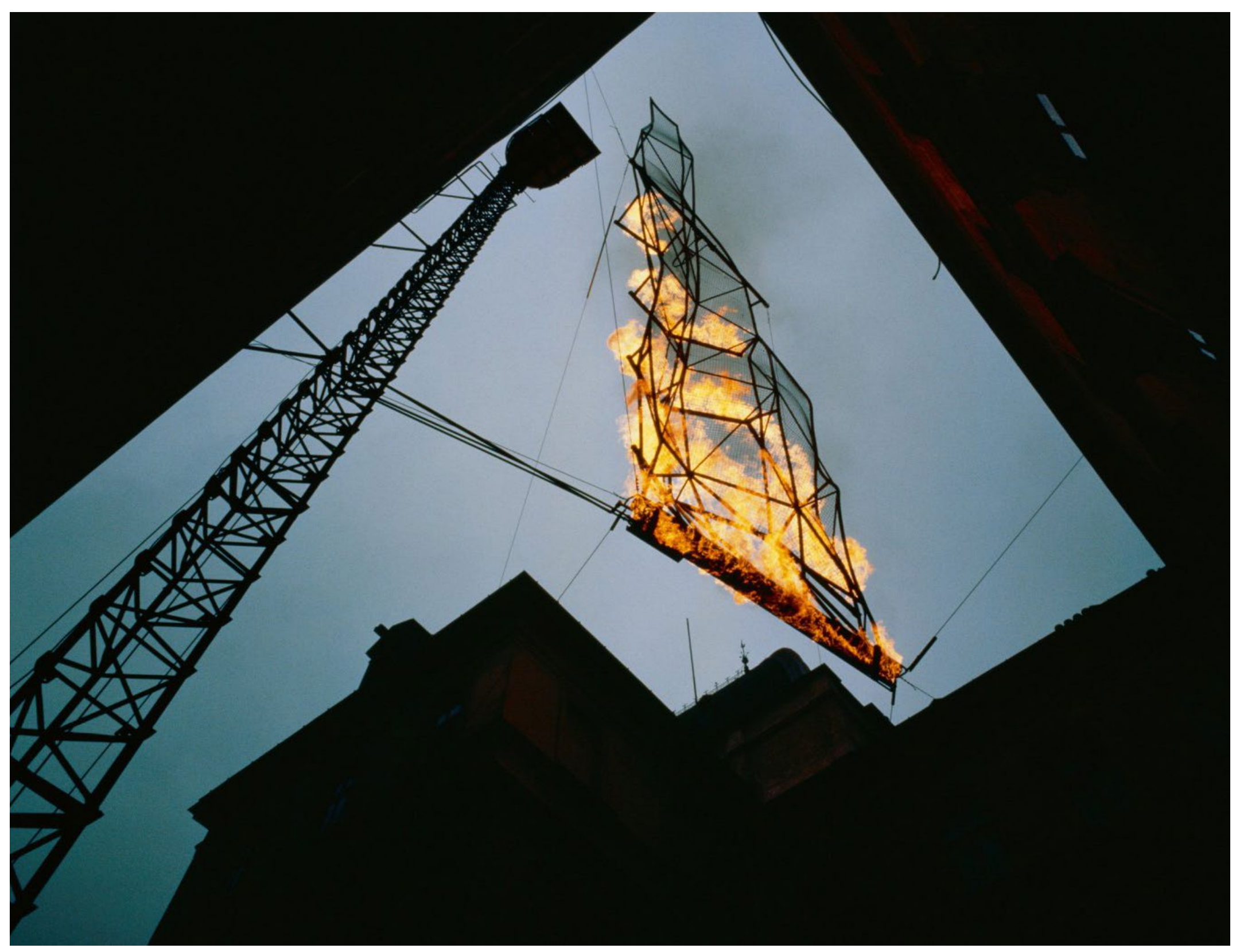


If cold, then cold as a block of ice.

If hot, then hot as a blazing wing.

\section{Architecture must blaze. ${ }^{13}$}

\section{Wolf D. Prix COOP HIMMELB(L)AU}

Prix uses "as" and "must" to urge the role of architecture, but let us reinterpret his manifestation in context to the shifted paradigm of the new millennium:

Let architecture be a cold block of ice.

Let architecture be a hot blazing wing. 
PART II

OBSERVATIONS 
Observation One:

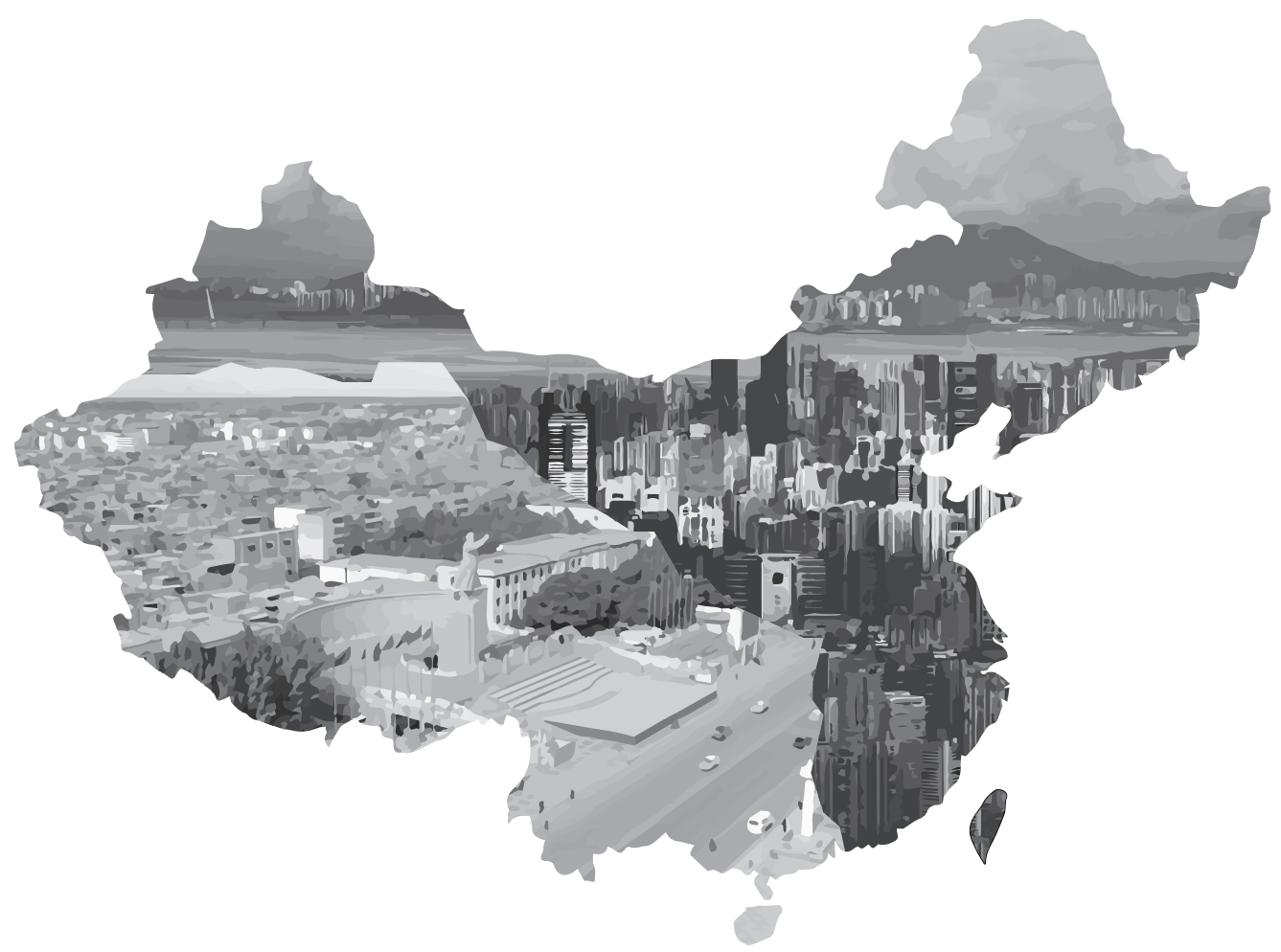




\section{HOW FAR IS KASHGAR FROM}

\section{SHENZHEN?}

Kashgar is a special case. Not only in that it is the new economic frontier of Northwest China, it is also a site of conflict. With the area designated as a Special Economic Zone in 2010, rapid demolition and construction has begun to proliferate on the homeland of the Uyghur. To further densify and intensify the urban area of Kashgar, the government policy rewards migrants and local Uyghurs who contribute to the massive urban restructuring project. The policy that allows two children per family subsidized housing and subsidized post-secondary education has attracted a significant amount of Han population from all over China to settle in Kashgar, alongside the opportunities in the construction and trading industry. In order to further the development of a Special Economic Zone, Shenzhen was appointed by the government of China to support Kashgar's development. This move will obviously introduce a completely new species of urban conditions into the ecology of Kashgar thereby changing the city's urban fabric and cultural landscape. 
A clear division between the new development supported by

source:Tianshan

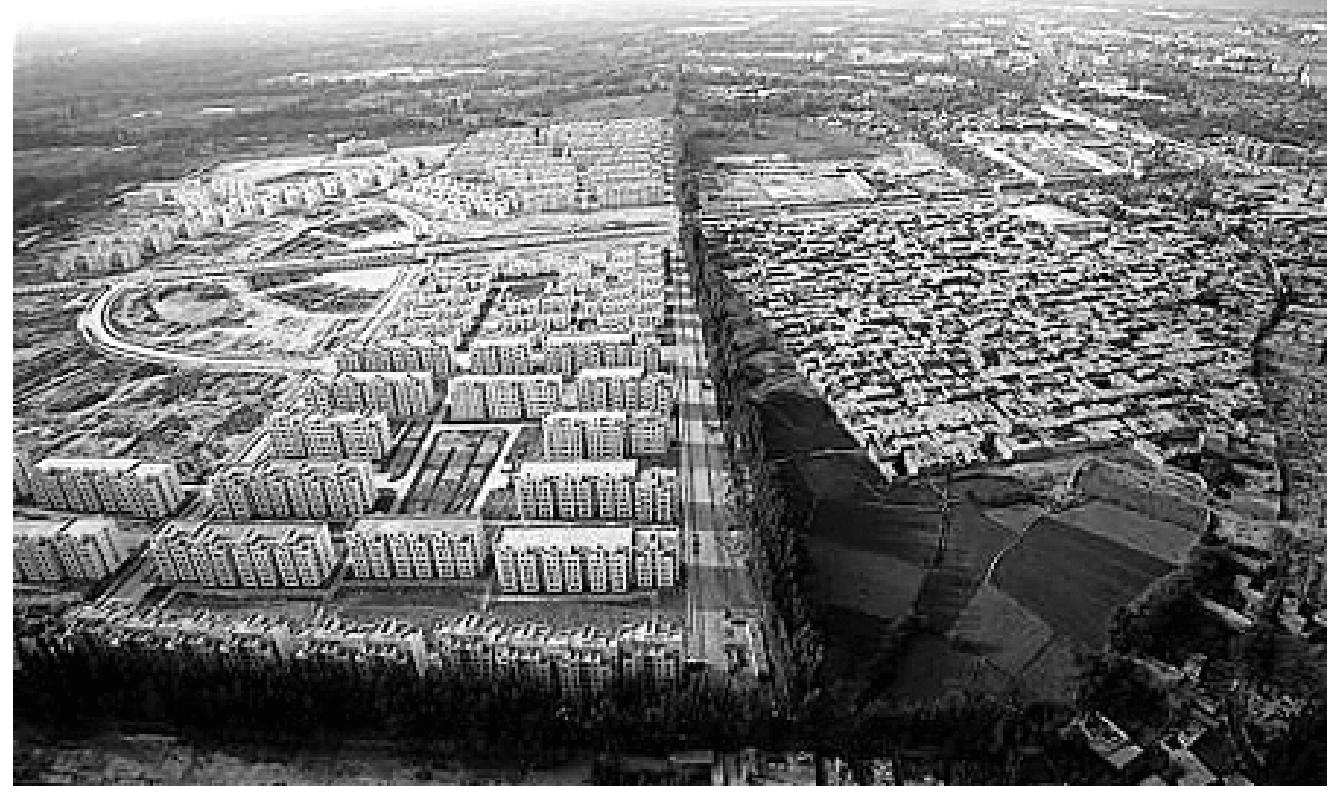


14. Deng Xiaoping lead the "Reform and Opening" of China in1978, an ambitious economic reform to encourage foreign trade and investments. Special Economic Zones were created in the south of China, which gave investors tax reductions in exchange for benefits such as revenue and technical knowledge.

"Quick guide: China's economic reform ", BBC News, last modified November 6, 2006, accessed March 31 2015, http://news bbc. co.uk/2/hi/asia-pacific/5237748.stm.

15. "KASHGAR: THE NEXT ECONOMIC BOOMING HUB - ANALYSIS " Eurasia Review, published June 28 2014, accessed November 30 2014, http://www.eurasiareview.com/28062013-kashgar-the-nexteconomic-booming-hub-analysis/

After the coastal development during the Deng Xiaoping regime ${ }^{14}$ that fostered Shenzhen as the most capitalized Special Economic Zone in China, the development shifted to the western region of China. This shift was to improve the living conditions of the less urbanized regions of China. This mostly consisted of autonomous regions of Guangxi, Ningxia, Xinjiang, and the municipal of Chongqing. ${ }^{15}$ The total area makes up $68 \%$ of Chinese territory and is home to numerous cultural minorities; the Uyghurs among them. Although considered to be "underdeveloped” by the Chinese government, the city of Kashgar was anchored at the Tarim Basin, an Oasis in the desert historically known for the production of fruits, crops, and animal products, and nowadays the production of fossil fuel. Kashgar's border condition with fourteen countries confirms its status as a trading hub between China and Central Asia. As early as Han Dynasty (circa 1450s), Kashgar as a portal of the Silk Route had already confirmed a trading relationship with foreign establishments in Central Asia. The trading connections also introduced the Sunni Islam practice to Kashgar and other parts of Xinjiang. 90\% of the population of modern day Kashgar is Uyghur Muslim. 
16. How The City Move to Mr. Sun: China's New Megacities is an

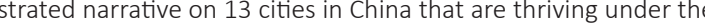
civil and economic development. The book discusses in detail the unstoppable urbanization in the next batch of Chinese megacities. As the book unveil its story: "Twenty years ago Mr Sun was a simple Chinese farmer. Today he owns a block of flats in the centre of a city of millions. And he didn't move an inch."

17. Hulshof, Michiel, and Roggeveen, Daan, How the City Moved to Mr Sun, 298, SUN 2010
Michiel Hulshof and Daan Roggeveen's book regarding their Go West Project How the City Moved to Mr. Sun ${ }^{16}$ has an interesting line describing Kashgar's position in China: "Kashgar is closer to the Mediterranean than to the East China Sea, and closer to Istanbul than Shanghai." ${ }^{17}$ The city itself is closer to Central Asia not only in geographical terms, but also from a cultural perspective. Its social economic context, religion, culture, and the arts differ greatly from the costal developments of China. Although Shenzhen SEZ proves the rapid “city-making” strategy successful, the method is clearly not meant to fit all future SEZs as Shenzhen, unlike Kashgar, has very little recorded history before it was announced as an SEZ. Although it is considered a disadvantage, the absence of a dominant urban fabric makes the site extremely easy for a Tabula Rasa development: implementing a Special Economic Zone. In contrast, Kashgar's long history has gathered an extremely vibrant mixture of different cultures which poses difficulties on its way towards "a global city". A generic fishing village where Shenzhen was founded is much easier to restructure than a city of historic importance like Kashgar. Not only a social economical restructure will impact the regional cultural context, the urban fabric also has to go through violent transformations in order to accommodate this rapid urbanization. 
18. "To Protect an Ancient City, China Moves to Raze It "New York Times, published May 27 2009, accessed March 12 2015, http://www.nytimes.com/2009/05/28/world/ asia/28kashgar.html?_r=0

19. Being excluded from a recognized organization such as UNESCO will increase the difficulty for Kashgar to obtain fundings and academic support towards the city's heritage protection.
One of the largest dilemmas of Kashgar's development plan is the urban renewal of the Kashgar Old City. Described by architect and historian George Michell Kashgar: Oasis City on China's Old Silk Road, 2008 and Michael Wines in The New York Times (2009)"18, stating Kashgar "the bestpreserved example of a traditional Islamic city to be found anywhere in central Asia”. The critical opinion on the fiery development of Kashgar carried out by the government of China also speaks to the difficulties Kashgar is struggling with. The vernacular architecture of Kashgar of mudstraw houses connected by small alleyways have not only been homes to the Uyghurs for hundreds of years, but are also an important touristic attraction according to the Chinese government, who see the value of Kashgar being one of the most important destinations on the Silk Road. Excluded from the UNESCO list ${ }^{19}$, the vernacular architecture that contributes to Kashgar's unique fabric is left to deteriorate by forces such as climate change, seismic activities, and poor maintenance. The vernacular dwellings, although structurally unstable for a seismic zone, are easily repaired, and all materials are reusable and sourced locally. Generations of Uyghurs constantly repair their inherited homes, making these fragile mud-straw constructions last hundreds of years. The Chinese government, according to Michael Wines 
20. Note from Editor: In comparison to cities evolved over hundreds of years with, Shenzhen was a man-made city. Urban strategies prototyped in Shenzhen resulting in its architecture and urban fabric will be easily duplicated and reproduced elsewhere to construct another new city alike. The duplicable urbanspaces can exist regardless of the situation of its site with no reflection of history and context. It is generic. in his journal, due to safety concerns has started razing the "unstable" vernacular architecture and replacing them with generic apartments reflecting no cultural context, and concrete replicas of Islamic dwellings that seem to be more structurally stable. The protection strategy that attempts to raise the tourism value is in fact erasing the authenticity of Kashgar. No tourist would visit a city of replicas, an edited and reproduced history indifferent from an artifact without its context.

While Kashgar struggles with its rich history being razed by ignorant bureaucrats, Shenzhen fears the opposite. The city is paving its own way to becoming as competitive as Beijing and Shanghai in the global context. There is some trepidation that Shenzhen will evolve into a generic city with no cultural sediments or preserved history. ${ }^{20}$ This fear raised a series of concerns around Shenzhen's heritage. Is the residual of the pre-SEZ fishing village that can be dated back to Song Dynasty, Shenzhen's cultural heritage? Or is the SEZ-era "Villages in the City", this extremely high density substandard dwelling clusters situated right at the city's business district, a heritage? The former is undeniably a heritage establishment due to its age and its vernacular architecture, but is the latter too? The clusters 
21. Notes from Editor: I spent many summers in Shenzhen traveling a cross the city to get to work. The bus rout always cross a "Village in the City" picking up a full load of migrant workers to the business district. They pick up breakfast at street-side shops right before squeezing themselves onto the bus. Passing through the narrow streets, the almost slum-like community unfolds its own ecosystem within: A grocery store owned by an elderly couple may double as a daycare for its neighbors; a hardware supplier offers cheap printing and bookbinding in his little store; a flower shop sells bubble tea adding a little romance in the dark alleyways... There are also bars, clubs, disco, and late-night diners of western influences with exaggerated neon lights. Anything that can be found in the vibrant business district of Shenzhen, there will be its sized-down doppelganger hidden inside these "Villages in the City". of "Villages in the City" ${ }^{21}$ are often migrant workers' first point of contact with the city due to the low rental rate, proximity to the city centre, and compact lifestyle offered. Illegally constructed to maximize the number of dwellings per parcel of land, the gap between two buildings only offers the width of one person: the neighbors can literally shake hands with each other from opposite balconies. In these "substandard" communities, the migrant workers thrive. These "Villages in the City" are homes of the people who pump new blood into Shenzhen, yet it would seem that they are not worth a place in the history. These substandard buildings are not designed to sustain the occasional earthquake of flood. The dark alleyways are breeding sites, not only health and safety hazards but also of rebellious gangs cause difficulties to the city authorities. The substandard conditions press the land value substantially lower than its surrounding neighborhoods. In the eyes of the city authorities and the more financially settled city dwellers, these substandard "Villages in the City" have to be replaced by new healthier communities that offer sunlight in every room and carefully placed Cantonese restaurants and the famous Seattle-originated coffee shops in lieu of cheap breakfast shacks, which will raise the living standards and land value to match the normal standard of Shenzhen. The result is 
22. Data obtained from China Knowledge

"Kashgar (Kashi) (Xinjiang) City Information", China Knowledge http://www.chinaknowledge.com/Citylnfo/City aspx?Region=Western\&City=Kashgar\%20\%28Kashi\%29

"Shenzhen (Guangdong) City Information", China Knowledge http://www.chinaknowledge.com/Citylnfo/City.

aspx?Region=Coastal $\&$ City=Shenzhen gentrification, because no migrant worker can afford to live there anymore even if they are offered dwelling units at the exact same location. They will be forced to the outskirts of Shenzhen just as the Uyghurs were "introduced" to new developments at the periphery of Kashgar SEZ.

How far is Kashgar from Shenzhen? Geographically, the distance is $5000 \mathrm{~km}$, from China's western most urban area to the South-China Sea. Economically, an almost 90\% difference in the two cities' GDP leaves Kashgar a long way to catch up. In 2013, the GDP per capita of Kashgar is RMB 15,016, in comparison to Shenzhen's RMB 136,947 (according to the China's Economic and Social Development Report) ${ }^{22}$. In terms of prospect, will the two be more similar? The demolition of the old mud-straw dwellings in Kashgar will give room for quality apartments, attracting investors to purchase, raising the land values. The native dwellers, the Uyghurs will be forced to close down their family businesses in the city and move to the periphery. Similarly, if Shenzhen's "Villages in the City" receives a redevelopment, the migrant workers who are the foundation of Shenzhen's heterogeneity will be forced to move to the peripheries only reachable via the light rail-- a prolonged journey from spaces of living to spaces of prode. 
When heterogeneity is erased, it reduces the distance between the two cities, Shenzhen and Kashgar, to zero: both with beautified and romanticized histories, both drawing a future inside replicas and empty façades.

To make Kasgar the next Shenzhen is clearly a radical leap not only in the monetary value an individual can generate, but also in the basic infrastructures, policies, business opportunities, and cultural developments depicted as tools of reversing the stereotypical "disadvantaged" Uyghur image. However the continuous upheavals in the region have led the government to suppress the damage of social disorder by targeting the Uyghurs directly. Making up 90\% of the population of Kashgar, the original inhabitants now seem unwanted by the migrant Han population. Ironic? Although the government of China is consistently supportive in making Kashgar the next Shenzhen, in the waves of riots, upheavals, and terrorist attacks, the future of Kashgar is still unclear.

The challenges Kashgar faces are vastly different from Shenzhen's 35 years ago. Being the Pearl of the Silk Road, Kashgar bears numerous vernacular 
and ethnic heritages. However, the radical urbanization that is capable of bringing the same wealth that founded Shenzhen has put Kashgar in a difficult situation: conflicting the old and new. Modern cities in China are spatially and socially zoned. The division between the migrants and Kashgar town-dwellers draws a clear line between the rich and poor, and in the case of Western China, between the Han and Uyghur. According to How the City Moved to Mr. Sun, "The danger lies in the forming of neighbourhoods where poverty and hopelessness coincide with a high concentration of a certain ethnic group- that is a recipe for tensions" ${ }^{23}$ The tension is the exclusion of the less advantaged groups from an urban scenario, the rejection of a seemingly chaotic coexistence. The distance between Shenzhen and Kashgar is in fact necessary, as the two will never be "matched" or measured at all. The city's vibrancy comes from a mixture of conditions, scenarios, and sometimes issues. The upheaval that swirled Kashgar into fear, can now be read as a longing for coexistence that constantly mediates and negotiates between the leading culture and the minorities. 


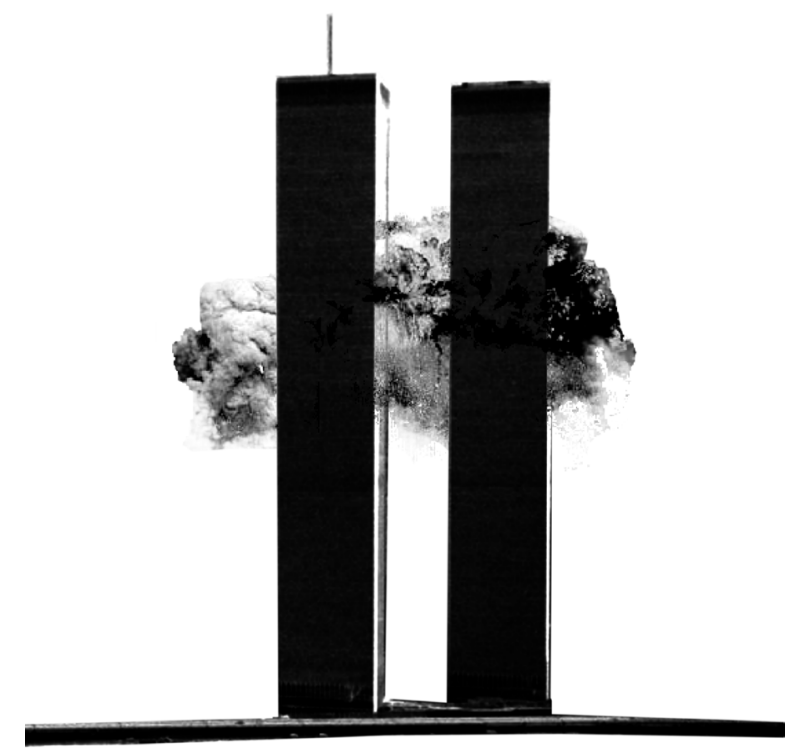


Observation Two:

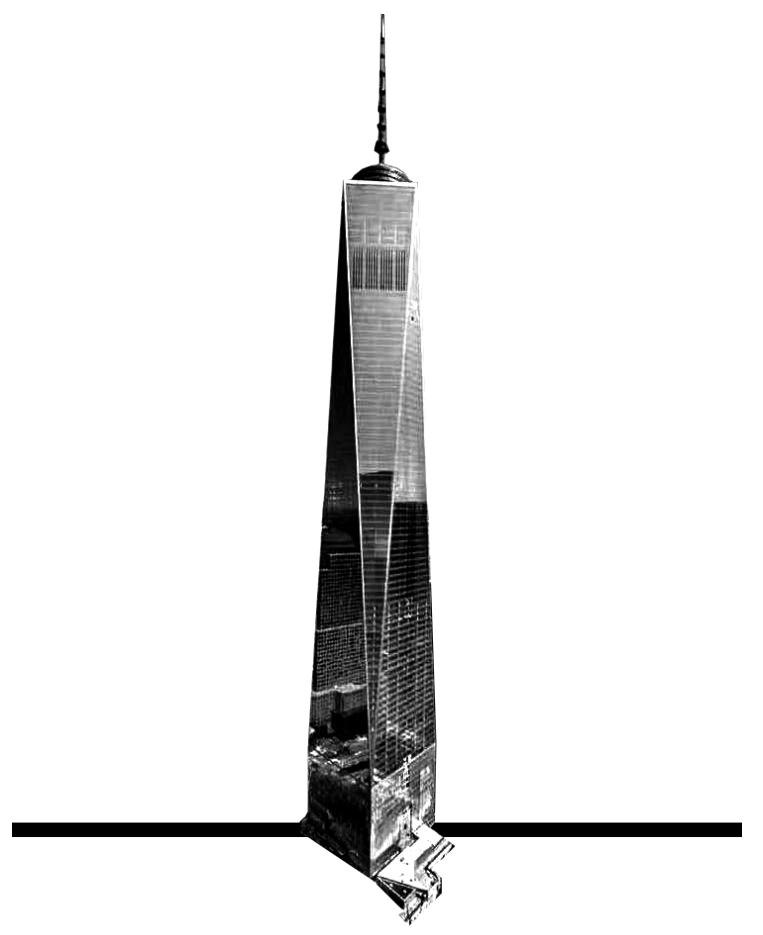

24 


\section{REST NOT IN PEACE:}

\section{WTC}

For centuries, we build for permanence, but entering the 21 st century the mindset seems to be rearranged. The existence of the built structures should be emphasized rather than striving a permanent imprint. As the density increases in the urban area, sites to build are extremely rare and valuable. Often before the new arrives, the old falls in many different ways. Buildings are not permanent either: they die. The site raises a new building, which may or may not reflect the past memories of what used to be standing in the same footprint. A piece of architecture, especially one that is rich in symbolism and social values, involuntarily participates in a sudden, unsolicited, and extremely destructive disruption; the building becomes a vessel, a carrier of both its former self and the shared memories of this event.

Like the building that witnessed a murder to go by the terminology used by architect Bernard Tschumi, the destruction of the Twin Towers, the World Trade Centre on September 11, 2001 is definitely the most horrifying and 
catastrophic event that was witnessed by architecture. It introduced to the participants of the event a reminder of the impermanence of architecture; the stability of a nation's icon was challenged and demolished in the blink of an eye, carrying thousands of victims down as the architecture itself turns to dust and rubbles. It not only suggested the fragility of built realities, but how the length of time of occupying a space can be shorter than one had envisioned in the first place.

The Twin Towers, namely the former 1 WTC and 2 WTC, designed by architect Minoru Yamazaki as part of Lower Manhattan’s urban renewal project was completed in 1970 and 1971. The program envisioned was the world's first World Trade Centre. Occupying significant cultural presence, the site not only becomes a stimulant of the financial activities, but also a major touristic attraction. The WTC Twin towers have its own zip code due to the density of the occupants sharing a singular address. It is a vessel to an entire biosphere of social phenomenon. It is a compressed heterogeneous entity anchored on a limited footprint. The value of verticality made possible by technological advancement; elevator shaft as the transient multiplier of spatial engagement at different scales of occupancy and pace. 
The Twin Towers, although manifested themselves in enclosed enclaves, allowed a certain degree of exchange and interaction between the public and private- for example the separation of areas of tourism and private businesses. The private enterprises provide a stable or permanent occupancy, and the tourists and visitors provide a rather ephemeral engagement.

The diverse social engagement internalized in the architecture enables a coexistence of seemingly unrelated activities. At the event of the tragedy, the WTC (of the total of all 7 buildings) housed more than 430 companies from 28 countries according to the CNN's report that has listed the occupants of WTC at the time. ${ }^{24}$ According to the same report by the CNN, an estimated 50,000 people worked in the WTC and another 140,000 visited the complex daily. With a high volume of transient population that engaged the spaces over the span of the architecture's lifetime, not only the public image that it portrays, but the amount of revenue that was generated has far exceeded the relatively inert leased offices.

As the spontaneous event disrupted a usual and peacefully busy morning at the financial district of Manhattan, the permanency and protectiveness offered by architecture was not the only aspect that was challenged. The 
towers that fell apart in the attack, were vessels carrying various spaces which collectively contributed economic values to the entire social context of the nation. The twin towers portrayed the icon representing the strength of a system: the political, social, economical stability that perpetually embedded them. In the architecture this symbol of the United States of America became an artificial ruin "choreographed” by Al-Qaeda terrorism.

The sudden attack of Al-Qaeda, deconstructing the WTC, transformed rapidly the mundane daily engagement between the people and architecture. The disturbance changed the stability of not only the architecture itself but also disturbed the state of equilibrium of the programs inside the vertical volume. The implosion caused by the impact of the aircrafts was like having food put in a blender as all the different spaces and programs in the architecture collapsed together. It is a process of rearranging the pre-existing order into a new order, which could be linked to how a layered cake is only proper if it is layered with a good mix of ingredients. As the architecture fell, there were no distinctions between business elites occupying the offices and tourists passing by: there were only casualties as the encoded spatiality collapsed. 
The architecture demolished by terrorism has spontaneously reinvented itself to become a newly constructed ruin. The rebuilding process slowly takes over and the "man-made ruin" is mixed and rearranged all over again, and then the process continues. The terrorist attack constructs an artificial ruin that claims the destruction as part of their engagement with the urban environment. In this constructed ruin, the hierarchical space that divides the architecture into different vertically stacked programs has turned in to entropy where all the molecules of the former physical space are still there, but only in a state of disorder.

The rebuilding of the WTC, although scraping out the remains of the former buildings still follows the spirit of the former architecture: a volume to contain an extremely broad spectrum from permanent occupancy to transient population. It is impossible to attain any visual resemblance of the towers that fell other than the two foundations, now turned into a memorial. The sentimental "heritage" is reconstructed under a new skin, a new vessel to host the same spirit. On November 3rd, 2014, the WTC One designed by one of the most technologically competent architecture firm 
25. Did the New World Trade Center Live Up to Its Expectations. Archdaily. date published October 4, 2014. date accessed October 4, 2014. http://www.archdaily.com/553708/did-the-new-worldtrade-center-live-up-to-its-expectations/

26. "1 World Trade Center: TIME's View From The Top Of NYC" Time, date accessed November 17, 2014 . http://time.com/worldtrade-center/
SOM, opens its door to public 13 years after the fall of the twin tower. It is announced to be the new iconic addition to the Manhattan skyline, but will it ever hold more importance than source of revenue and a monument of the past? Mainstream architectural journals such as Archdaily has criticized the WTC One as a product of compromise. ${ }^{25}$ Time Magazine on the other hand dedicated an interactive web-zine ${ }^{26}$ filled with articles, documentaries, and stunning photos to give the WTC One tower a warm welcome. The tower appears to be minimal yet filled with humble dedications to the fallen Twin Towers: the square footprint and rooftop, and a height of $1,776 \mathrm{ft}$ not only claiming the tallest of North America, but also reflecting the number of casualties of the 9-11 Attack. The glass trophy camouflages into the scenery of Manhattan, silently changing with the city. There are no strong statements and pretty words. The criticisms are possibly correct with the tower's "compromise”, but perhaps it is never intended to be a morphing sculpture or a memorial of the tragedy. It is what it once was: a hub of global economy movement.

The site preparation took the majority of the construction, clearing out the reminiscent of the twin towers. The reflective facade diminishes the urban- 
scape that is constantly in flux marking a new age for temporal, mobile, and responsive architecture to reach a new stability through capturing movements of its surroundings and its inhabitants.

Architecture did not radicalize architecture, the tragedy did. As the entire social belief restructured and values reassessed, architecture changes from a statement of existence to a camouflaged supporter of the city. 
Observation Three:

\section{Common ground}

noun

an agreed basis, accepted by both or all parties, for identifying issues in an argument/Collins English Dictionary

\section{COMMON GROUND}

The 2012 Venice Biennale curated by David Chipperfield suggested the theme of "Common Ground", an interest emerging out of resonance from and with the past. Chair Paolo Baratta suggested to try "built architecture, from full scale reconstructions of existing buildings to the emerge from intricate balances of structural forces; from the materialization of the concept of architectural and cultural heritage as a basis « for the search for and construction of new realities»»" 27
27. "13th International Architecture Exhibition", La Biennale. http://www.labiennale.org/en/architecture/archive/13th-

exhibition/13iae/ 


\section{common ground?}

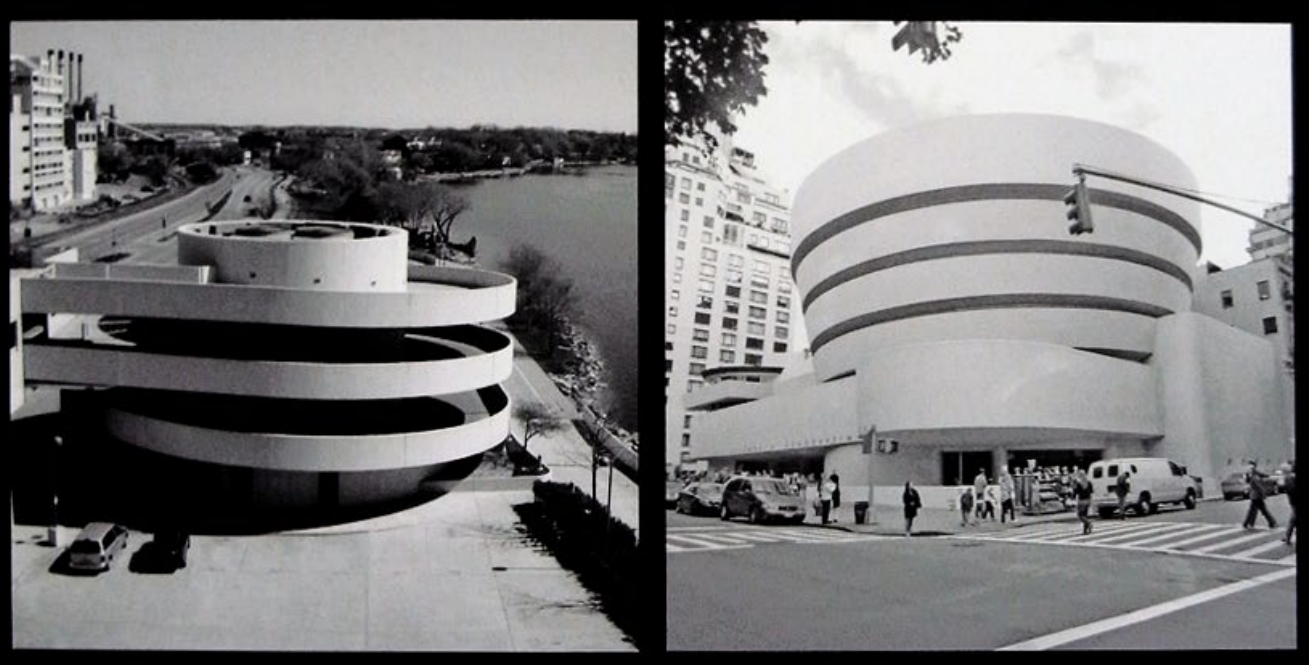

Architecture is not only what it looks like, but also what it does. 


\section{common ground?}

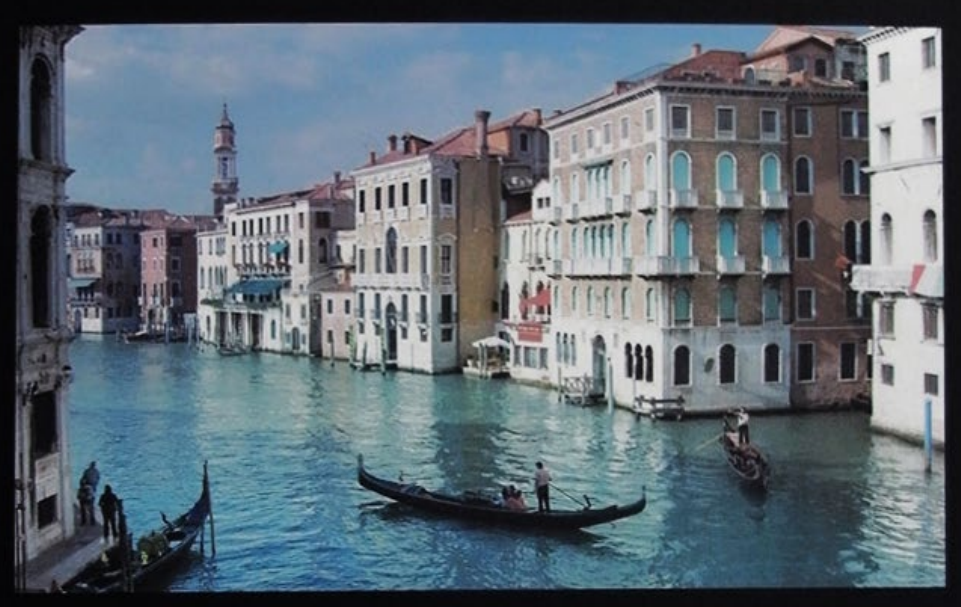

Concept, not form, is what distinguishes architecture from mere building.

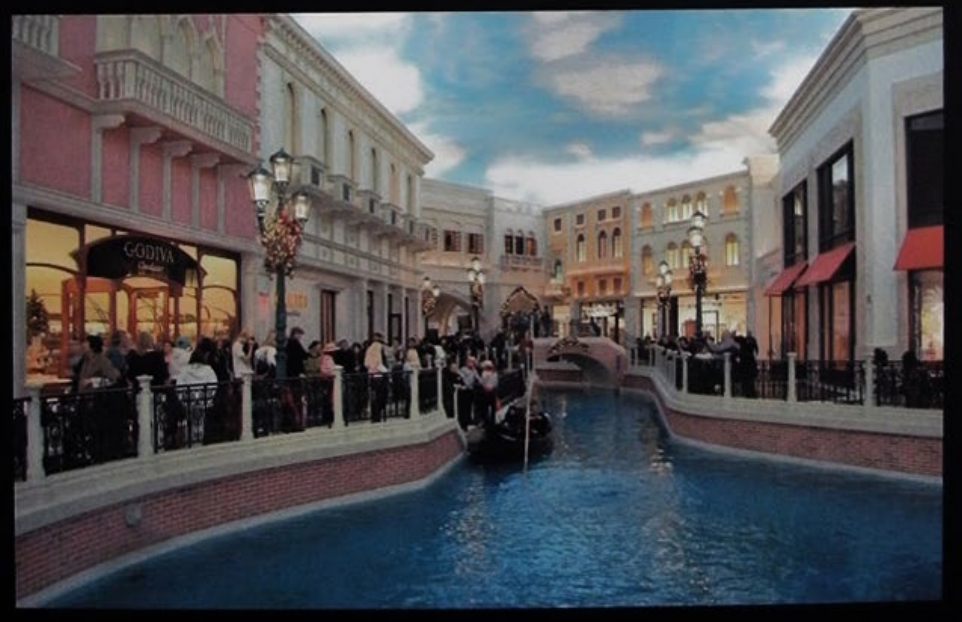

commonplace 


\section{COMMON GROUND:}

\section{SIDE A}

To ground the experience of the 2012 Venice Biennale curated by David Chipperfield, images from Bernard Tschumi's Advertisement for Architecture was used as its preface: a series presenting a juxtaposition of an approved architecture and a formalistic approach in built reality. "There is no way to perform architecture in a book." Tschumi writes, "Words and drawings can only produce paper space, not the experience of real space. By definition, paper space is imaginary: it is an image" ${ }^{28}$ Staging the imaginary world is what media is founded upon and architecture has always presented itself through publicity. In fact, it has never been out of what concerns publicity As backdrops to events, expected or unexpected, architecture is being seen and means to be seen. Publicity is a common ground, where everyone finds something worth to believe in. Unlike the postcards from 1966, the 
In the age where iconic architecture pierces from the ground to the sky with enormous speed achieved by technological advancement, what shall the audience look at: the so-called star architect, the iconic, or mere architectural ego? What is the common ground? Is the common ground "designing for the public”?

"Do not simply respect others, but offer them a common struggle, since our most pressing problems today are problems we have in common." ${ }^{29}$

- Slavoj Žižek

Of course it is impossible to please all by designing for the public. Shortly after the launch of the event, Wolf D. Prix criticized that the 2012 exhibition “Common Ground” as completely banal: “This event is an expensive Danse macabre. In a city of plunder (an exhibition of plunder) hordes of tourists (architects) roll along broken infrastructure in order to satisfy their petit bourgeois desire for education (in the case of the architects: vanity, envy, schadenfreude, suspicions). Even the glamour that the visitors are supposed to feel is staid and faked by the media for whom a star architect is like a film star." ${ }^{30}$ Interestingly the desire that is fulfilled by untruthful media draws a
29. Žižek, Slavoj. The Year of Dreaming Dangerously. pg 46 London: Verso, 2012. Print.

30. "'Venice Architecture Biennale is exhausting bleak and boring' says Wolf D. Prix", Dezeen, date published 30 August 2012. date accessed November 17 2014http://www.dezeen.com/2012/08/30/ venice-architecture-biennale-is-exhausting-bleak-and-boring-sayswolf-d-prix 
31. "David Chipperfield Deplores the "Impotence" of Contemporary Architecture at the London Design Festival" BlouinArtinfo, date published September 25, 2012, date accessed December 4, 2014

http://blogs.artinfo.com/objectlessons/2012/09/25/david-

chipperfield-deplores-the-impotence-of-contemporary-

architecture-at-the-london-design-festival/ fine line with Tschumi's advertisement underlining "imaginary" and "image".

"Common Ground" satisfies every single criterion that pleases its visitors:

the concerns of preservation and sustainability, resonance of history, and reflections on cultural heritages, all romanticized by the participation of the so-called star-architects and their iconic visions.

In reacting to Prix's criticism, curator Chipperfield initiated a similarly rhetoric debate according to Archdaily, "with a world plagued by the current economic crisis, David Chipperfield fears that the architects' role is shrinking and the professions ability to influence the shape of our cities is diminishing." He blames the politicians that solely favours results: "A museum gets built and all of a sudden they're interested in it - not because it's a museum but because they can sell it as part of a regeneration program." As quoted from Tschumi, architecture is what it does. It is a the world dominated by publicity and media is an instrument to draw another social image. It is a regeneration program, it is a petit bourgeois desire, it is what it looks like. In addition to commenting on politicians, Chipperfield criticized the media for "sidelining architecture in the lifestyle pages." ${ }^{31}$ 


\section{COMMON GROUND:}

SIDE B

In contrast to the "star-filled" events like the Venice Biennale, unsolicited architecture seems to grab on to the idea of "common ground" tighter than the "star-architects" under the spotlight. The simplicity and elegantly reduced ideas of pavilion architecture allows the spontaneous injection of positive urban action.

In 2010, DUS Architects hosted an unsolicited dance party on the street of Rotterdam. "The Bucky Bar" as they called it, utilized usual daily objects umbrellas as material to construct a dome structure that became the heart of a spontaneous event on a winter night. The umbrellas attached to each other to become a big shelter. The party came alive at $10 \mathrm{pm}$ and lasted a few hours before the police came in to terminate the unsolicited event. Similarly unsolicited, even announced illegal by the government of P.R.C., the 2014 "Umbrella Revolution" in Hong Hong (formally Occupy Central) also attempted to create a better future with joint effort. With such spontaneous gathering, student protests and demonstrations have originated near the MTR 
The Bucky Bar inspired by Buckminister Fuller Image Source: DUS Architects

The action word describing "holding an umbrella" is synonym of "support" in written Chinese. On October 3th 2014 in Causeway Bay, supporters raised their umbrellas forming a symbolic "roof" to support democracy in Hong Kong. / Image: Jennifer Chan
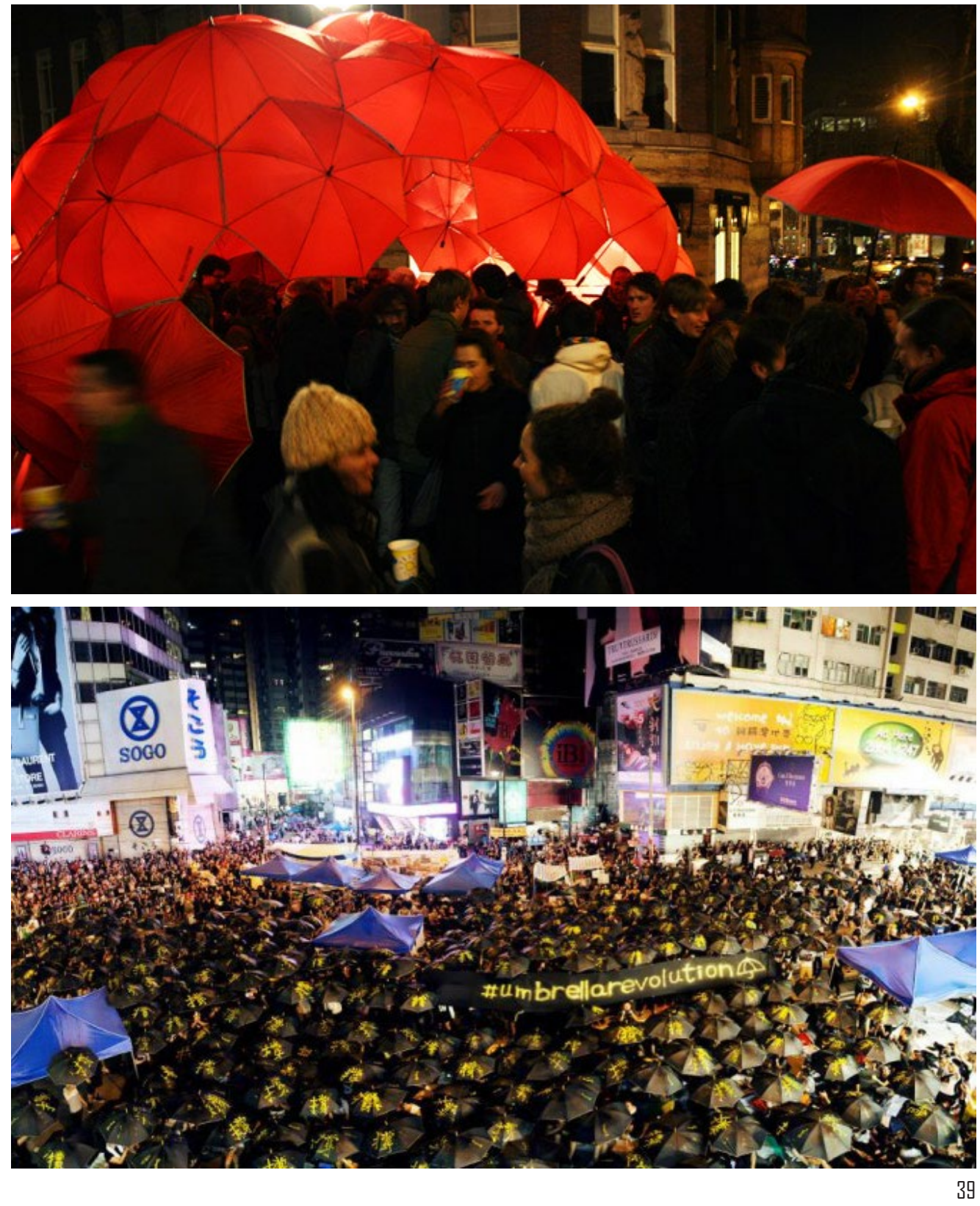


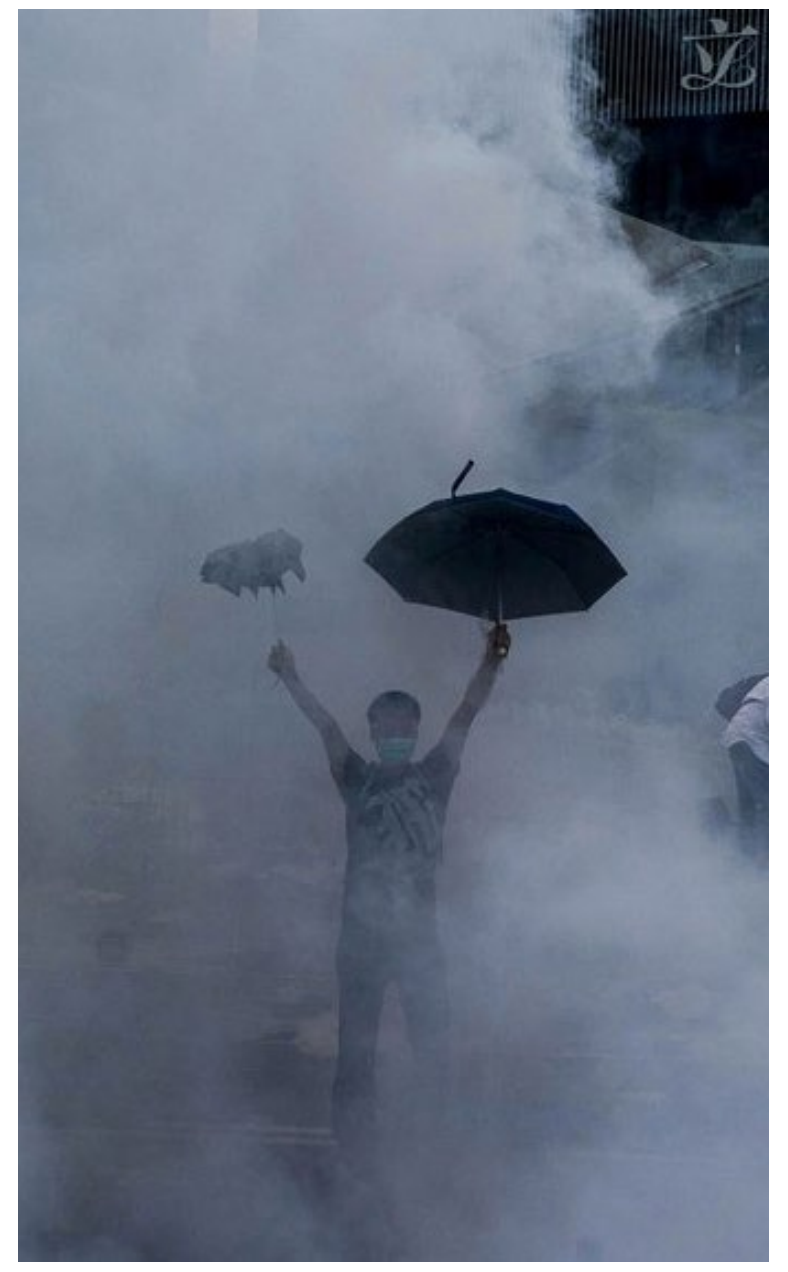

The man holding umbrellas is portrayed as a reflection of "The Tank Man" recalling the tragedy in 1989. Image Source:Xaume OllerosG

32. "Umbrella Revolution Explained", Yahoo, http://news.yahoo. com/katie-couric-now-i-get-it-umbrella-revolution-175949877.htm stations of Central and Admiralty located in Hong Kong Island. The event has gained support from citizens of Hong Kong on the fight for democracy, transparency in publicity and education. The Occupy Central with Love and Peace demonstration started on September 27th 2014 after nearly one year of planning and small-scale protests. On September 28th 2014, the police launched 87 tear-gases attacks in attempts to evict the demonstrators from the area which brought the event to a climax. ${ }^{32}$ The conflict between the government forces and protesting citizens of Hong Kong had then risen to a new height. Depicted by mass media, the image of a pro-democracy protester standing in front of the Hong Kong Legislative Council building is portrayed resembling “The Tank Man” recalling 1989 Tiananmen Square tragedy. The figure holding an umbrella as a means of protection quickly became the symbol of the Occupy Central with Love and Peace demonstration. The tear-gas "attacks" from the police quickly triggered anger among students and workers of different field. Since then, the area of the demonstration has spread to other major business districts including Mong Kok, Causeway Bay, and Chai Wan. Many protesters have chosen to hold umbrellas, wear masks and goggles not only to protect themselves from tear-gas and pepper spray, but to show support and respect to the pro-democracy activists. The image of umbrellas 
covering streets quickly gained popularity in the advertisement industry and social media network, causing the exponential exposure of Occupy Central on publicity. The increasingly populated event also impacted and paralyzed the affected areas influencing local businesses, daily commute, and other soft infrastructures of Hong Kong.

Let us return to the "Bucky Bar" of DUS Architects, which showcased the power of using umbrellas, a common daily object, as the replicating units for a spontaneous architectural pavilion for an unsolicited event. Although ending with the disruption of the police officials, the event was described as fun, enjoyable and positive. "The title refers to the great American inventor, Buckminster Fuller, who demonstrated how minimal energy geodesic domes could open a way to a more environmentally sustainable future." As they noted on their website, "The Bucky Bar is a full-scale model of such a future. It shows the power of space for spontaneous gathering, for improvised shelters to host conversations, debates, games or even parties." 33

Hong Kong took an alternative approach: by conducting spontaneous 
the people come together to express a common longing. The image of an umbrella as a means of support and protection quickly multiplied into thousands of umbrellas forming one single entity, spreading through the entire street with an "umbrella roof" supported by activists longing for change. The completely self-generated "umbrella roof" in Hong Kong that never intended to carry any architectural value has a shared common goal with "the Bucky Bar": to promote social improvement through uniting the tiniest units that make up our world.

These upheavals, demonstrations, and protests are reactions to the social, political, and economic realm. The initiators have a longing for certain goals, and through actions although violently portrayed, they claim their will. These are often associated with abandoning old ideas to make space for the new to change. In contrary, architecture has become more and more of a perfectly preserved urban artifact. It has become a slave of the global economy.

On December 11, 2014 the demonstration "Occupy Central” reached a conclusion followed by the closing of associated websites. The movement started by mocking the famous Occupy Wall Street ended with a symbol 
of umbrella and the unofficial name: "Umbrella Revolution". Although the activists failed to improve political freedom, the movement has been a powerful expression reaching for a common goal: democracy. The protest field thus becomes the common ground where the tiniest particles of the society speculate a possible change in the future. In reverse, if taking the world and unfolding the globe as Buckminister Fuller did himself, the whole world fits on one page -- we are all connected.

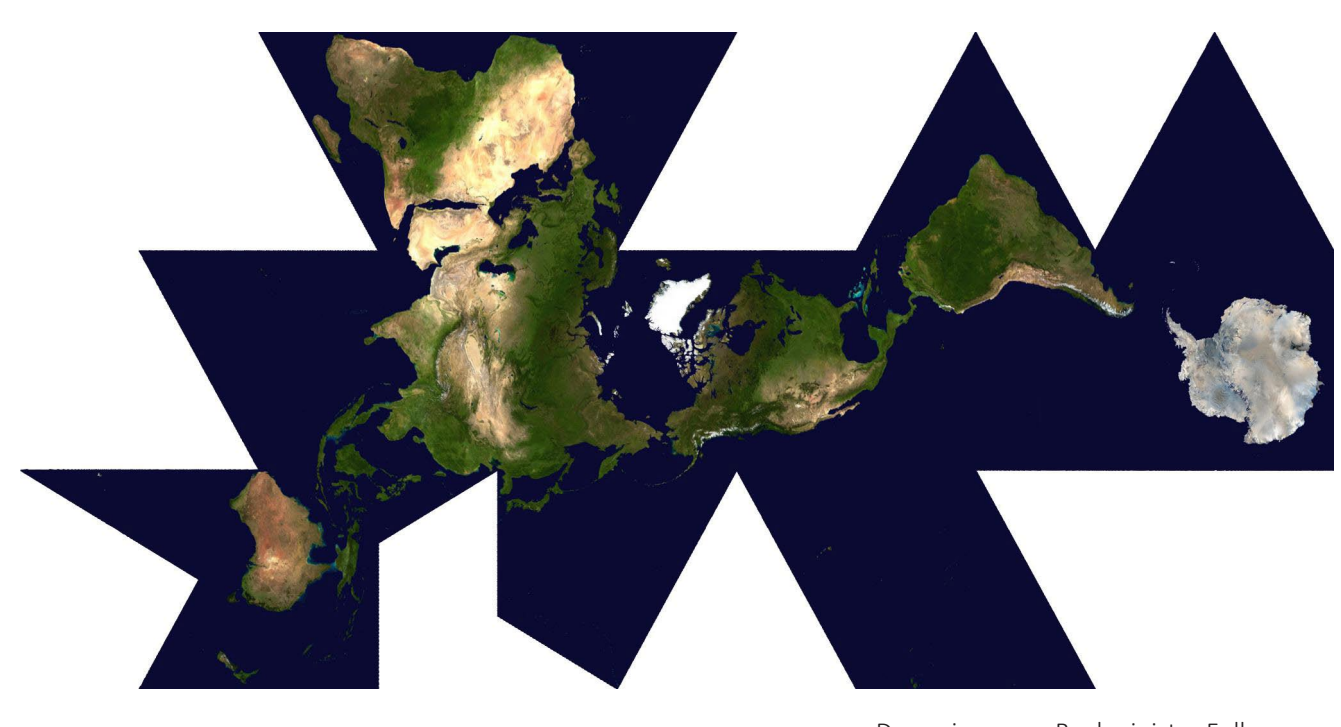




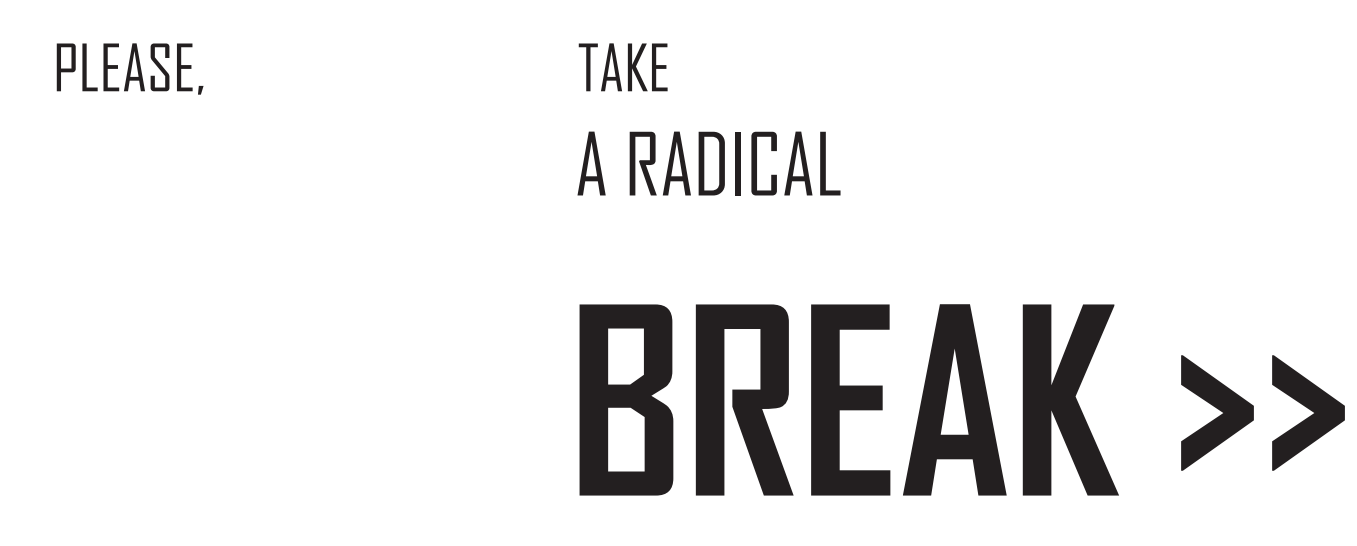


PART III

PERFORMANCES 


\section{DANGEROUS DREAMS}

\section{OF THE SOMERSET HOUSE}
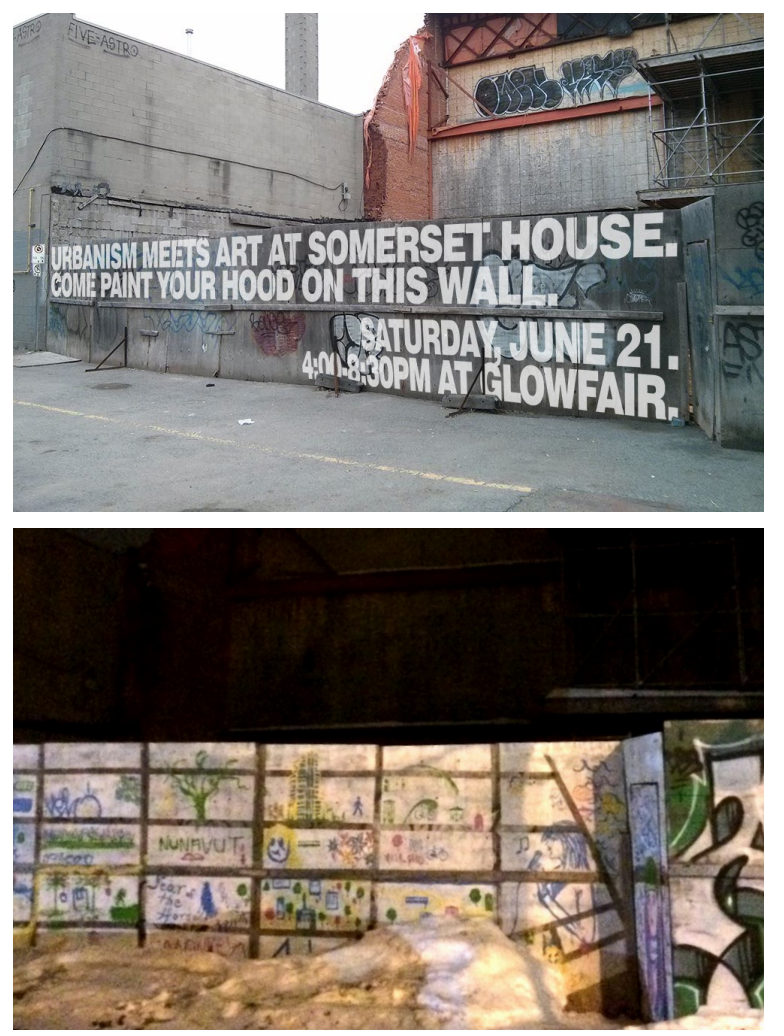

Image above : an event advertisement as part of a voting campaign to involve the public in producing a mural collectively./Image Source: http://newottawa.ca/events

Image below: the mural as of February 2015/Image by author

34. Martin Canning Campaign, Facebook event, June 21,2014, https://www.facebook.com/events/1496900537207084/
The accident in 2007 during a structural retrofit left the Somerset House dysfunctional. The rear of the building was removed with only the street façade standing. It is like an architectural taxidermy preserved by I-beam exoskeleton. Safety is once again secured with barricades. The remains of the house that was considered as an eyesore, now is an opportunity for a hit on publicity. In June 2014, the collapsed portion of the Somerset House was used as a backdrop for Somerset Ward, Martin Canning's voting campaign. “Together, we're going to witness urbanism meet art, imagine what our ideal neighbourhood looks like, and see it come to life on the East-facing construction wall of Somerset House." ${ }^{44}$ The barricade becomes a canvas for "creating art" and "participating together". Note the existing graffiti at the site that are calling a rebellious dream: a dream that is not of a choreographed event to participate, a discovery of under-used space that can become an infrastructural space to target common issues. 


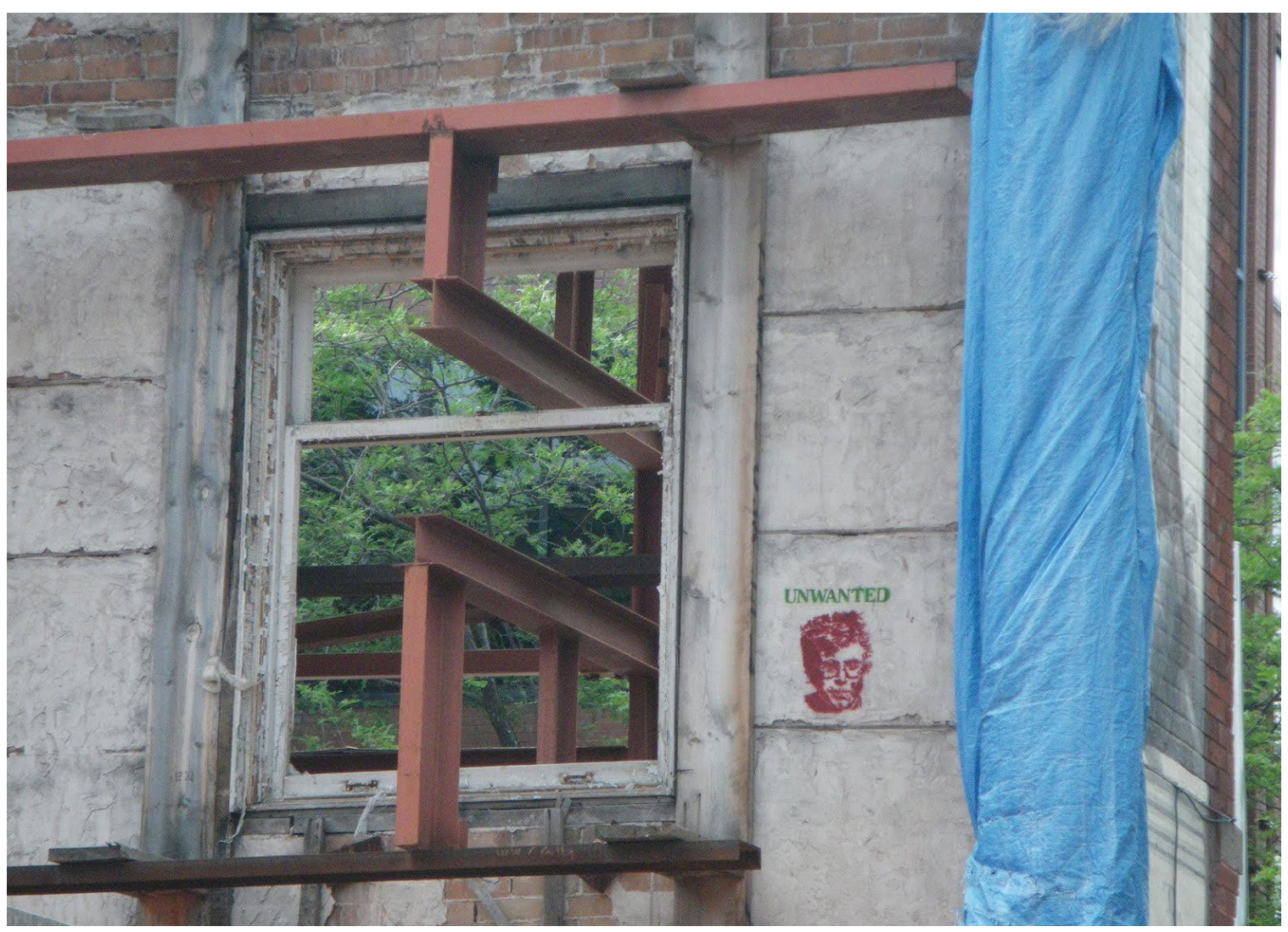

UNWANTED? 


\section{ORIGIN:}

THE LOCATION
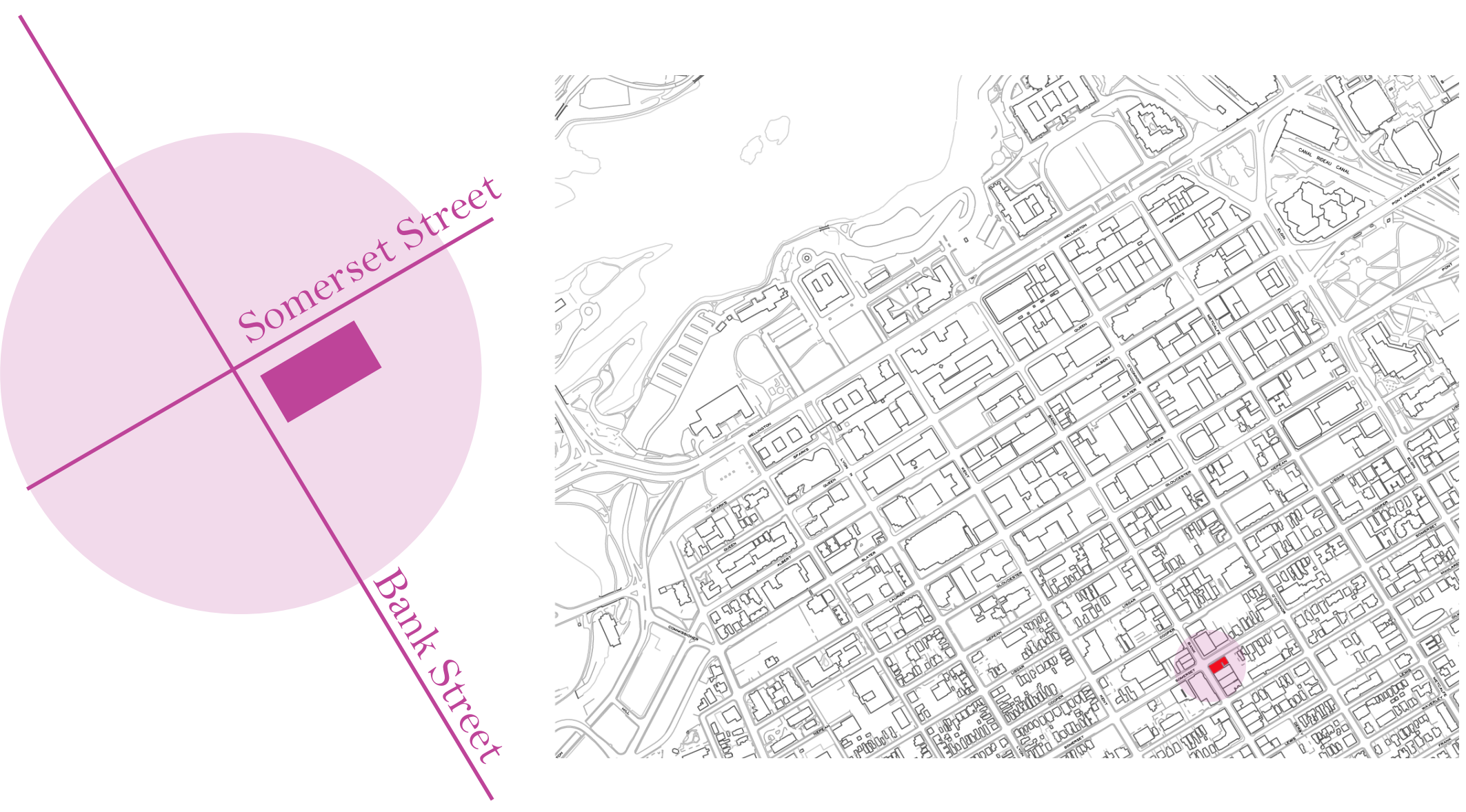


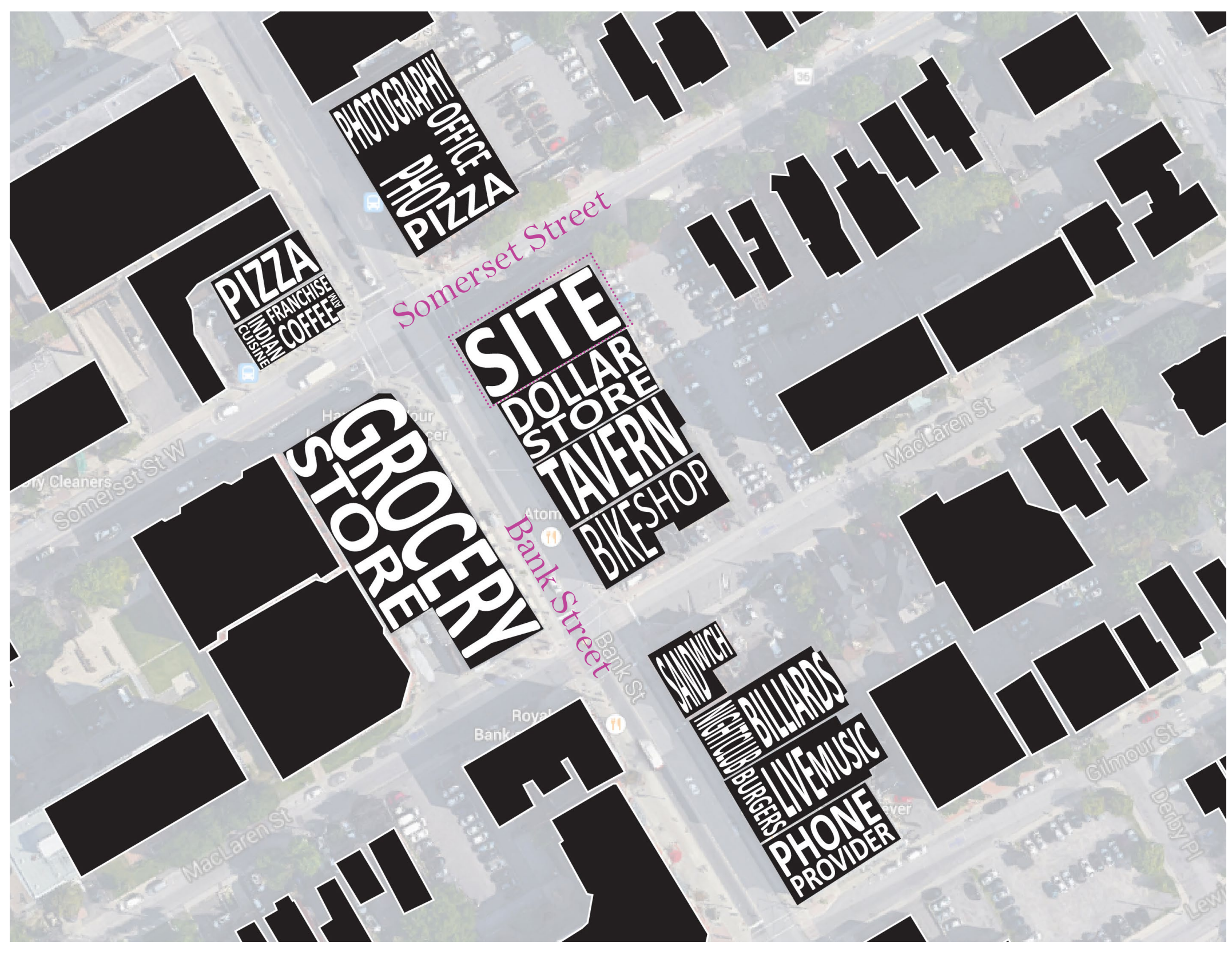


http://urbsite.blogspot.ca/2012/10/the-haunted-hotel-somersetritz.html

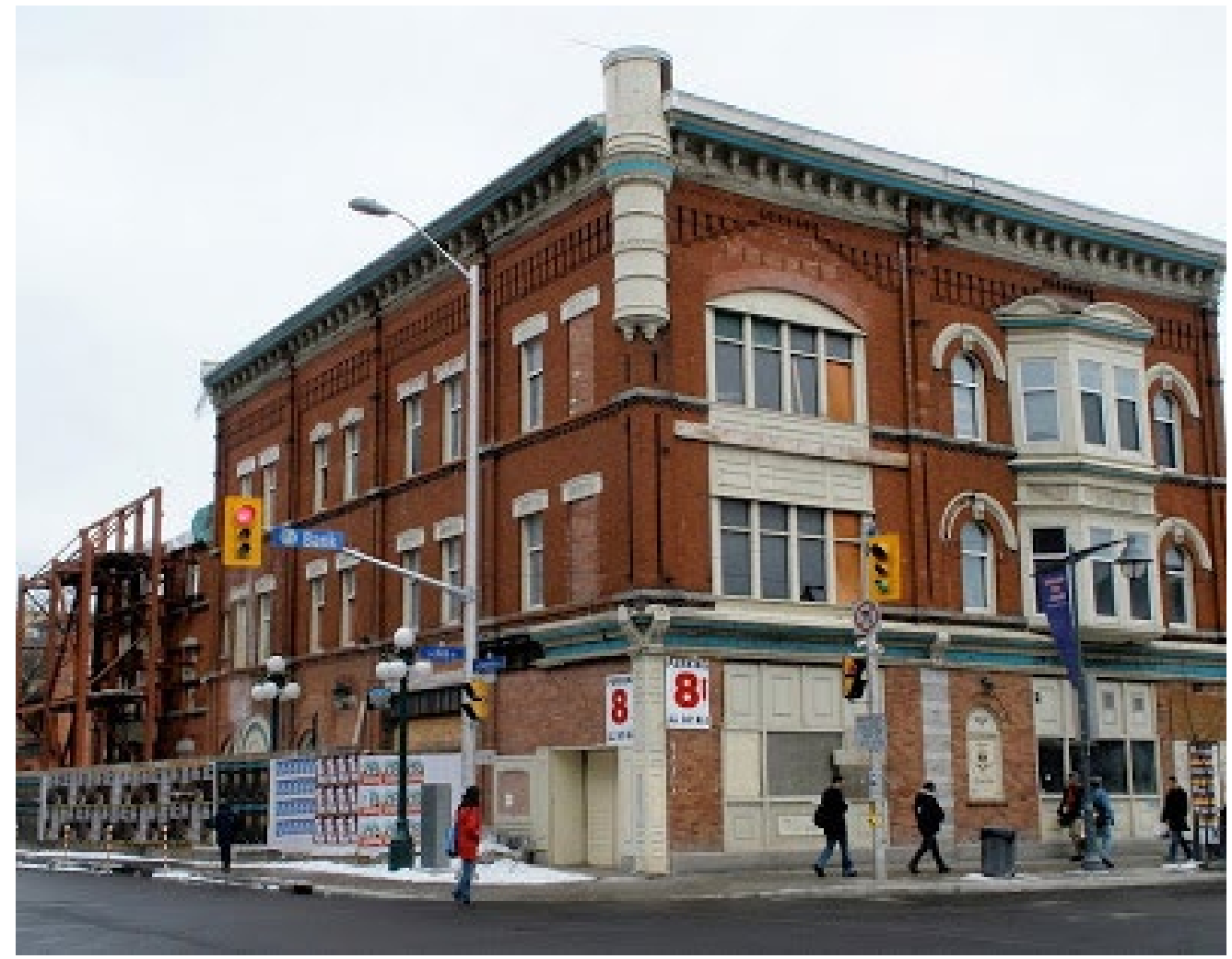




\section{ORIGIN:}

\section{THE STORY}

35. "A Digital History of Eastern Ontario and Western Quebec, Canada Including the Cities of Ottawa and Hull / Gatineau 1600 to 2014". Bytown or Bust, date accessed January 172015 http://www.bytown net/ottawaname.html

36. "The House They Called Home" The Ottawa Citizen,

December 7, 2009, accessed January 17 2015. http://www. canada.com/story print.html?id=6e3f7abf-0dd9-4239-be25-

$7 \mathrm{~d} 2338644070 \&$ sponsor $=$

The name Ottawa originated from Algonquin word adàwe which means

"to trade". The city of Ottawa has a long history of timber trading and processing. In the $1890 \mathrm{~s}$, Ottawa was still semi-industrial and the area where the current Somerset House situates was once a timber mill owned by Daniel O’Connor Jr. Later, as Bank Street became an area of middleclass settlement, the owner of the timber mill sold the corner of Bank Street and Somerset Street and moved further south on Bank Street. The house that takes the corner of Bank Street and Somerset Street was built in two portions. The oldest portion was built in 1896 to welcome the Crosby, Carruthers Company Dry Goods with its store on the sidewalk. In 1902 a four-storey addition was constructed as the Somerset House Hotel and Somerset Apartments, giving the building its current name: Somerset House.

The building was later acquired by C.W.Mitchell, a veteran of the U.S.

Civil War and owner and editor of the Ottawa Free Press. His son Edgar inherited the building in 1936 and turned it into the Ritz Hotel. Not only 
did he transform the dry goods display into a streamline façade, a basement was excavated in order to open a dining salon where dancing and full-course meals were served. The Mitchell family ran the building for 68 years and dedicated their energy to the liveliness of the neighbourhood. In 1979, the grandson of Edgar Mitchell, Edgar Mitchell II renovated the hotel rooms and opened C.W.'S, a jazz lounge. In the process of repair works on the hotel rooms, one of the bay windows had to be replaced. Later, he opened the Lockmaster and Duke of Somerset, a tavern and a pub where one could find entertainment ranging from live music, karaoke, to sports. The hotel business also turned into apartment rooms for rent in the 1980s. A mural depicting the transient, lively Somerset Street was painted to the back of the Somerset House in 1991.

This building at the intersection of Bank Street and Somerset Street holds a long history of housing a heterogeneous volume: a hotel, apartments, restaurants, bars, and other activities. The transient population that occupies the spaces temporarily continuously stimulated the area unlike a building of a homogeneous program. The occupancy ranges from a spontaneous event to an extended stay for years. The spontaneous kind, such as watching 
a game over a few pitchers of beer with friends at the bar, or a short stay at the hotel, engages more interactions of strangers, in opposition to the long-term occupancy that develops a stronger bond amongst other long-term residents. In a heterogeneous space where the two coexist, the building is neither independent nor dependent. It is a permeable enclave that allows the exchange of values, creating a platform to host a greater diversity of population in a shared time-frame. Unlike a closed community, a heterogeneous space like such has no defined borders therefore there will be no inclusion or exclusion. The boundaries of elasticity allow the interior spaces to engage with the urban spaces through inviting the urban dwellers to participate in the encoded program.

The elastic boundaries do not reflect a set form defined by "commercial" or "residential" that separate the outward and inward functions. In fact the liveliness comes from a mixture of activities distributed throughout its occupied spatial volume and its time of operation. Short-term occupancy relates directly to the more permanent occupants, as distinguishable in the drawing of the façade of the Somerset House: the hotel addition right against the apartment floors of the original 1900s building as one singular 
37. Airbnb is an online platform to provide alternative options of hospitality established in 2008. The sharing model of Airbnb originated from providing an airbed (or a bed/room not being used at the moment) and breakfast for short-term guests. By utilizing and reactivating redundant spaces in a private property or an apartment leased long-term, profit can be generated through providing hospitality services as per availability. property owned and managed by the Mitchell family. The juxtaposition between spontaneous and permanent is elaborated during the boom of sharing communities such as Airbnb ${ }^{37}$ in the 2010s. Airbnb is branded to offer "authentic cultural experiences" by staying at a room offered by the local (permanent) dwellers in opposition to a stay in a chained-hotel which by public perception, a non-local entity. The boom of Airbnb cornering the hotel industry is not only a result of the more personal and economical stay for travelers, but it shows that the "local identity" has become an attraction on top of traditional traveling destinations such as museums and monuments.

In 2004, Edgar Mitchell II stated that "The sense of hospitality, of being a publican, of running a place where people socialized and interacted in their community--we're losing it," and sold the building to Tony Shahrasebi, an Iranian immigrant who he believed to have the interest, capability, and resources to renovate Somerset House.

Heritage Ottawa granted Somerset House its status as a fabric heritage due to the level of architectural detailing preserved, and the shared memories 


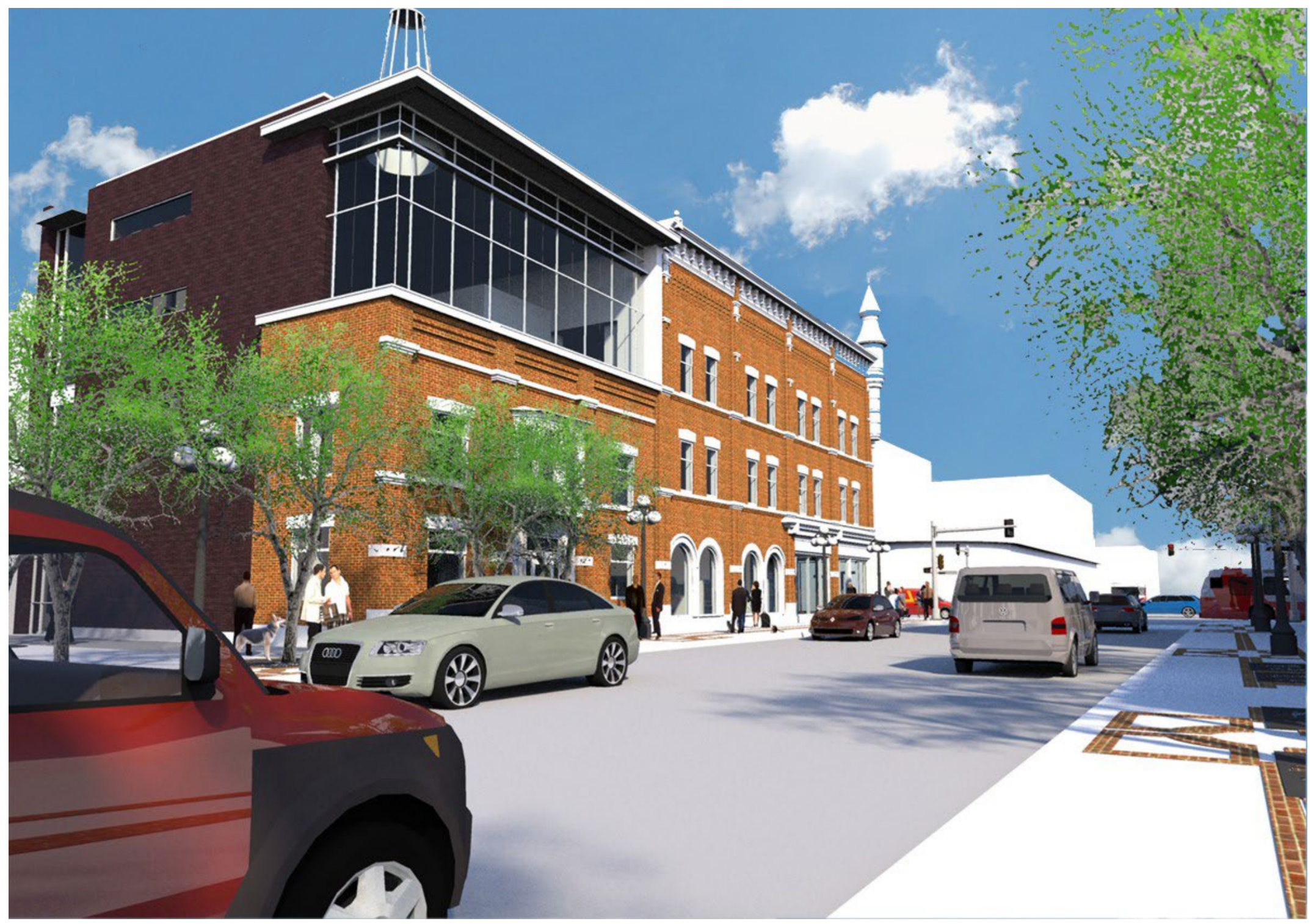

Latest proposal of the Somerset House by Derek Crain Architects

Image source: http://www.primecorp.ca/historic-somerset-house/ 


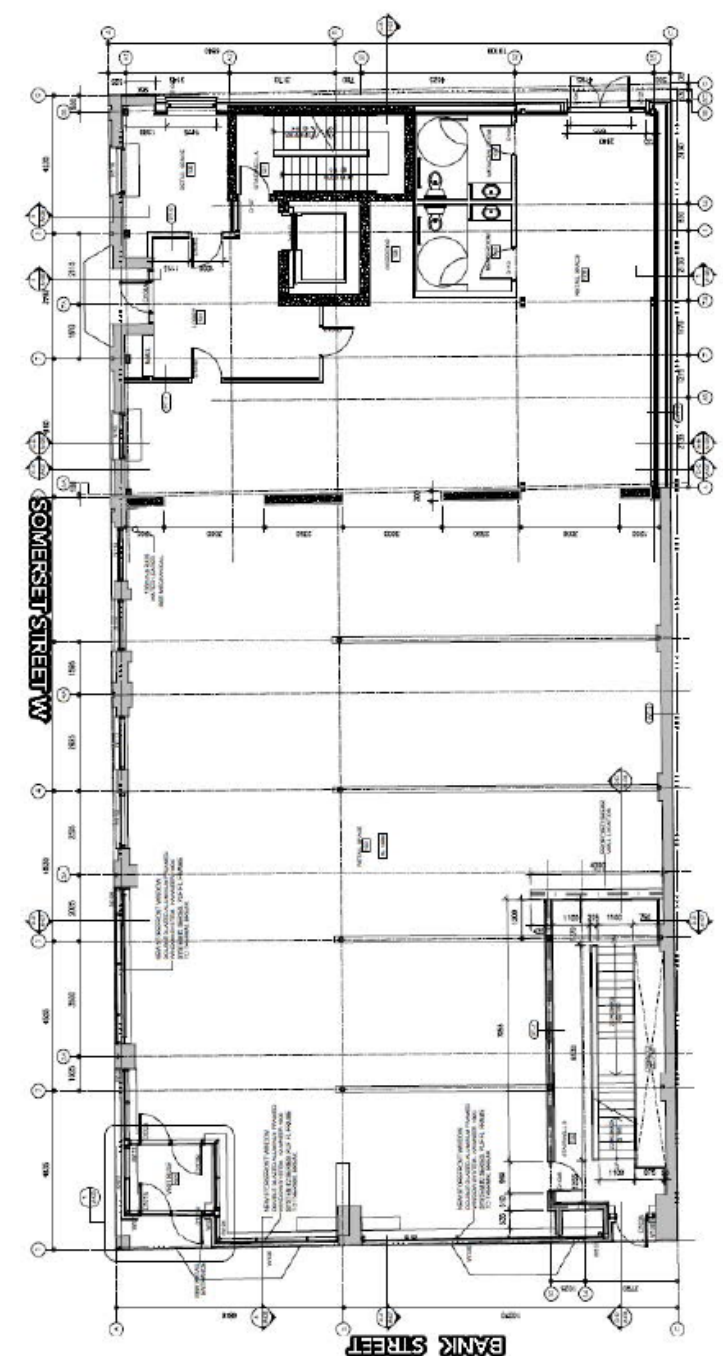

Ground floor plan of Somerset House

Image source: http://www.primecorp.ca/historic-somerset-house/ prior to its collapse. The formed-tin cornices, the bay windows, and the corner turret made Somerset House one of the most unique buildings in Centre-town Ottawa.

In the current proposal by Derek Crain Architects, the new design stresses the use of replica to restore the Bank Street façade to reflect its original 1896 design. The address 352 Somerset Street, once refurbished, will be used as office spaces and ground floor retail. The current house is an artificial ruin constructed by both the structural failure of the physical and spatial architecture. The artist rendering depicting the new construction shows a misalignment between history and future. The future drawn out to be the new renovation does not reflect the former architecture although inheriting the same skin. The façade will be restored into its original state with the bay windows and ornaments reconstructed. The walls of the addition will be stabilized in order to house the new function as a four-storey commercial space. The completion of the physical restoration of the street fronting is only a matter of time; however, will the house continue to be a site of vibrant activities enjoyed by both the local dwellers and the travelers? 

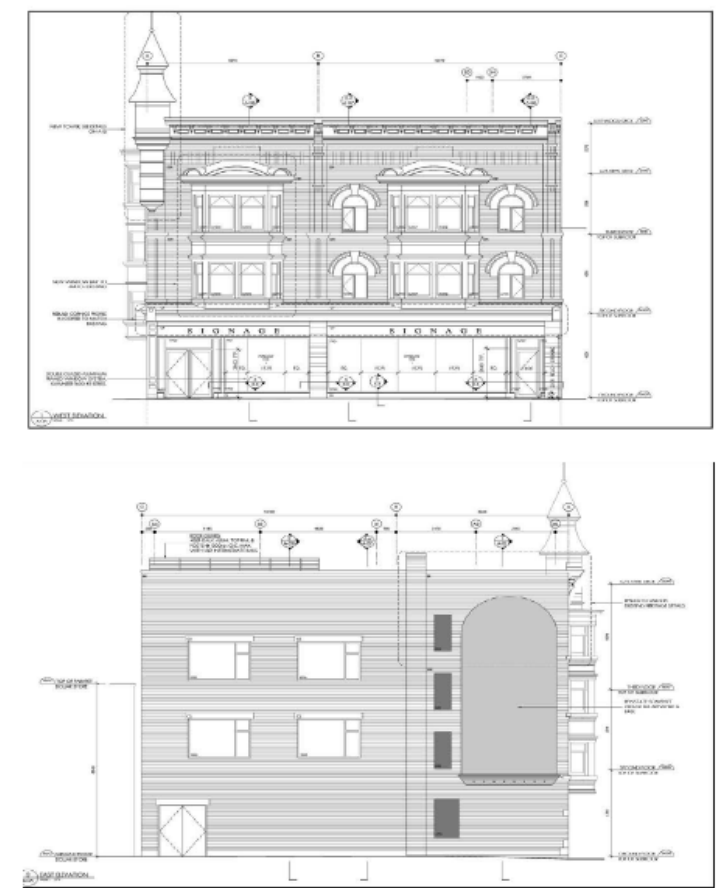

Elevation drawings of Somerset House prior to its collapse Image source: http://www.primecorp.ca/historic-somerset-house/

38. Anchor Tenants are usually the first, and the leading, tenant in a shopping center whose prestige and name recognition

attracts other tenants and, it is hoped, shoppers. Anchor tenant generally pays rent rate lower than that paid by ancillary tenants.

"Anchor Tenants". Business Dictionary. http://www. businessdictionary.com/definition/anchor-tenant.html.

39. Khan, Adella. "Somerset House seeks tenants." Centretown News, February 20, 2015: 1-2
In an issue on February 20th 2015 of Centretown News, an article elaborated the urgency for the Somerset House to anchor tenants ${ }^{38}$, filling the large spaces at 6000sqf on each floor. By so doing, the so-called "anchor tenants" that are capable of filling up the spaces and generate stable revenue will facilitate the upcoming renovation in June 2015. The current owner, Tony Shahrasebi has previously been working with a national retailer, but the long process has lead him to seek alternatives. The house was considered an eyesore for the community, explained in the news journal. It has attracted various political voices to participate in "fixing the problem". However, there seems a new ruderal ecology within the "eyesore", the unwanted. A ruderal species, in botanical terms, describes plants that thrive and colonize in disturbed area or waste spaces. The urban reaction to the unwanted artificial ruin of the Somerset House gives a similar expression: artist's graffiti on the barricades, layers of posters take over the broken windows and doors, and an occasional person who wanders and peeks into the locked spaces of the ruined house. ${ }^{39}$

The house is not unwanted. Its valuable spaces provide a ground for local inhabitants to manifest their view in an unsolicited fashion. The currently 
abandoned spaces allow transient participation at different times by different individuals. The familiarity, recognized as "the eyesore", does not come from an anchoring object that occupies the space permanently, but comes from the constant regeneration of materials such as posters and graffiti tags layering and overlapping onto the barricades. Here, the barricades are the infrastructural backbone that enables such regenerations of visual stimulus to take place and renew themselves due to timely constraints of either the events promoted by the posters or the deterioration of the pigments of the graffiti tags. The temporal spatial engagement of a person with the house is no larger than the volume of one's own body and no longer than the length of time to poster or paint. The actions that generated the layered visuals onto the "unwanted" Somerset House are extremely transient and ephemeral, with the participants' very existence only traceable via the reminiscence of their actions: posters and coloured pigments on the barricades.

The ephemeral participation at the ruined Somerset House leaves a reminder of the sharing economy led by the trending Airbnb model of hospitality. Airbnb is not a hotel yet the network of Airbnb, utilizing the Internet as its infrastructural backbone, has enabled homeowners or tenants of rental 
properties to participate in the constant regeneration of its flesh: a freshly made bed revealing no traces of the past travelers in an authentic cultural context. Although the spaces are rearranged anew each time a traveler comes for a short stay, they leave traces behind in related spaces: a gift for the host, a comment on the Internet page etc. The action of engagement and exchange here is visually manifested and added to the "authentic cultural context" that Airbnb is branded upon. The exclusive space for the transient travelers is narrowed down to a bed, and the rest a shared space with the owner as part of the "authentic cultural context". In contrast, a hotel room inherits no visual traces of its past occupants. The clean, pristine appearance of a hotel room creates an illusion of exclusivity at a larger scale: the room that is cleaned and arranged on a daily basis as a generic space just like every other room within the building, or even within its chain-brand management. The passage to connect with the "context" is erased with the cleaning services, unlike in an Airbnb property, while the bed is exclusively made for the guest, the guest may engage with the cultural context visually through the setting of the room and through interacting with the host in person. Through minimizing exclusive spaces, a variety of scenarios can occur thus resulting in completely different sets of experiences that constantly excite 
the journey instead of the "standard hotel room" containing what is always expected.

Similarly in Cities, events area promoted via posters throughout the scattered devalued spaces in cites, for example light posts and barricades.

The devalued spaces become the infrastructure enabling unsolicited actions, in this case postering, resulting in a better connected artist's community by promoting individual events. Unlike common publicity, these devalued spaces require minimal efforts and costs to propagate advertisement yet always in the most unignorable position to be seen: they coexist with the everyday life of people. Not only in itself the act of propagating posters is an action of transiency, the viewers participate to validate the valued transient engagement. 


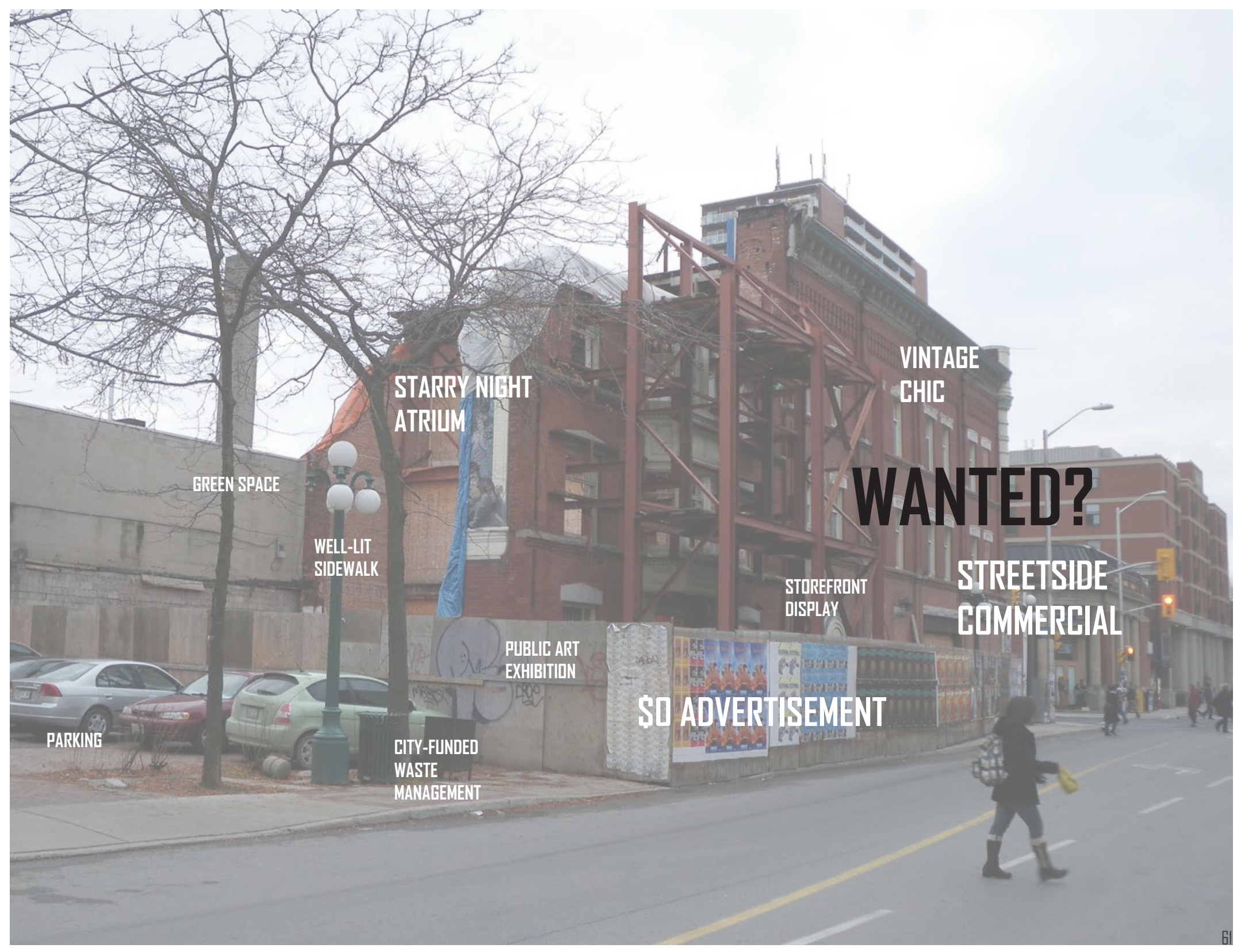




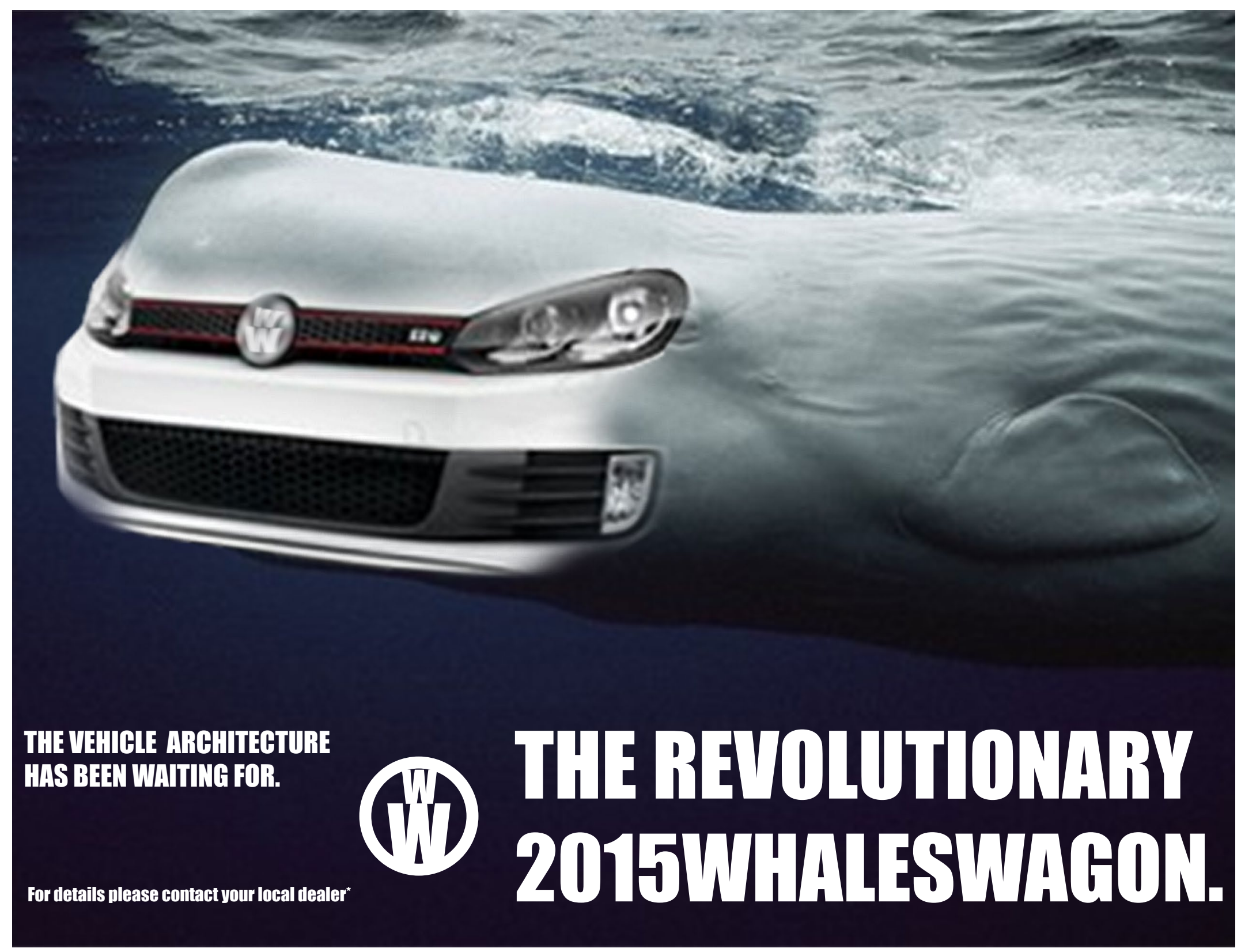


Back Stage:

Upeaval as an

Architectural Performance

40. Data obtained from Primcorp <http://www.primecorp.ca/ historic-somerset-house/>

\section{FUTURE:}

\section{A SPECULATIVE ALTERNATIVE}

Currently the property 352 Somerset Street is advertised as four levels of office spaces; ranging $\$ 10$ to $\$ 35$ per sqf, the 6000 sqf floorplate ${ }^{40}$ will generate a stable income if leased. It will welcome anchor tenants that are capable of promising long-term profit for the owner. Once again, the owner stresses that the visual aspect of the house will be "beautifully restored" revealing the brick texture at the interior of the office spaces. However, going through the history of the Somerset House, the renewed house that takes the same skin is losing its history as the once loved destination in the neighborhood. Of course there is a market for commercial or office spaces, but in what way can a workspace become heterogeneous and ignite more collaborative engagement without compromising its function to serve the 9 to 5 workdays? Taking inspirations from unsolicited events such as the Bucky Dome and Occupy Central Movement, can the spontaneous flow of public engagement inhabit the skin of the Somerset House differently? What

if the stable 9 to 5 lifestyle can coexist simultaneously with the transient 
public participation in a limited footprint throughout the 24-hour day so that the house itself becomes a heterogeneous enclave that never falls asleep?

By turning the off hours into on hours, the architecture becomes a machine, a generator that keeps the community engaged not only within its physical floor area that it can offer, but in the measure of time: the house that functions 24 hours per day. Given the 8-hour office habit of the modern lifestyle, the office space is usually vacant $2 / 3$ of the day. The remaining 16 hours out of the 24-hour day is undervalued, just as the ruined Somerset House is viewed by the neighbourhood an eyesore, or an airbed tucked away in an Airbnb listing. If set aside 1/3 of the floor area of the Somerset house for the permanent office area that operates $1 / 3$ of a day's hours, the other $2 / 3$ of the space that can function in a longer hours should take responsibilities to generate more opportunities to enable activities that are heterogeneous and potentially unsolicited. The ruined Somerset House expresses a perfect opportunity from its collapse; the event of destruction is an upheaval and frees up the rare half of the building from its rigid functional space. The tragedy should not be taken as an unfortunate event but should be transformed into a new ground for speculative architecture. An 
architecture that is constantly in action, not as a heritage building preserved in stills for storytelling, but a framework that allows multiple stories to be expressed: an expressive architecture that is like a screenplay constructed from different frames and angles of perception, except that in the experience of architecture, each participant of the spatial and timely configuration is an actor, each eye is a camera, each encounter draws an episode, and the stories of different individuals intertwine into endless dramatic scenarios without intermission.

Through appreciating the undervalued spaces and hours, the value generated is not limited to the monetary revenues resulting from previously assured models such as the "anchor tenant" leasing strategy and mixed-use with street level commercial, but more by allowing values to be discovered, tested, and generated by the participants of the architectural spaces themselves. Like posters and graffiti which redefine the values of the barricaded "eyesore" by benefiting the public exposure of different communities of artists, the new Somerset House should be inhabited by an eclectic collection of architectural environments suitable for both work and leisure. 
Of course it is impossible to re-write the history of the Somerset House since its collapse, but it may still be worthy to suggest an alternative scenario to speculate what could happen in an imaginary imagery: as Bernard Tcshumi would say "architecture in paper space". 


\section{WANTED}

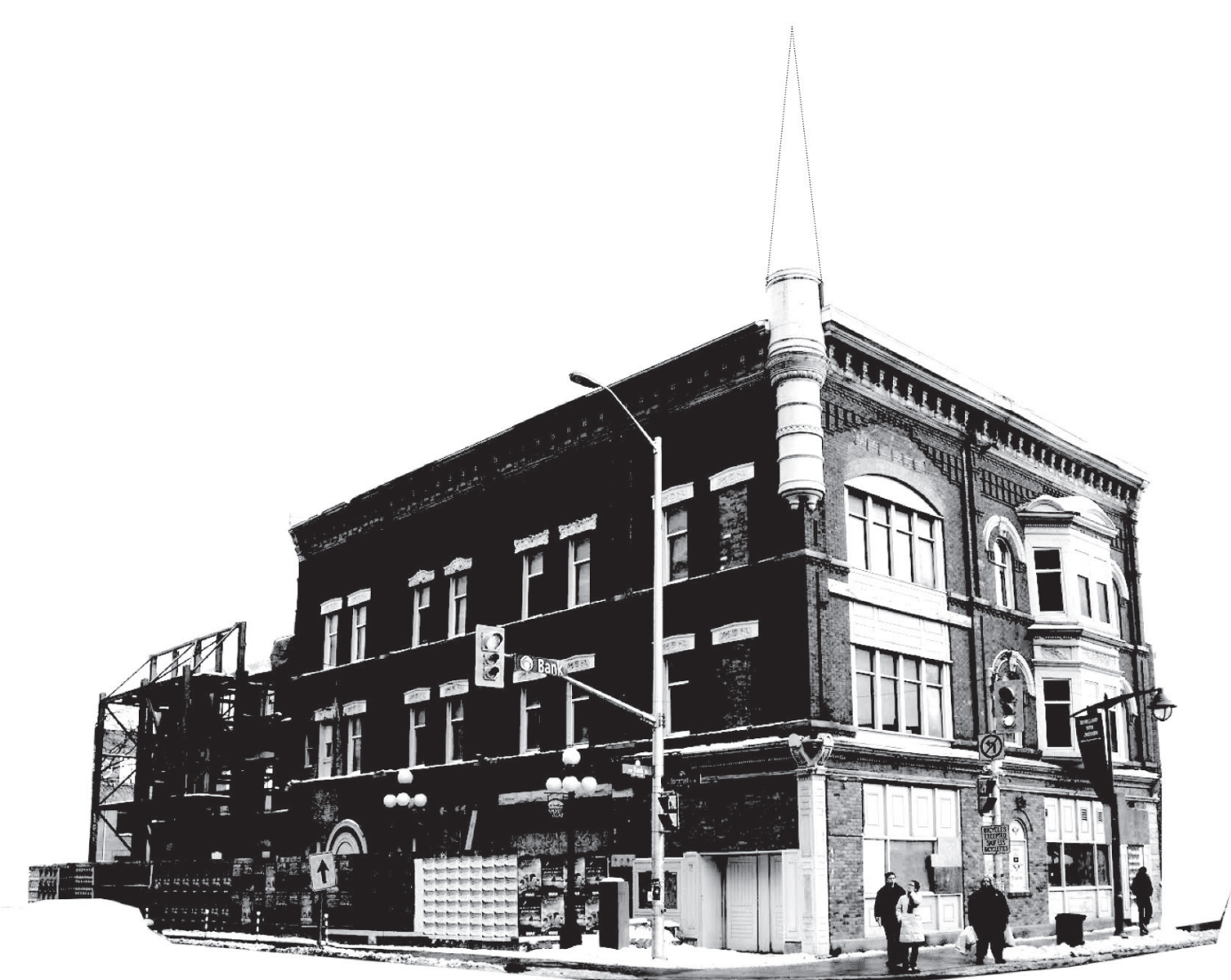

Centuny/22

Getting what you've always wanted is never this easy. 


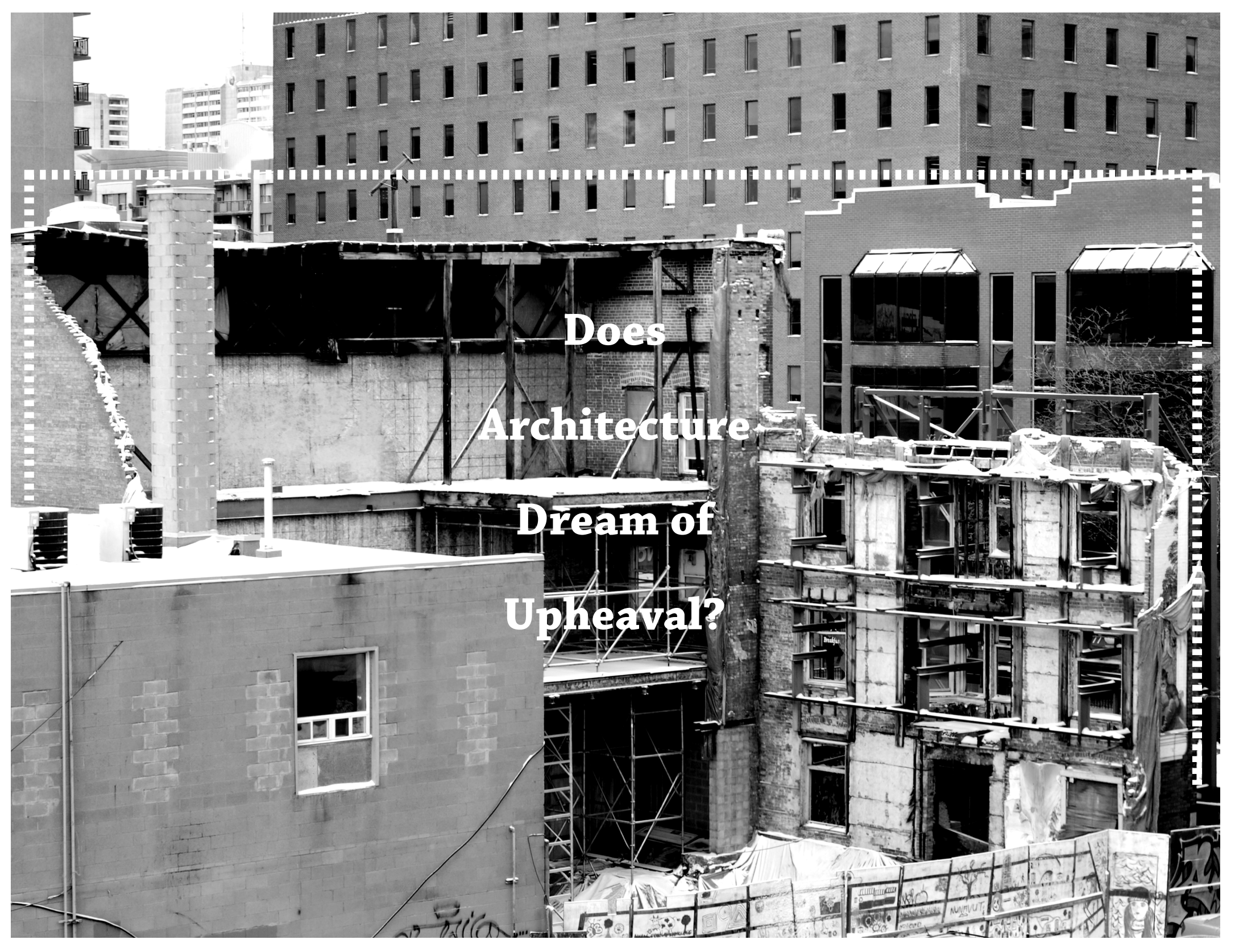


Act I 
Act I

Scene O

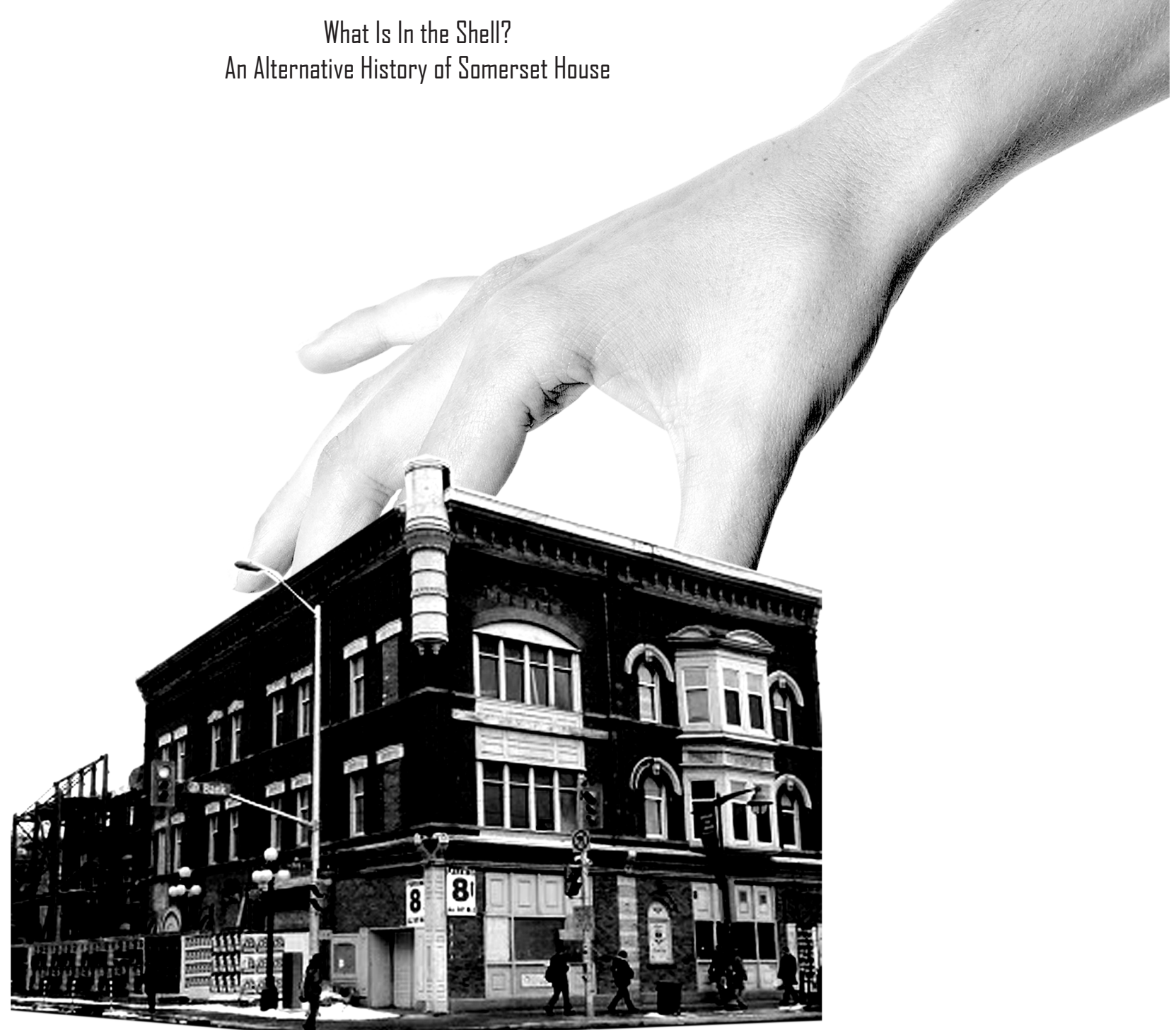




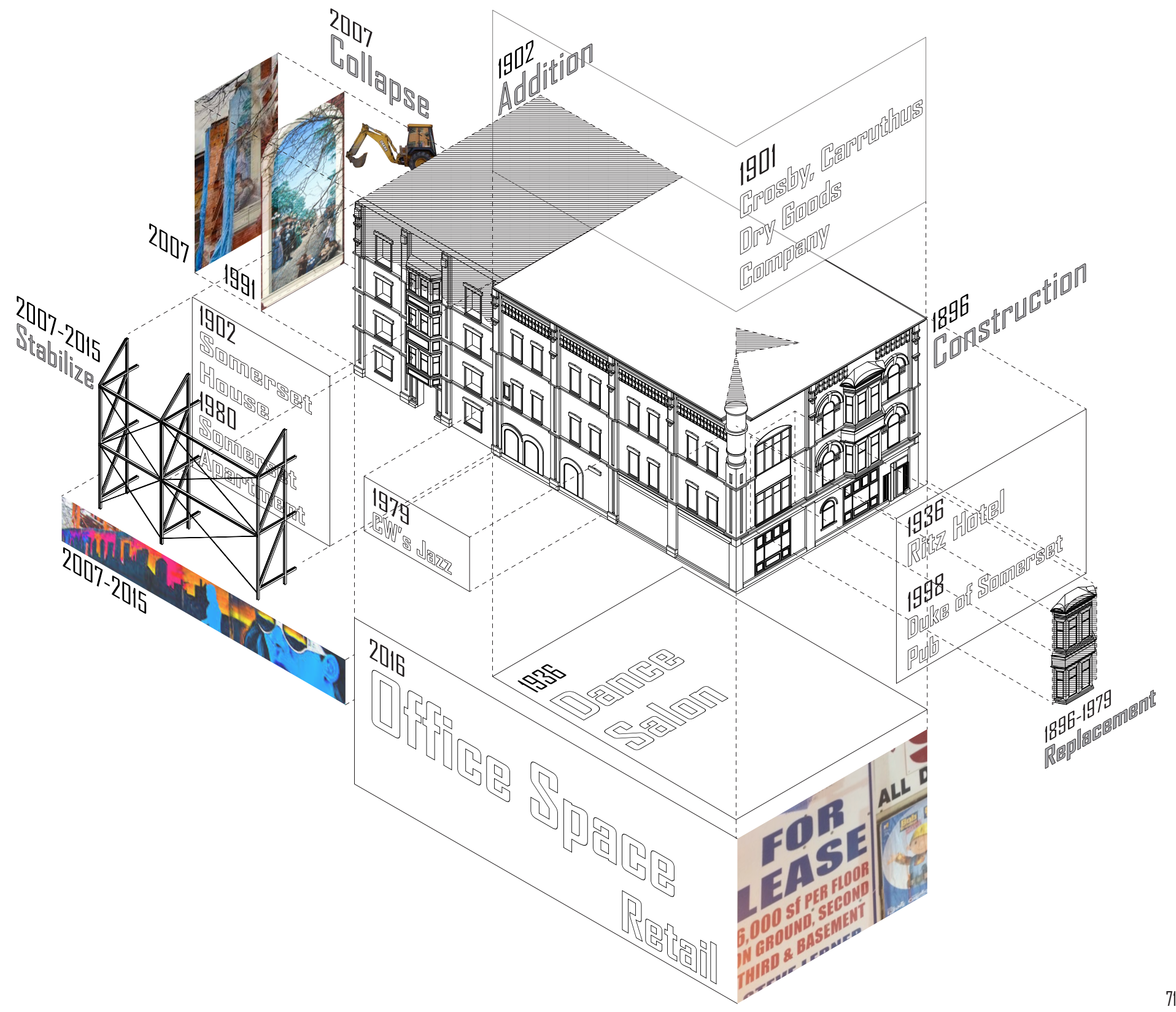




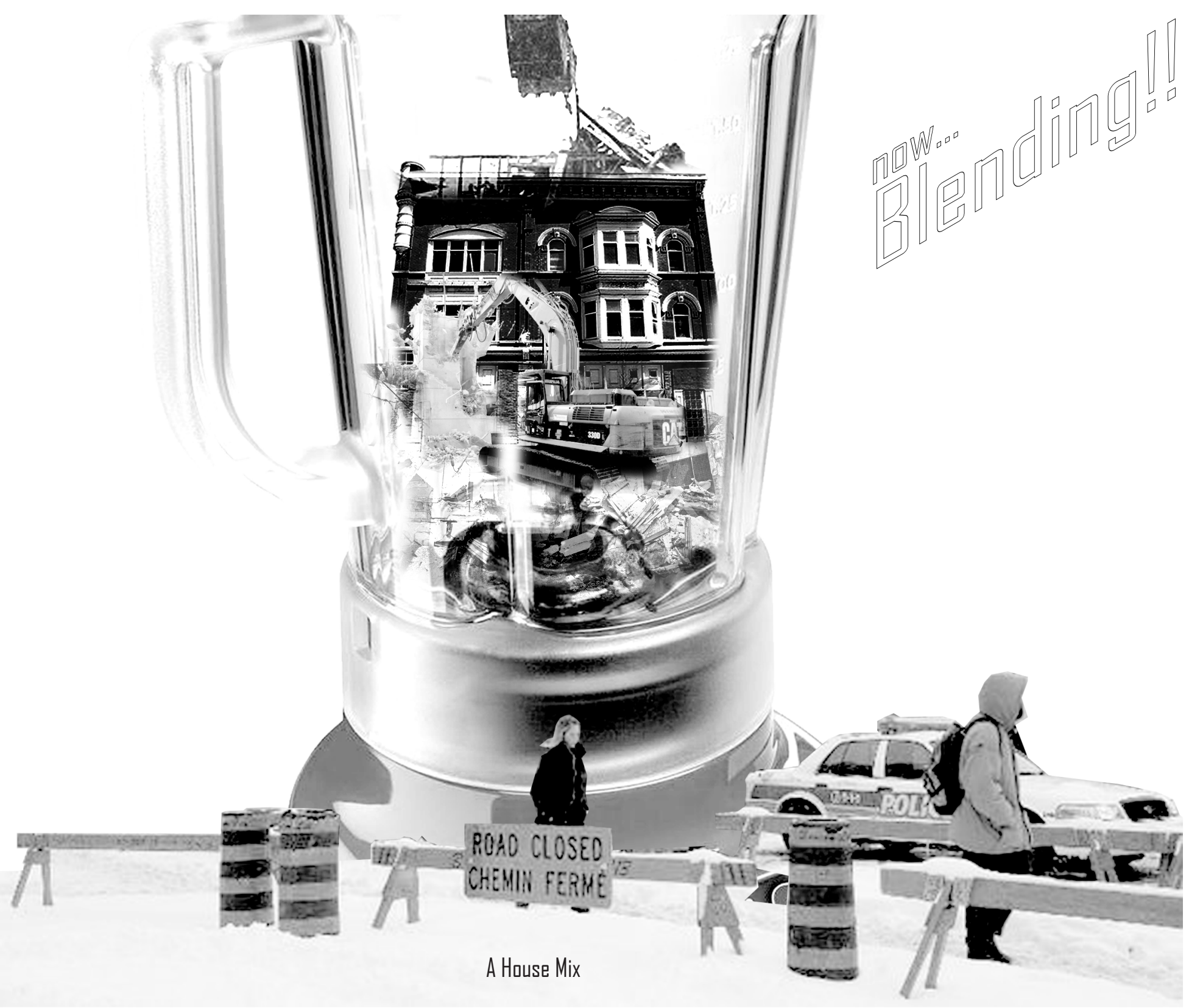


Act II 


\section{TURNING THE GEAR:}

\section{THE BIG BOX OFFICE}

To turn the financial gear, 352 Somerset is in need of an anchoring tenant.

The anchoring tenant will not supply a good source of revenue for the

property owner but also ensures a stable financial state of the new Somerset

House.

The 1890 s house is also in need of a structural retrofit, so that the façade of this fabric heritage at the corner of Bank and Somerset Street can continue to anchor onto the historic site that has witnessed Ottawa's transition from an industrial town to a city supported by businesses of different scales. To invite the anchor tenant as soon as possible, a box is prefabricated off-site and assembled on site. The deteriorated interior floors have been stripped away and replaced with a new structure to welcome the insertion of the box, the Big Box Office. The box appears afloat, leaving the ground level longing to be filled with air and movement. It is the Blank Space that will be taken over in no time by both artificially propagated greeneries and daily engagement

of human activities. It is an internalized botanical landscape that keeps the 
city dwellers reminded of the reprise of seasons and the scents of moistures in the soil where life sprouts and grows. As the sunlight travels through the gaps between the Big Box and the 1890s façade unintended by any architect's vision, time leaves its trail for the inhabitants of the space to catch. Soon the trail of light disappears as one tries to approach it as the passing of hours becomes increasingly vivid. While the sun draws its traces of time, the botanical species pass life cycles significantly slower than the rays of the sun. The city dwellers have their own cycles of inhabiting this space as well: the 9 to 5, Monday to Friday work cycle. The space of the shell is inhabited, with times at different paces from observable motions of sun rays to the unnoticed unfolding of a seedling's leaves. 


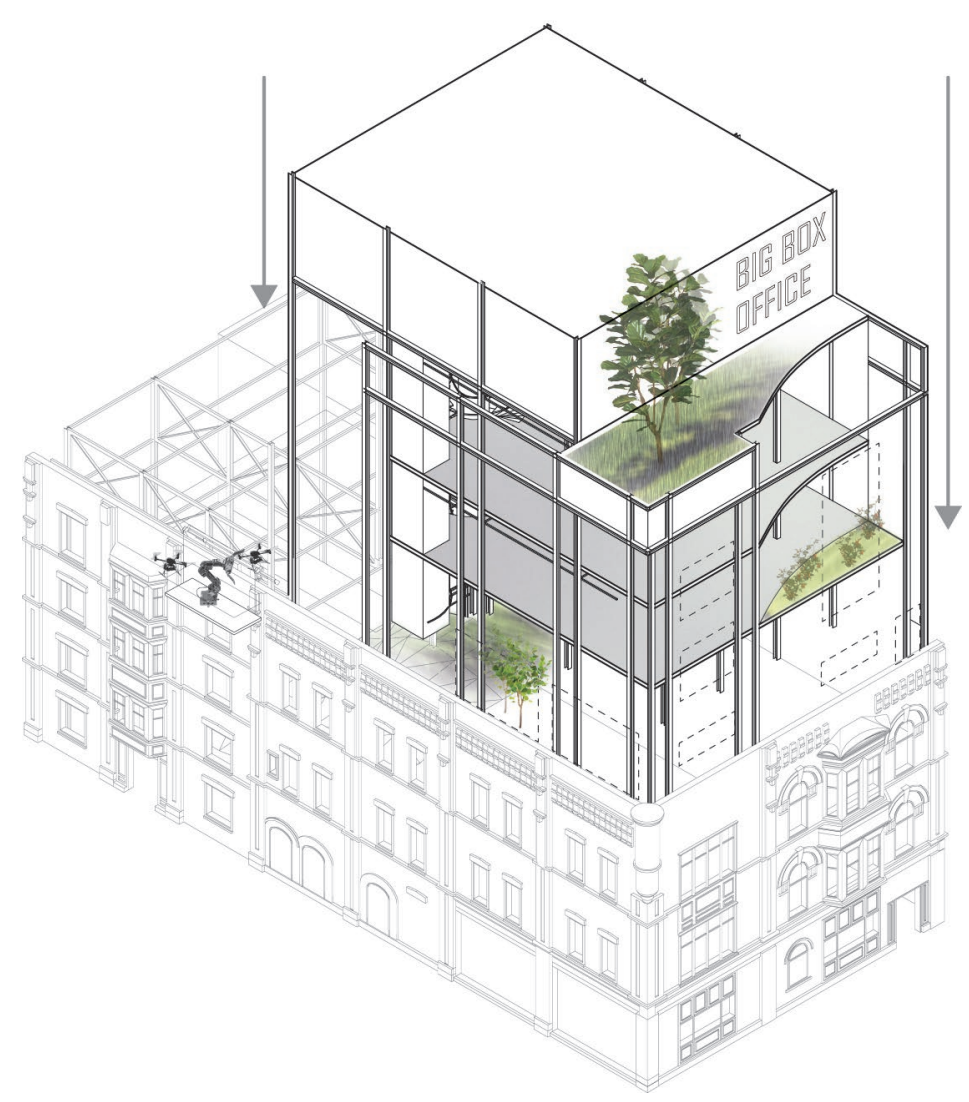

Dccupying the Shell 


\section{ROBOTICS AND 3D PRINTING MOUNTED ON ARMATURE...}

... restoring the architectural integrity of the collapsed portion

The Big Box has welcomed its tenants to work inside the skin of the former Somerset House. Now steel armatures are set up so that the cubical offices for the technicians and the harnesses for machineries are plugged in place to initiate the second phase of the restoration at the rare façade at Somerset Street.

A typical day:

Early morning, a group of drones fly over the collapsed façade to inspect the conditions of the ruin while the technicians work to coordinate the sequence of the day's work and sending the codes to operate the $3 \mathrm{D}$ printer. At the same time a truck arrives with cartridges of filaments for the $3 \mathrm{D}$ printer and then a drone assists to unload and install the cartridges to the 3D printer. 


\section{WELCOMING THE 1/4 OFFICE}

The robotic team silently dismissed from the space leaving the armature and the empty technician's cubical standing behind the newly printed façade of Somerset House. A young entrepreneur picking a piece of onion off his 8 " greasy pizza sliced into quarters from the pizza shack across the street from Somerset House, staring at the peaking corner of the cubical through the voids on the façade at Somerset Street. There used to be windows, but now just empty openings. Actually it does not look bad at all: as you can observe what is behind the wall through the voids, fantasizing that the wall is a piece of contact sheet that a photographer carefully examines in search for a perfect moment framed and captured. With the roaring noise of trucks, the robotic team returns with parts to assemble into additional cubicles. Among the parts waiting to be assembled, a signage appears attractive to the young entrepreneur, as he wipes the grease off of his fingers ready to throw away the remaining $1 / 4$ of his pizza that he could not fit into his stomach. It reads, "The coin operated Cubicle Office: $1 / 4$ of a dollar gets you 1/4 of an hour and 1/4 of an office!" 
Act II

Scene 3
"Second thought," a voice in the young man's mind hovers, "I'll pack up the remaining $1 / 4$ for dinner...”

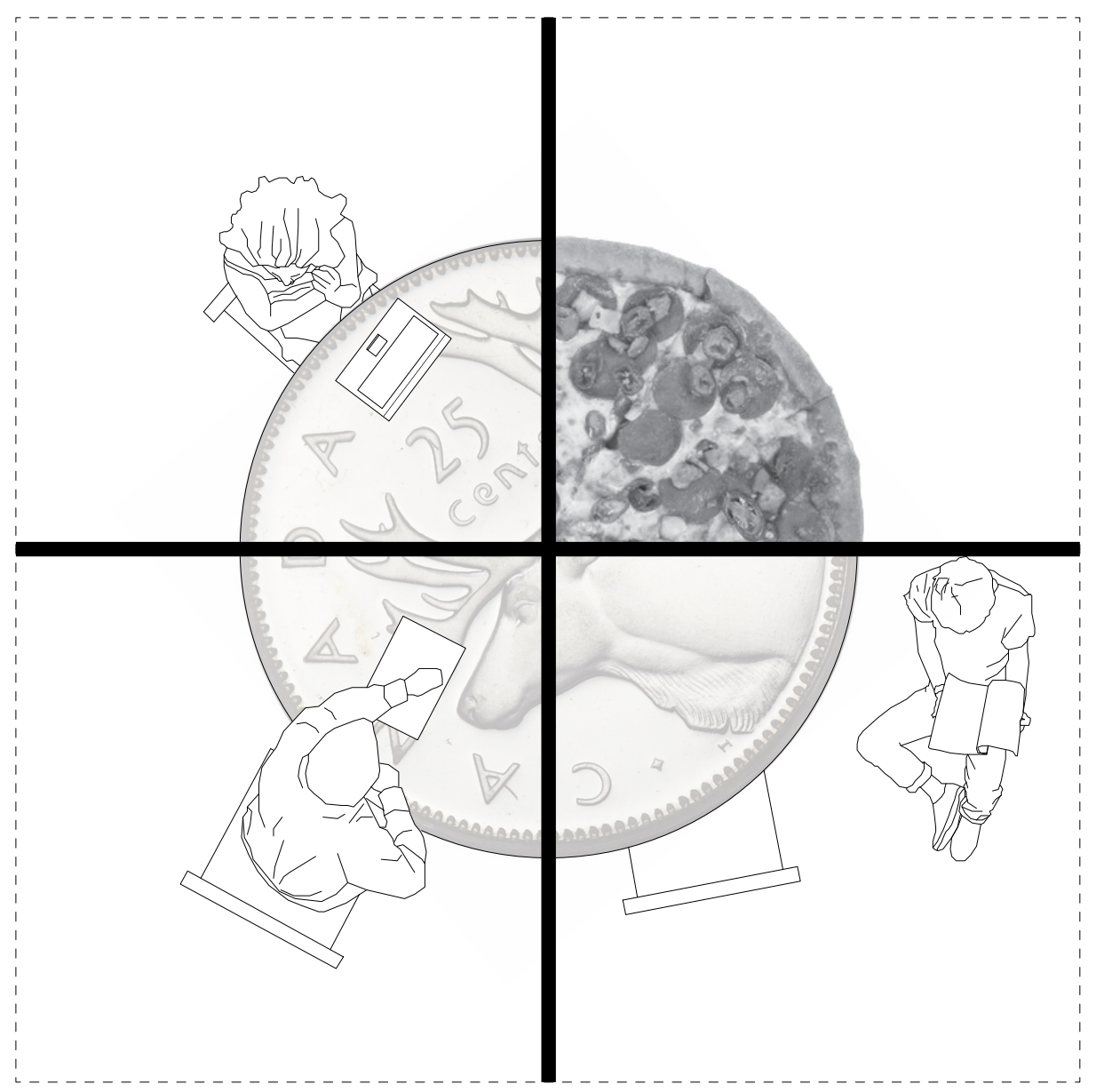


Act III 


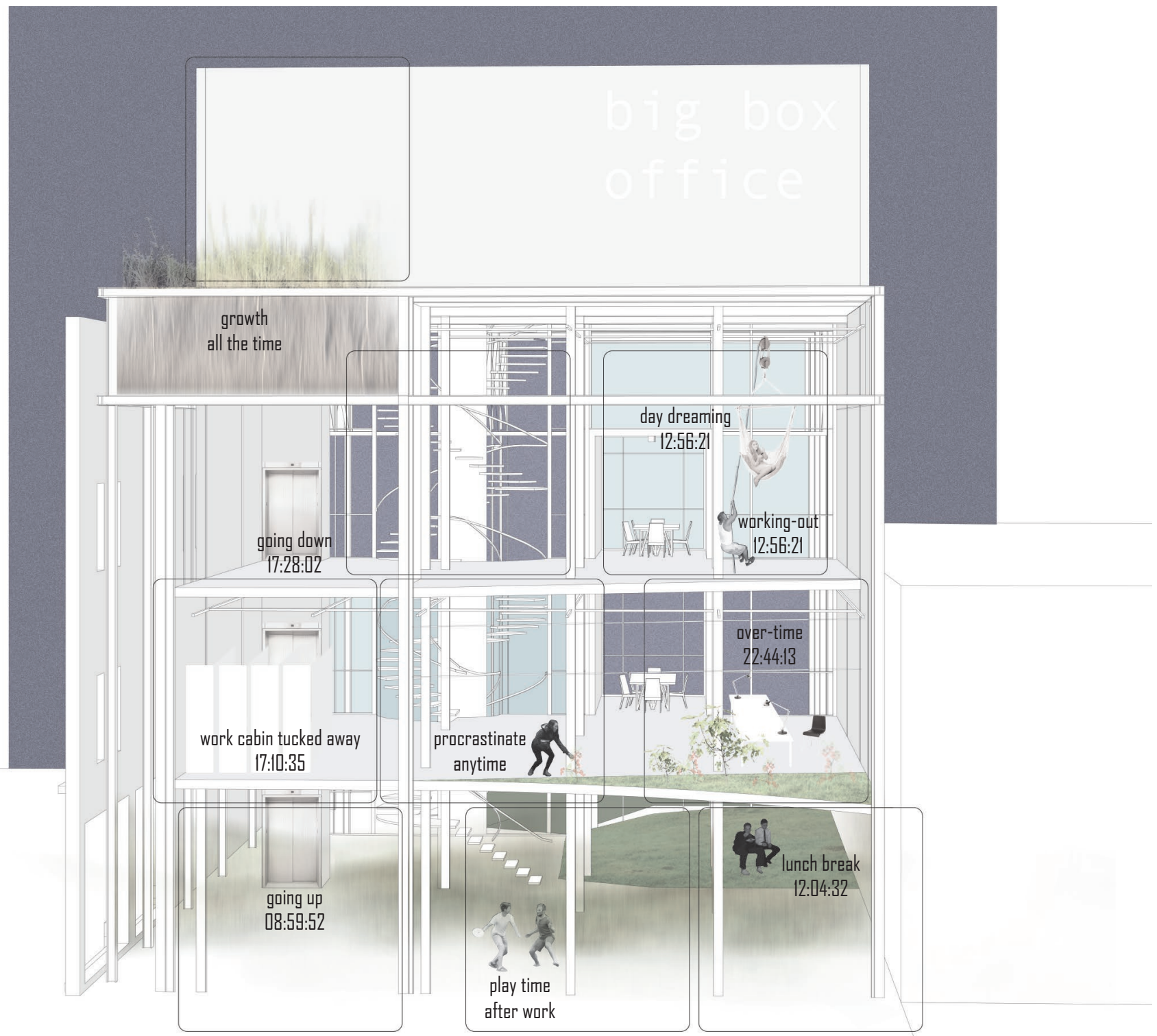

A day inside the Big Bax 
Act III

Scene 2

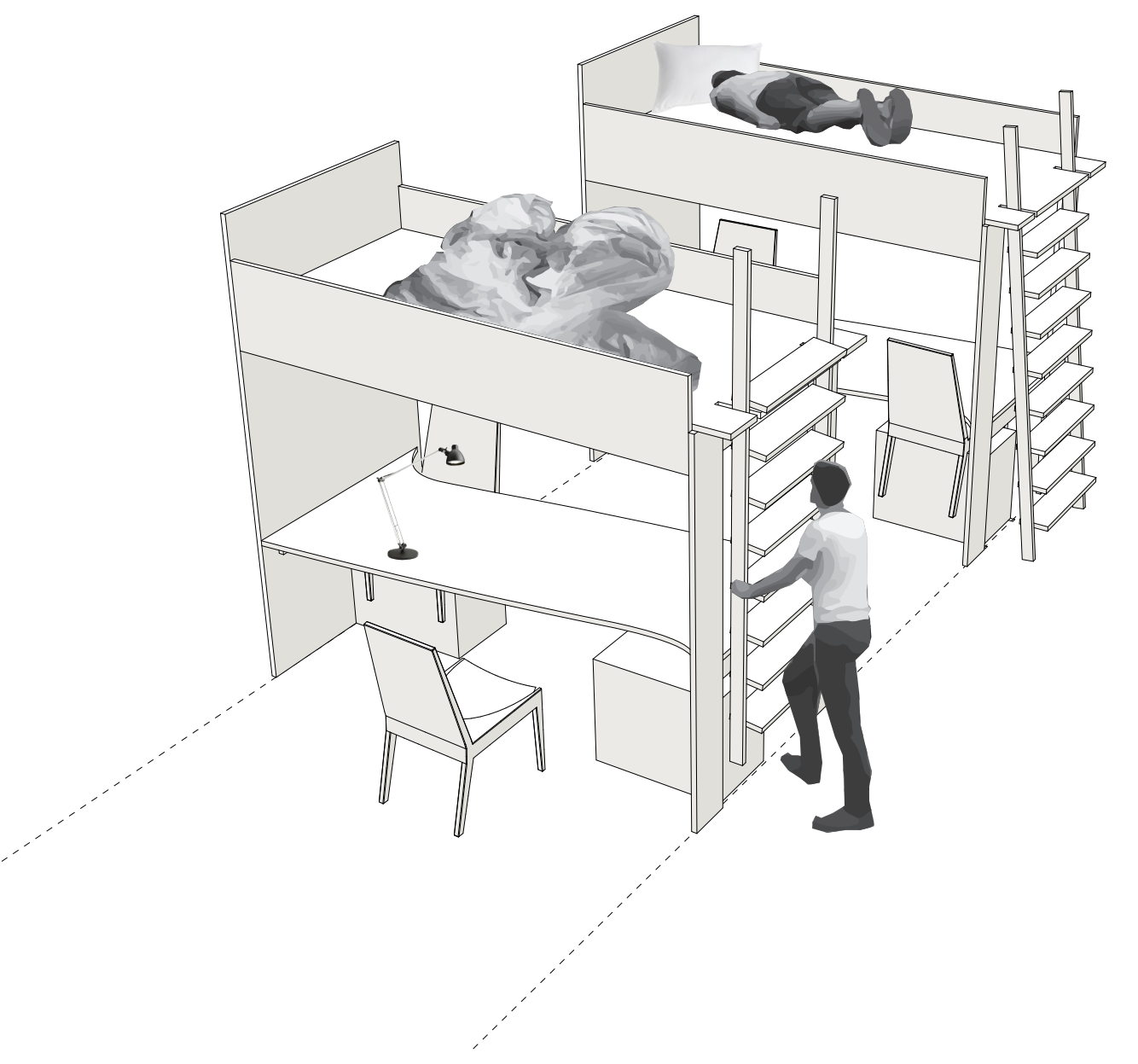

Work Cabin + Power-nap Station 
Act III

Scene 3

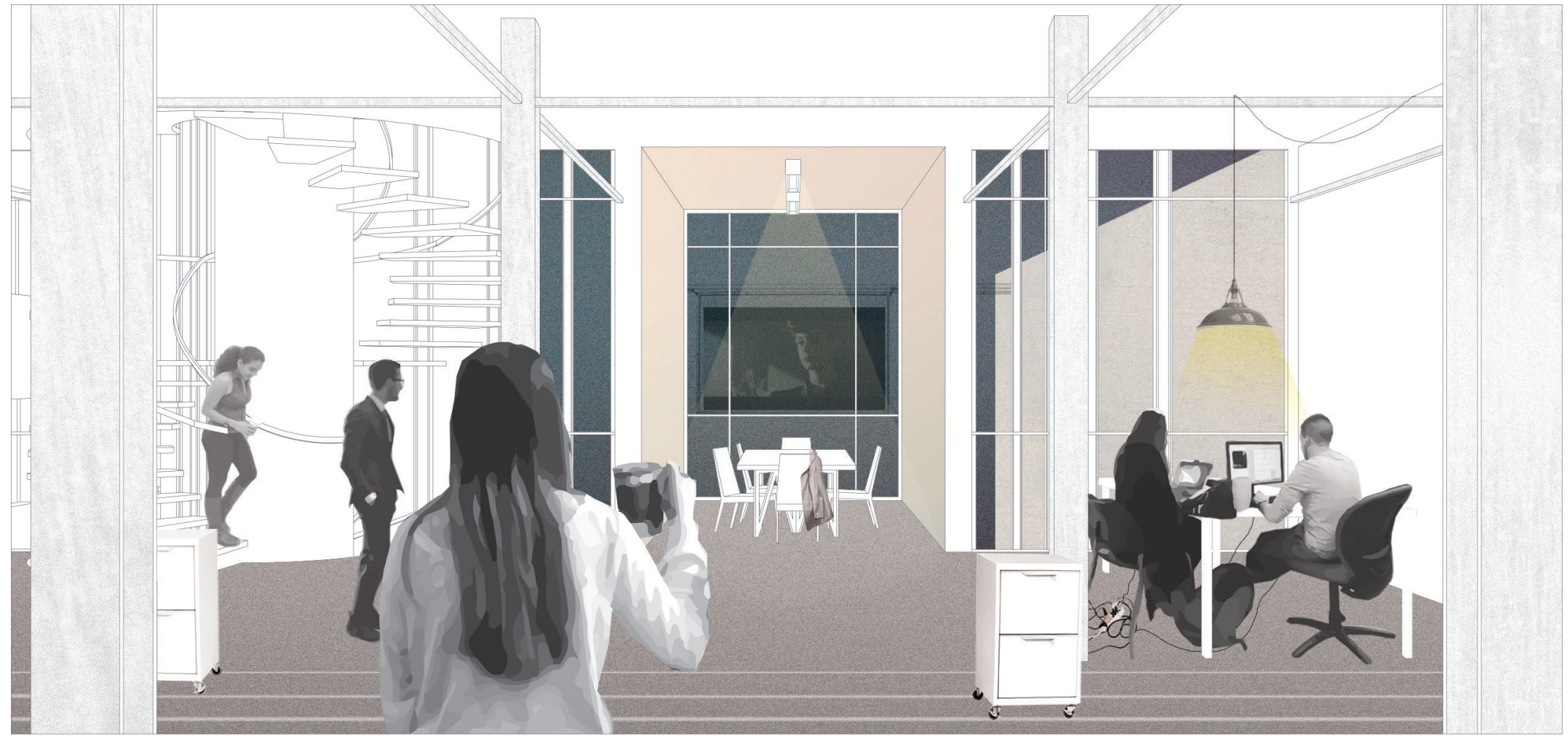

Not Your Usual Dffice Dvertime 
Act III

Scene 4

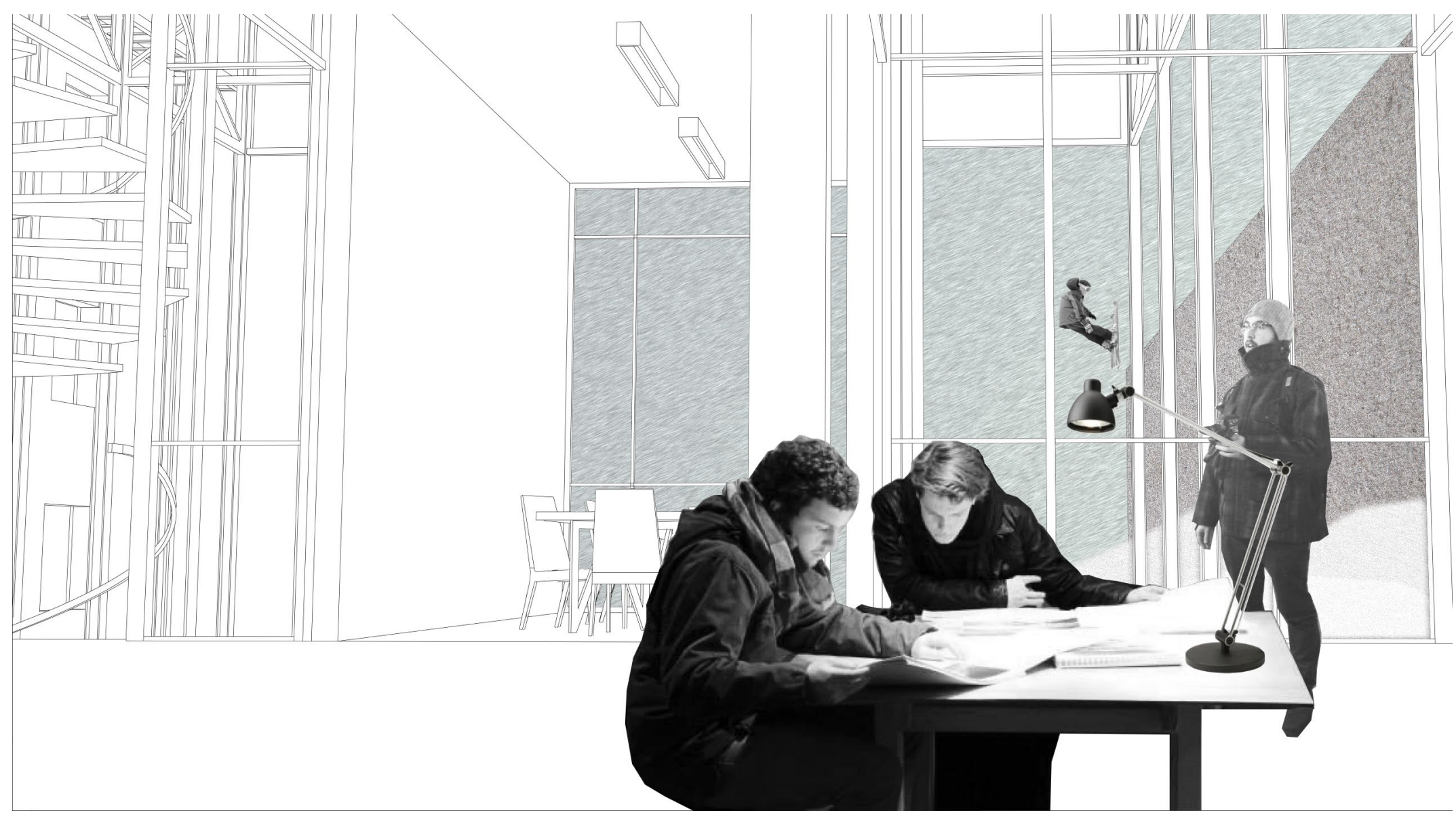

」: "Wait, you guys see that? Skiing on a snow dump..haha"

TI \&TZ: "..hmmmm...just let us work..." 
Act IV 


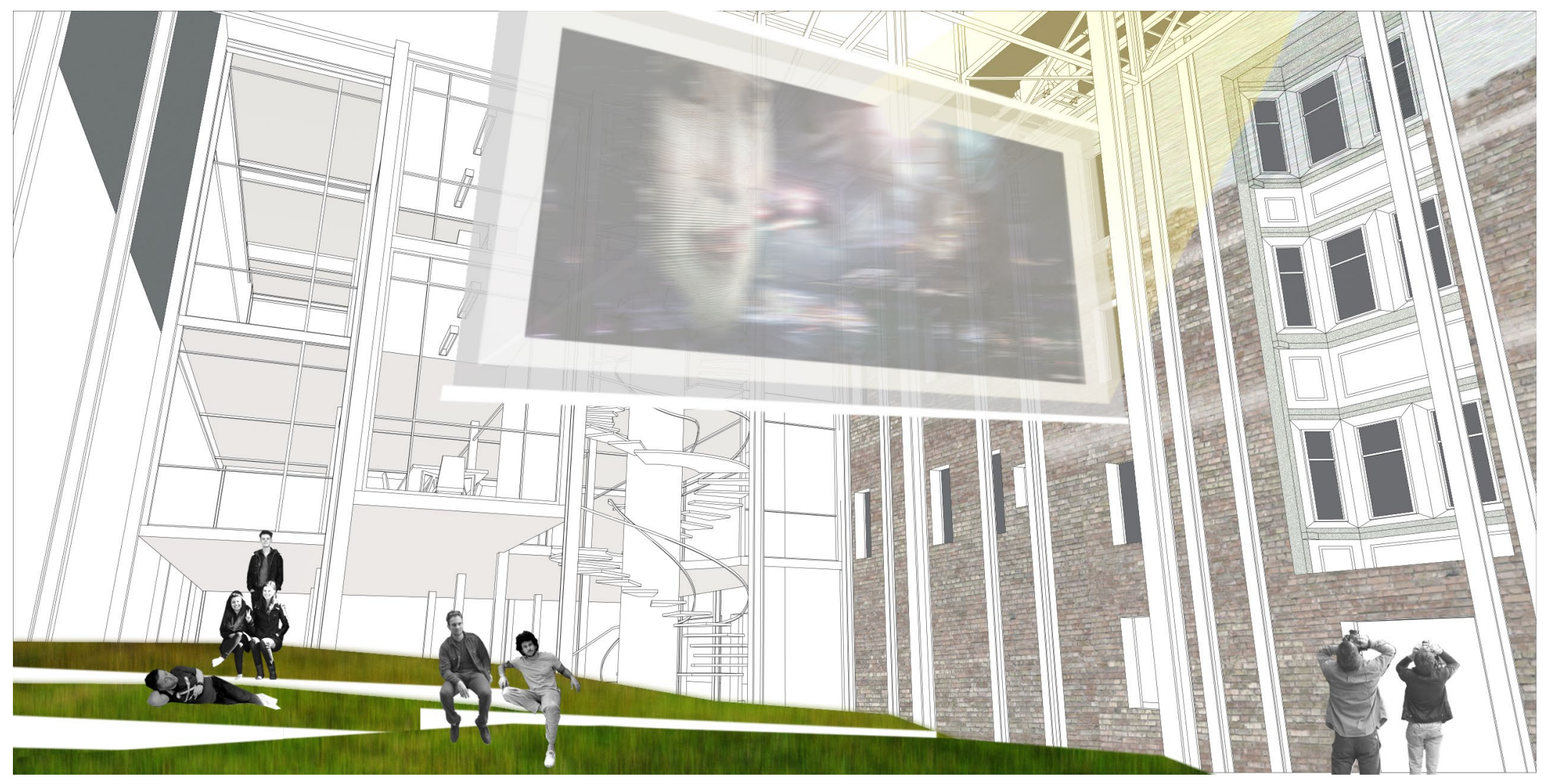

A sheltered green space becomes an open cinema 


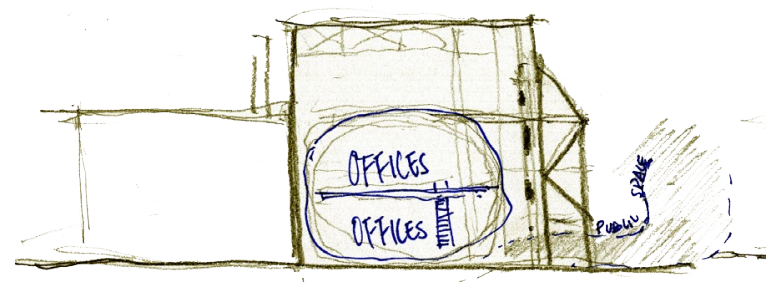

The space separating, more precisely, lifting the Big Box from the ground is a space that engages art and cultural events in the city. Paved by greeneries at the interior, the space is a micro-oasis in the heart of Centretown Ottawa regardless of the exterior weather. Artists will occasionally drop by, asking the possibilities to exhibit their works or to perform an abstract musical composition among the thriving botanical species overtaking the Blank Space. Here, the creative inspirations of human

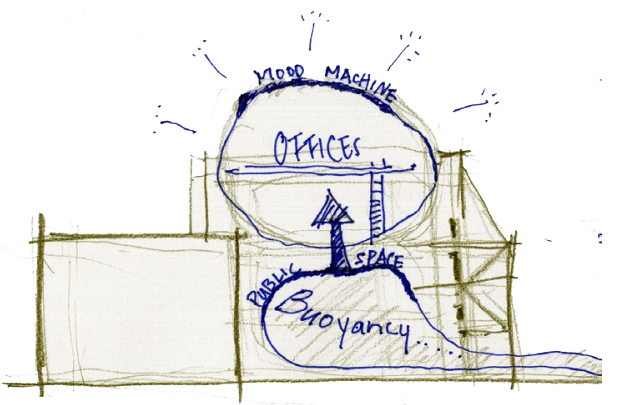
activities coexist with the illusive natural phenomena recreated by the gardeners of the Blank Space Gallery.

The Buoyancy Generator, advertised as the Blank Space Gallery, is now an artificially constructed nature, a quick-fix forest trail to suit your necessary procrastination-like how you would blow up your airbed for your guest right when they need a place to sleep. 


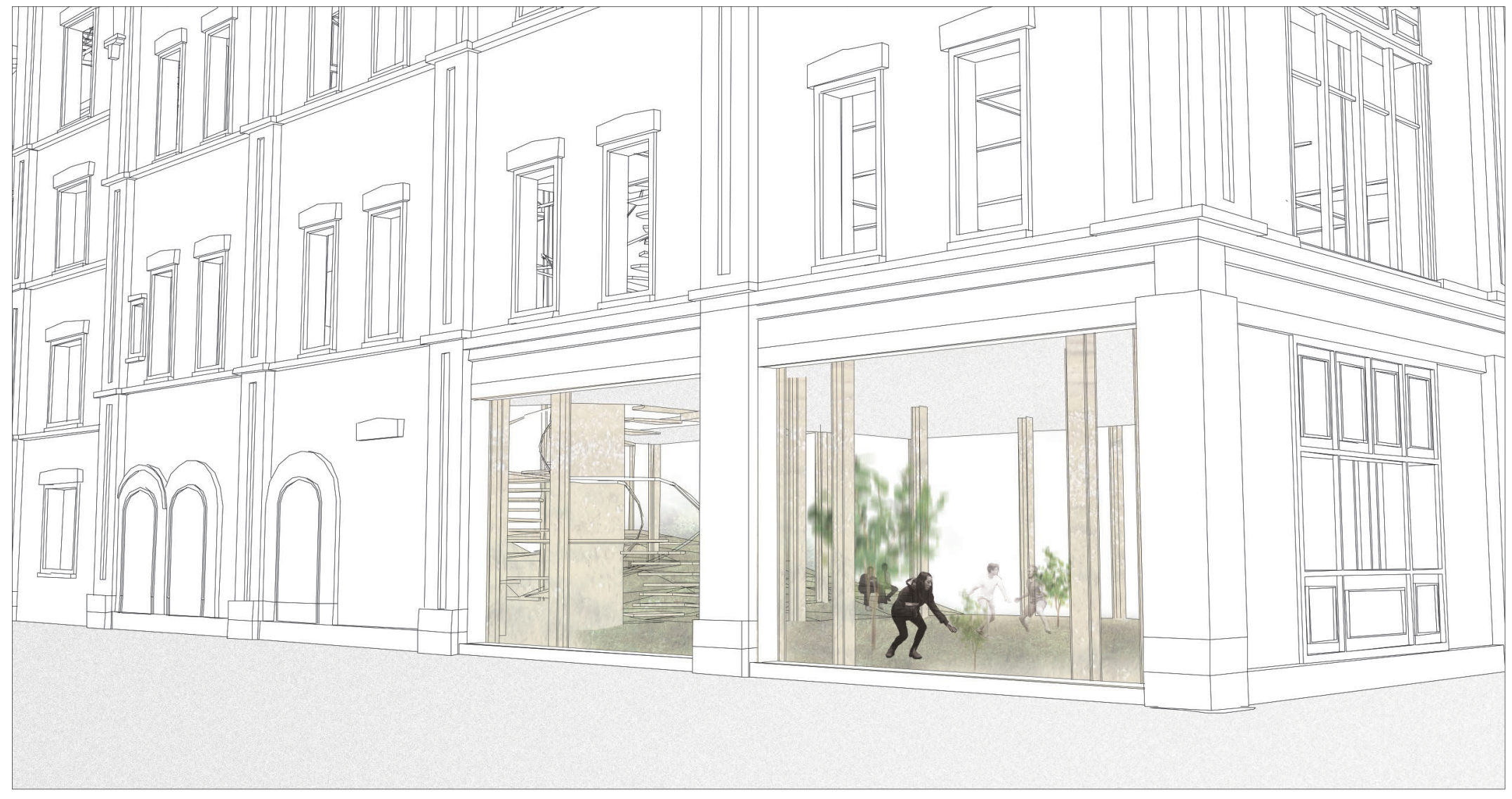

Blank Space is a gallery brought to life by gardeners. 
The botanical garden is not bounded inside the limitation of the Buoyancy Generator, it is intentionally made to trespass into the public spaces of the city and manifest itself as a comfortable seating area for an open-air cinema on one of the summer night.

In the winter, the space generously accepts all the snow from the parking lot right adjacent to it, somehow resembling a micro imagery of the Austrian Alps where one would imagine a skier descending down with invisible wings.

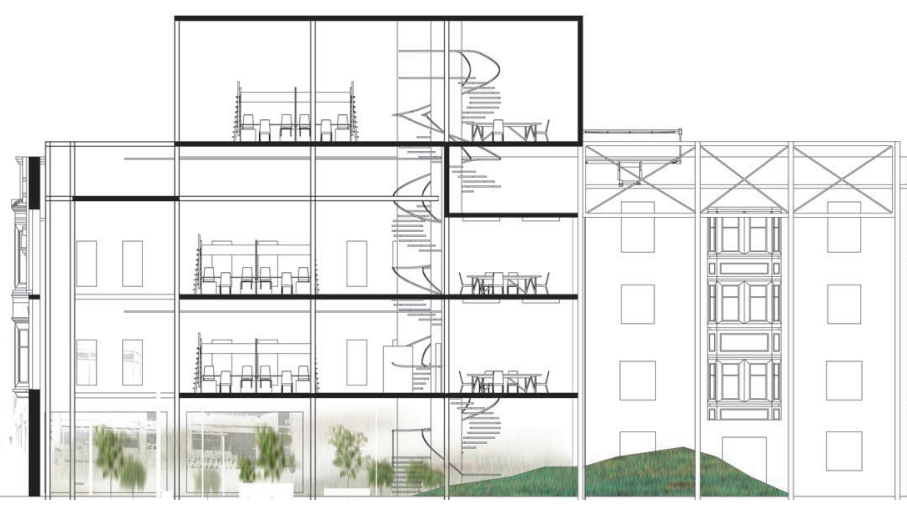

summer

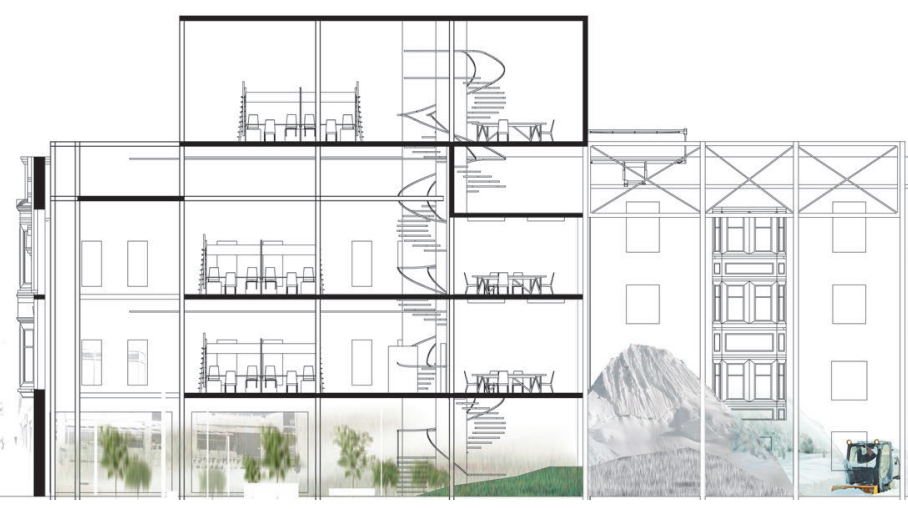

winter 


\section{UNDERWATER}

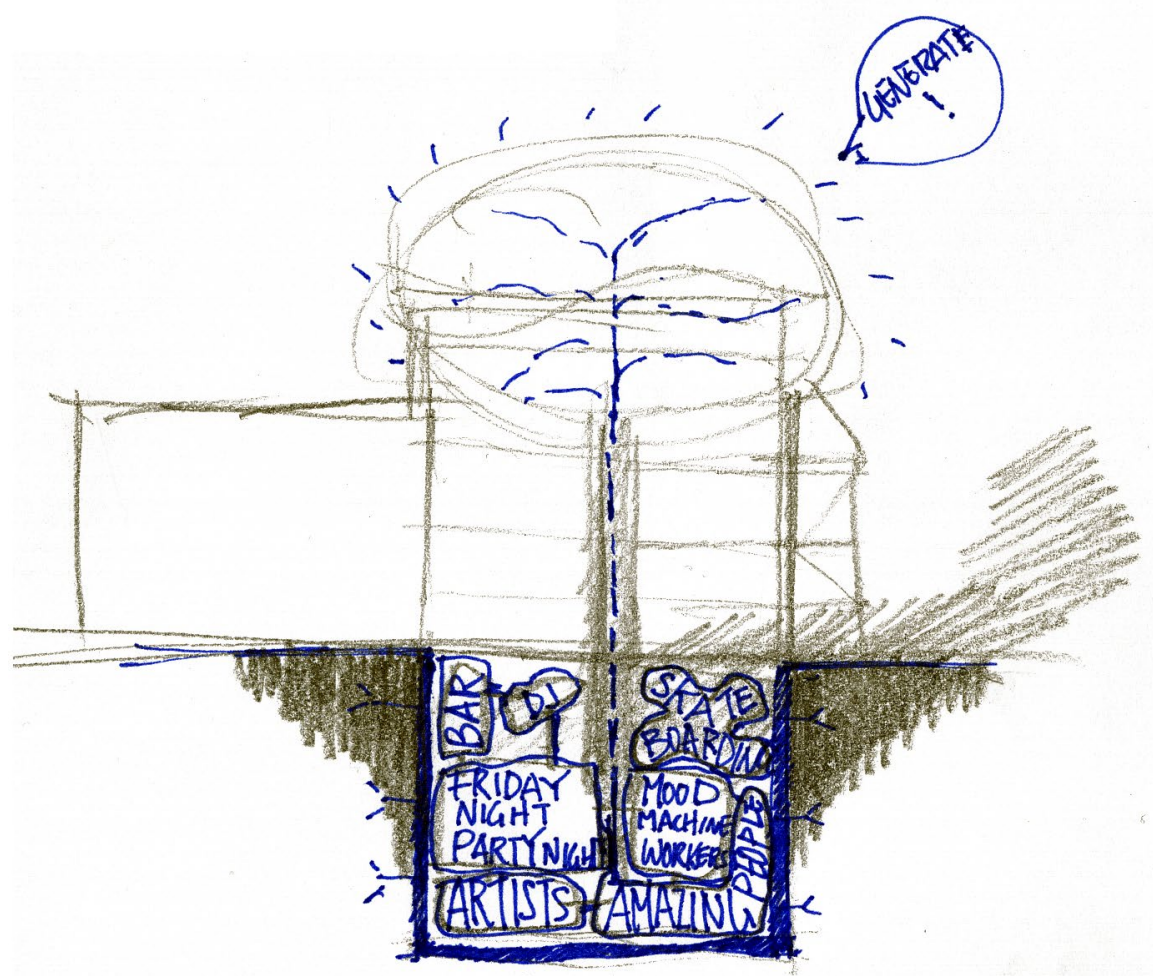


Underwater is a basement venue for the occasional swimmers.

The basement was originally excavated in 1936 to serve the function of a dance salon: a space dedicated to entertainment and relaxed gathering. It was exposed to the sky as the building collapsed during the accident in 2007 , however restored thanks to the team of robots and drones. 16 metres in width, the spacious basement is definitely capable of housing a scene unseen. To borrow from the former bar setting, the underground is not only a new nook for the community to spend their leisure hours, it is also a new venue for sound and visual brought by the artists inhabiting in the city. To entre, from the back of Somerset House through the narrow stairs tucked away from being seen, the seemingly dark and unwelcoming basement reveals its own charm as one approach to the space: sometimes a swimming pool but sometimes not.

The Underwater is so versatile that the space will come to you, please do not let it pass you by. It is at 352 Somerset Street, but the entrance is only from the back: a space tucked away like that airbed for your unexpected guest. 
Act V 


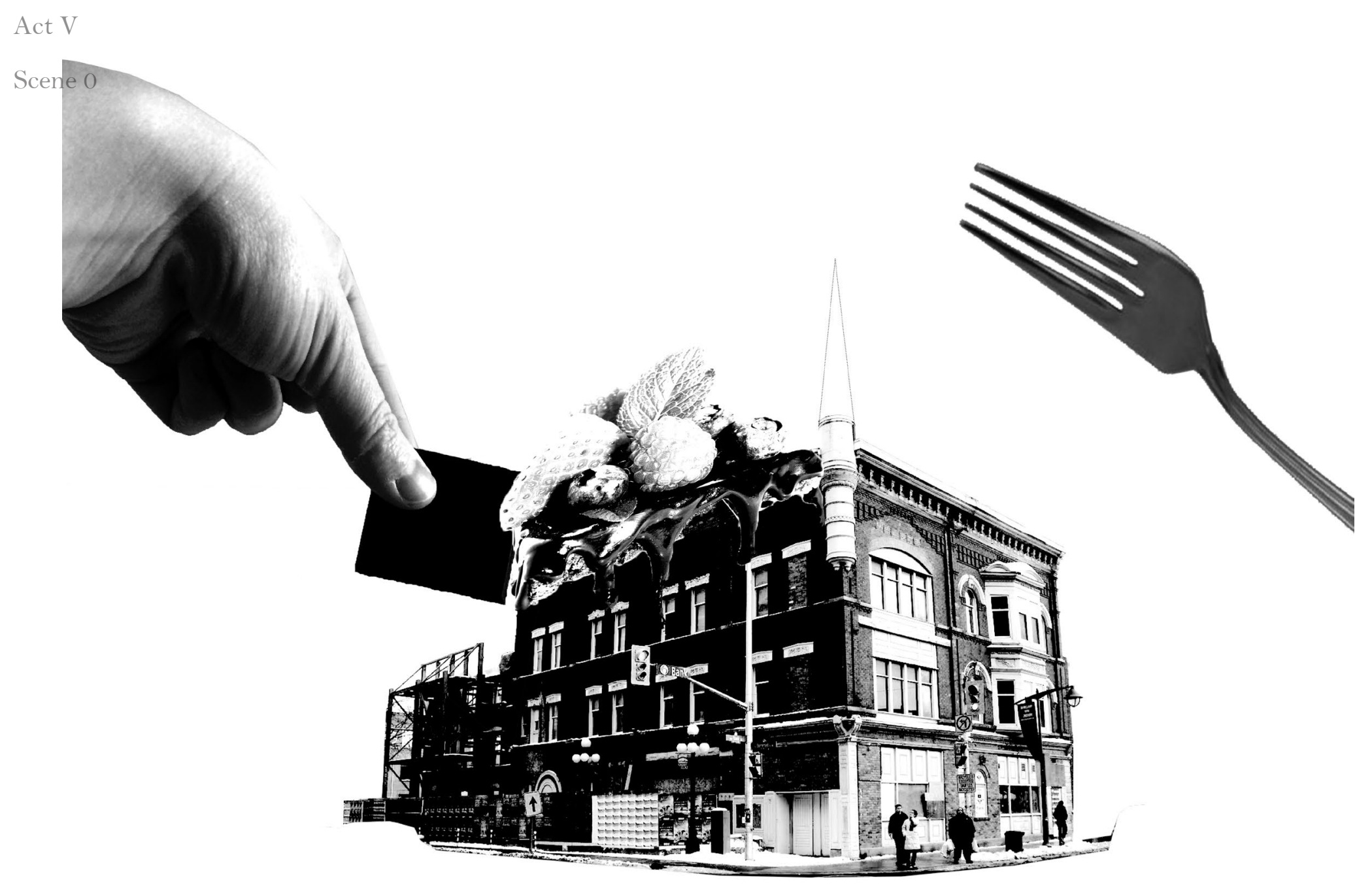

Everyone wants a bite of the cake,

Perhaps a little bit of deliciousness to share? 


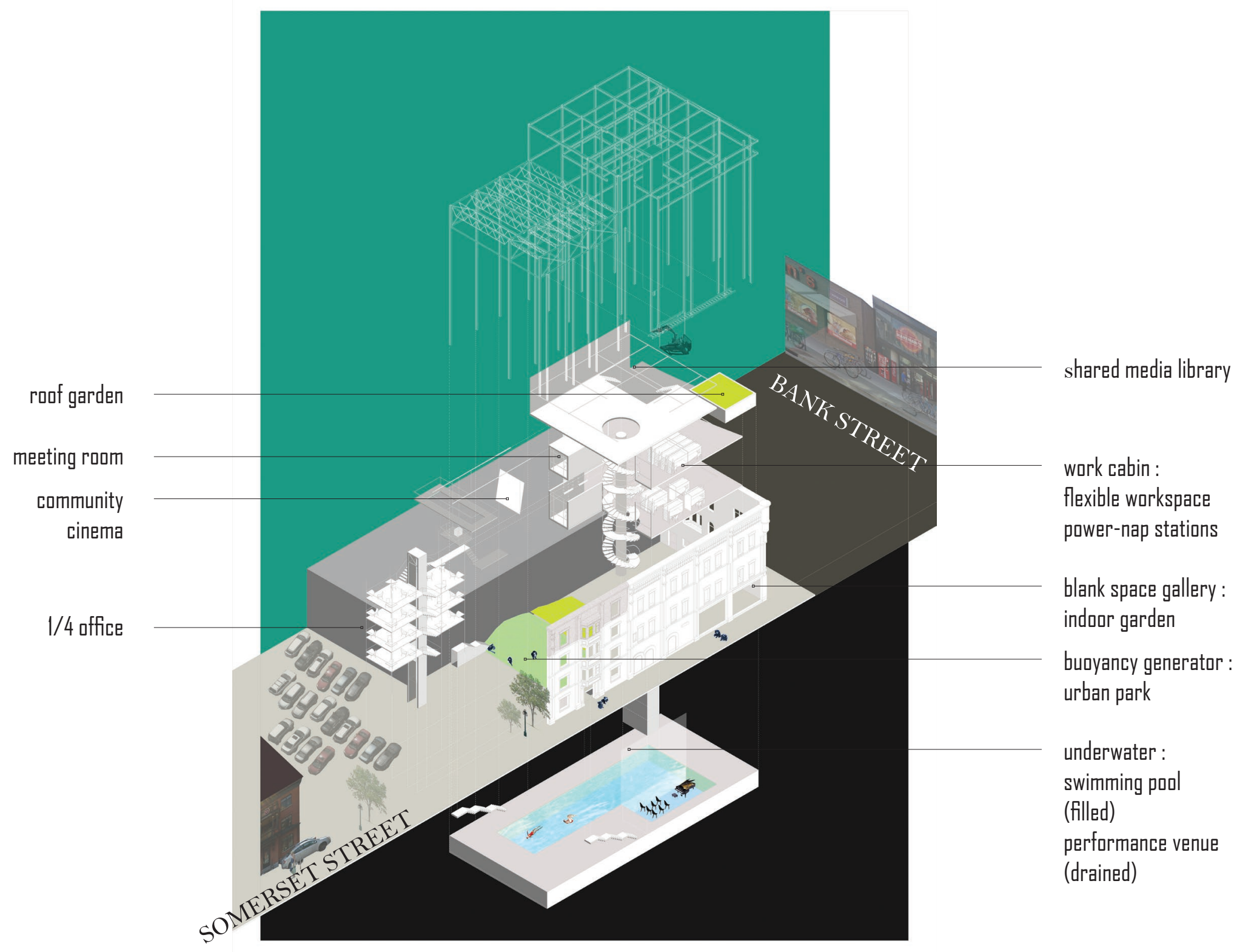




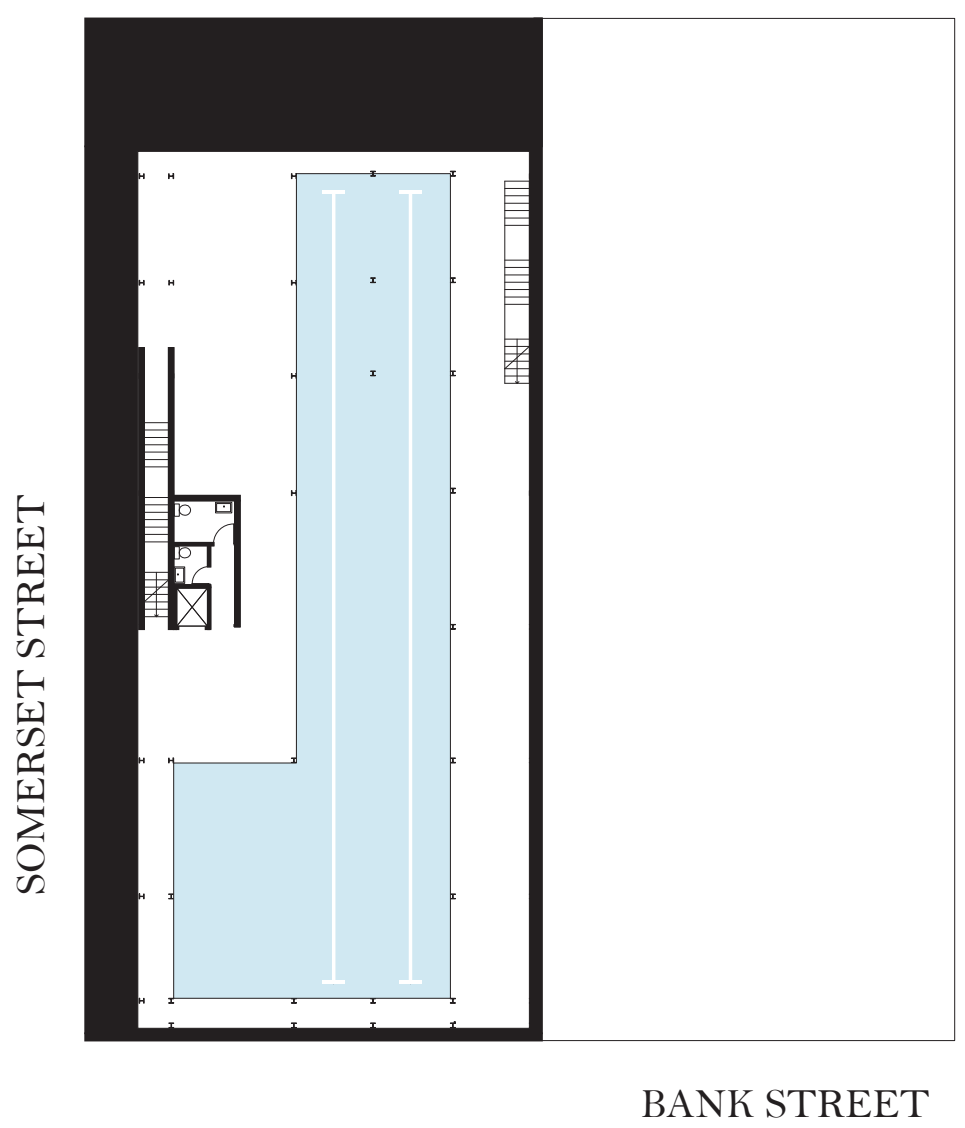

- FLOLR PLAN I:400

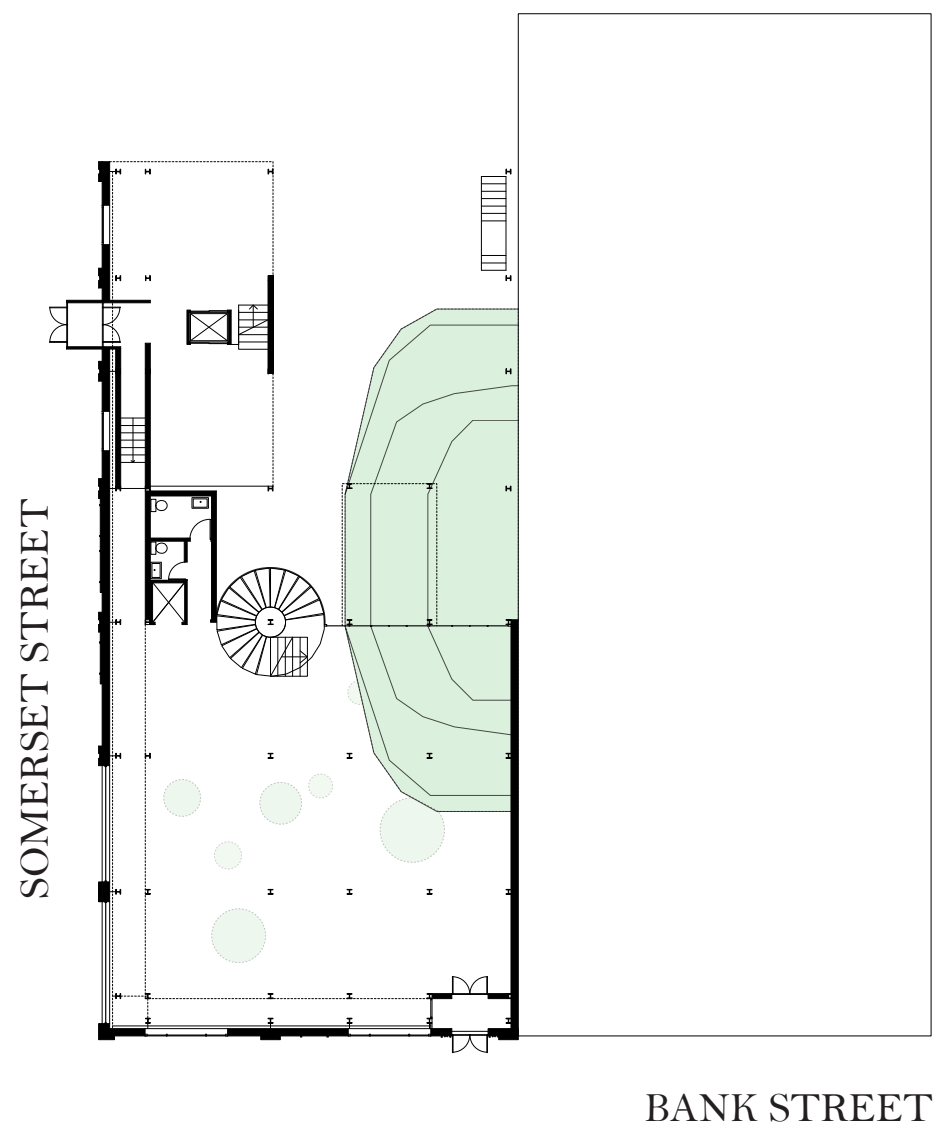

GRDUND FLOTR

PLAN I:400 


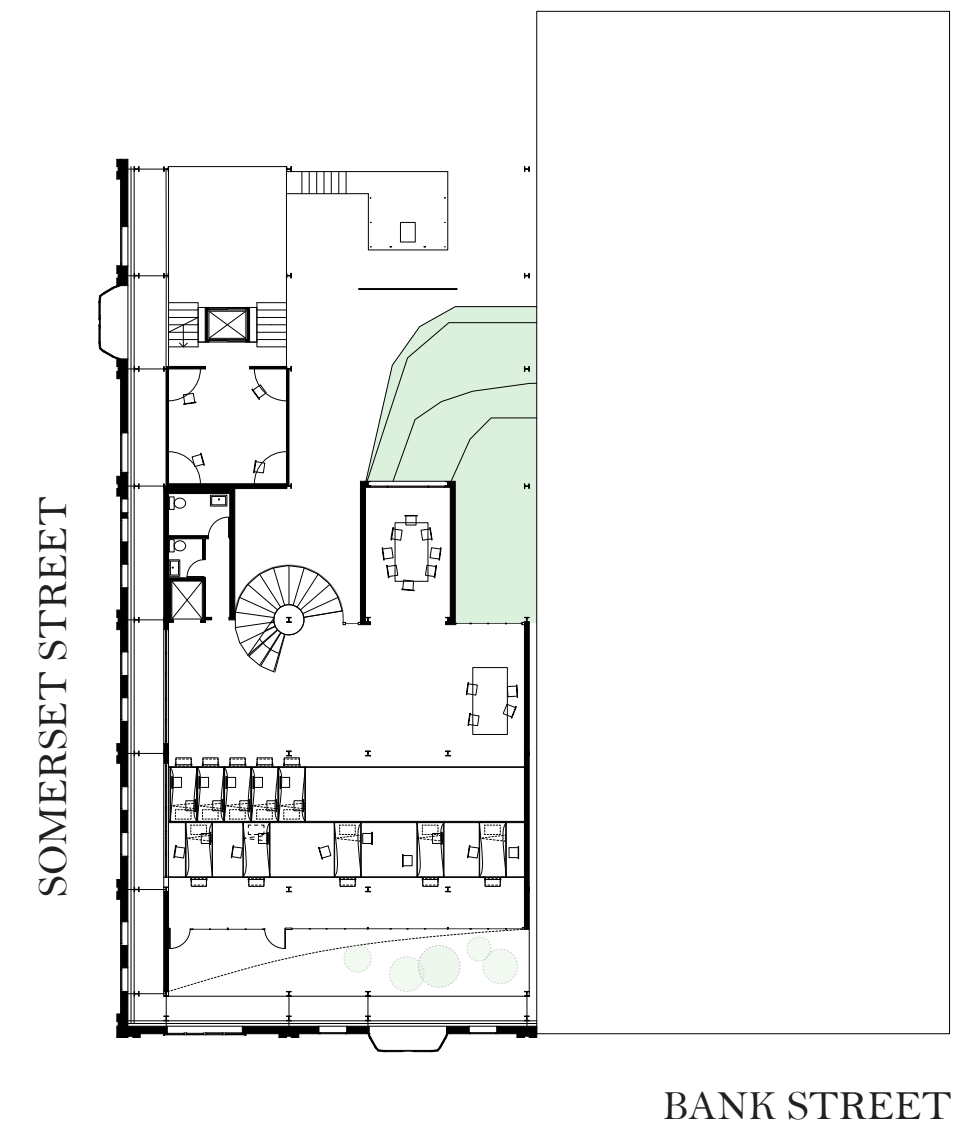

SECEND FLOUR PLAN 1:400

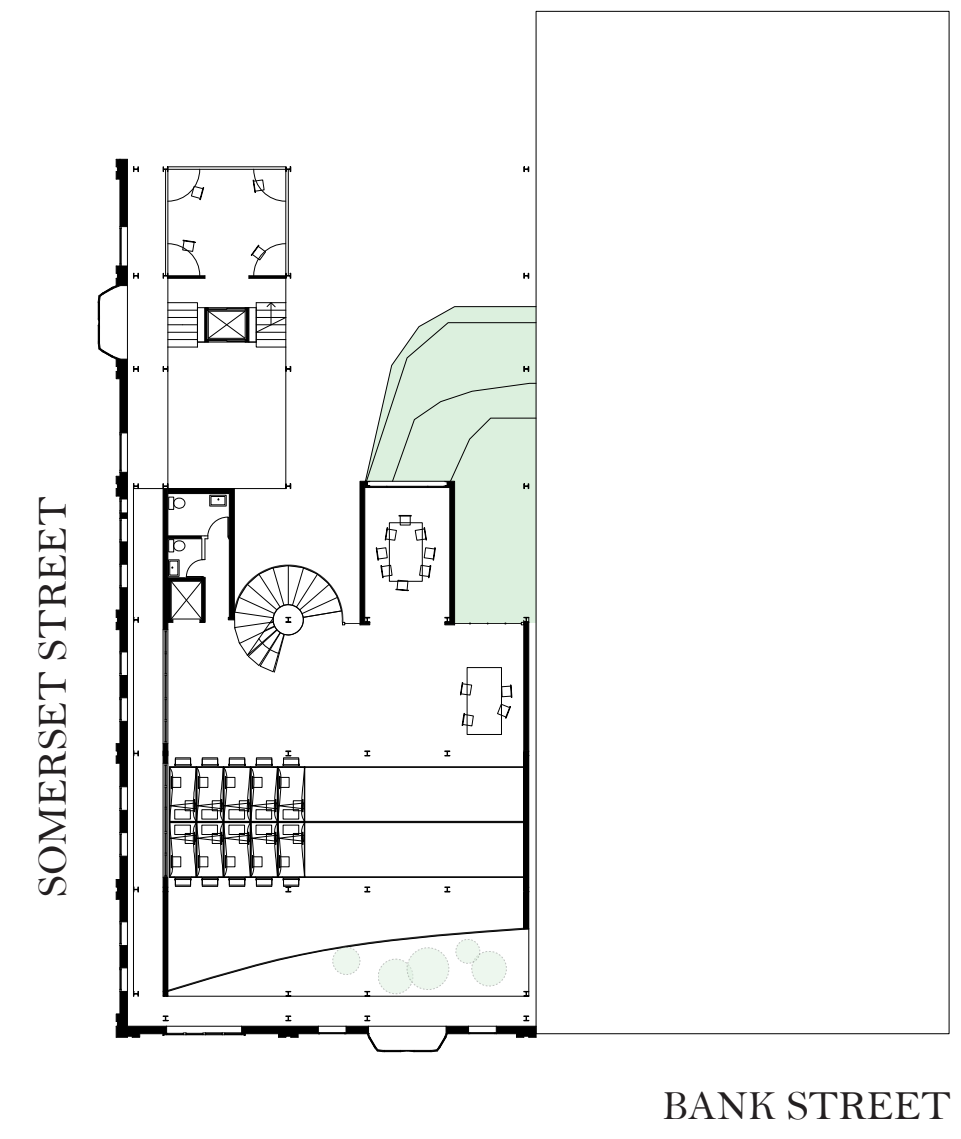

THIRD FLLOR

PLAN 1:400 


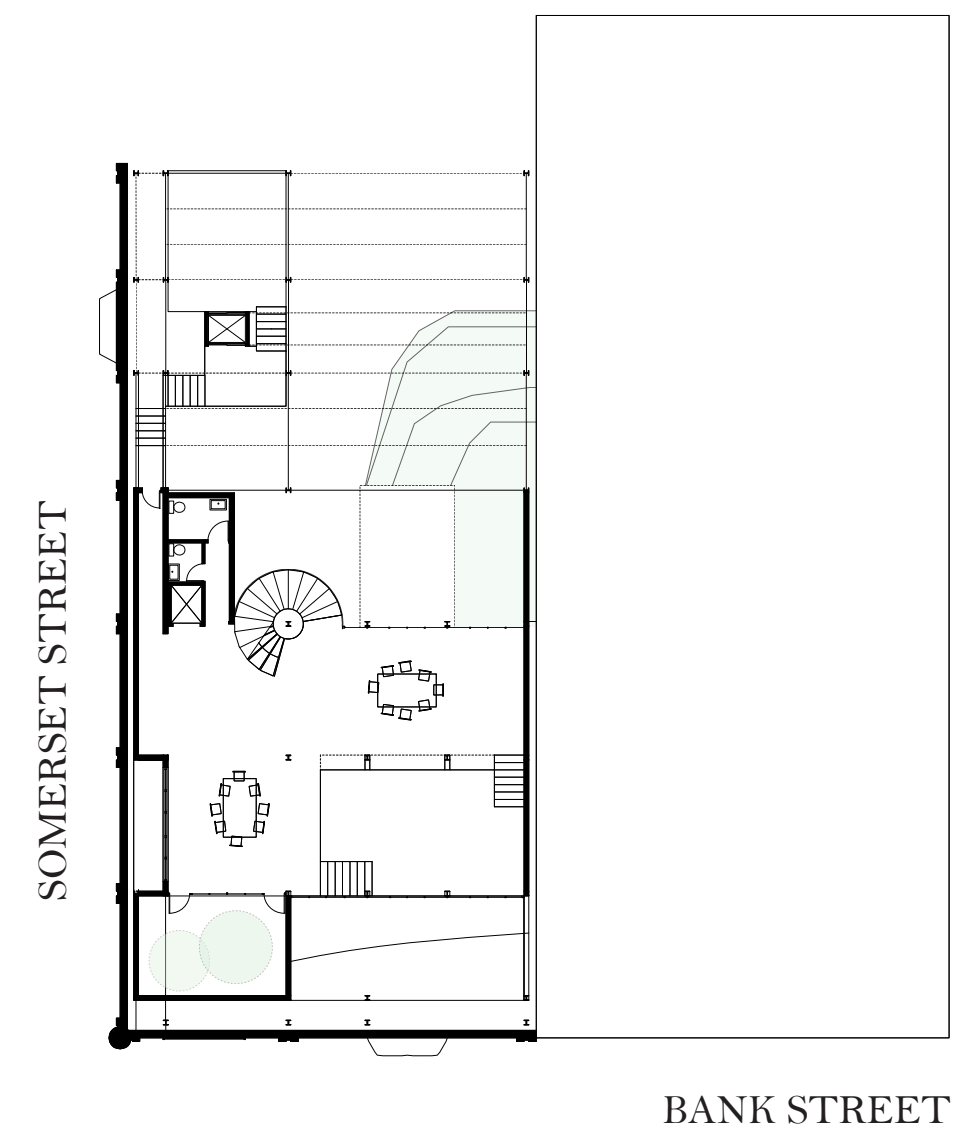

FQURTH FLORR

PLAN 1:400 
The new Somerset House is an eclectic enclave that has a concentrated mixture of a variety of phenomena existing not only in the urbanscape but also a hint of nature. Layers over layers, it is a cake bursting in flavor. Instead of stacking up or expanding the edge, the Somerset House intensifies inwards to form a dense mixture that contains-things that are expected, and things that are not. There are things that float like whimsical leaves in autumn with the uplift of wind, and there are things that root into the ground like an anchor to the ship. From micro to mega, within the physical boundary of Somerset House, the scale shifting between transient to permanent is a freedom generated by the occupants.

Buildings deteriorate at the rate determined by the material; however us, the inhabitants of the city keep the history alive and afloat. Somerset House is not the end of the story. In a city capable of constant regeneration, urban ruins are frequently constructed, creating many opportunities for speculative public engagement. The physical destruction due to material decay and 
structural impermanence is not a disadvantage to be pitiful upon. In fact, the degeneration is an upheaval generated from both the external and internal forces of the architecture, announcing that architecture is not only a static building but a generator of urban engagement.

By transforming the deteriorating Somerset House into a volume suitable for transient and stationery occupants both at once, such undervalued space can re-integrate back to the urbanscape by offering a greater functional space to its community than it used to present itself: an eyesore. Somerset House is not alone. The amount of undervalued space hidden or exposed in the city is countless. Imagine injecting multiple functions into all the undervalued space such as bus shelters and parking lots during their "off-hours": instead of sites that are much needed during daytime yet unwanted at night, spaces providing continuous services to the community will be far more beneficial in creating a ground where the urban inhabitants can engage and contribute to a mutual uplift. Just like the whale that leaps to keep itself alive, the urban inhabitants through enacting undervalued space in the city with their own actions are collectively pushing the city towards its "leaping moment": the upheaval. 


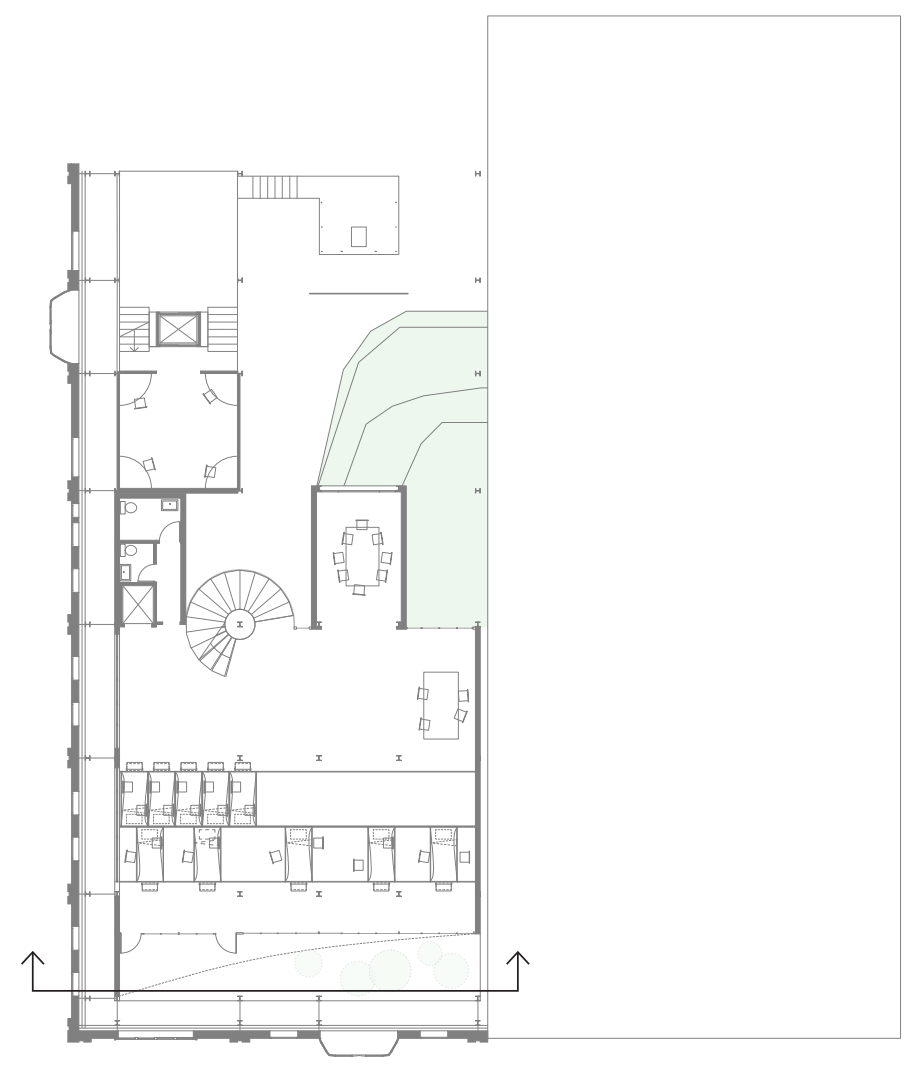

SECTIONAL PERSPECTIVE

VIEW FRDM

BANK STREET

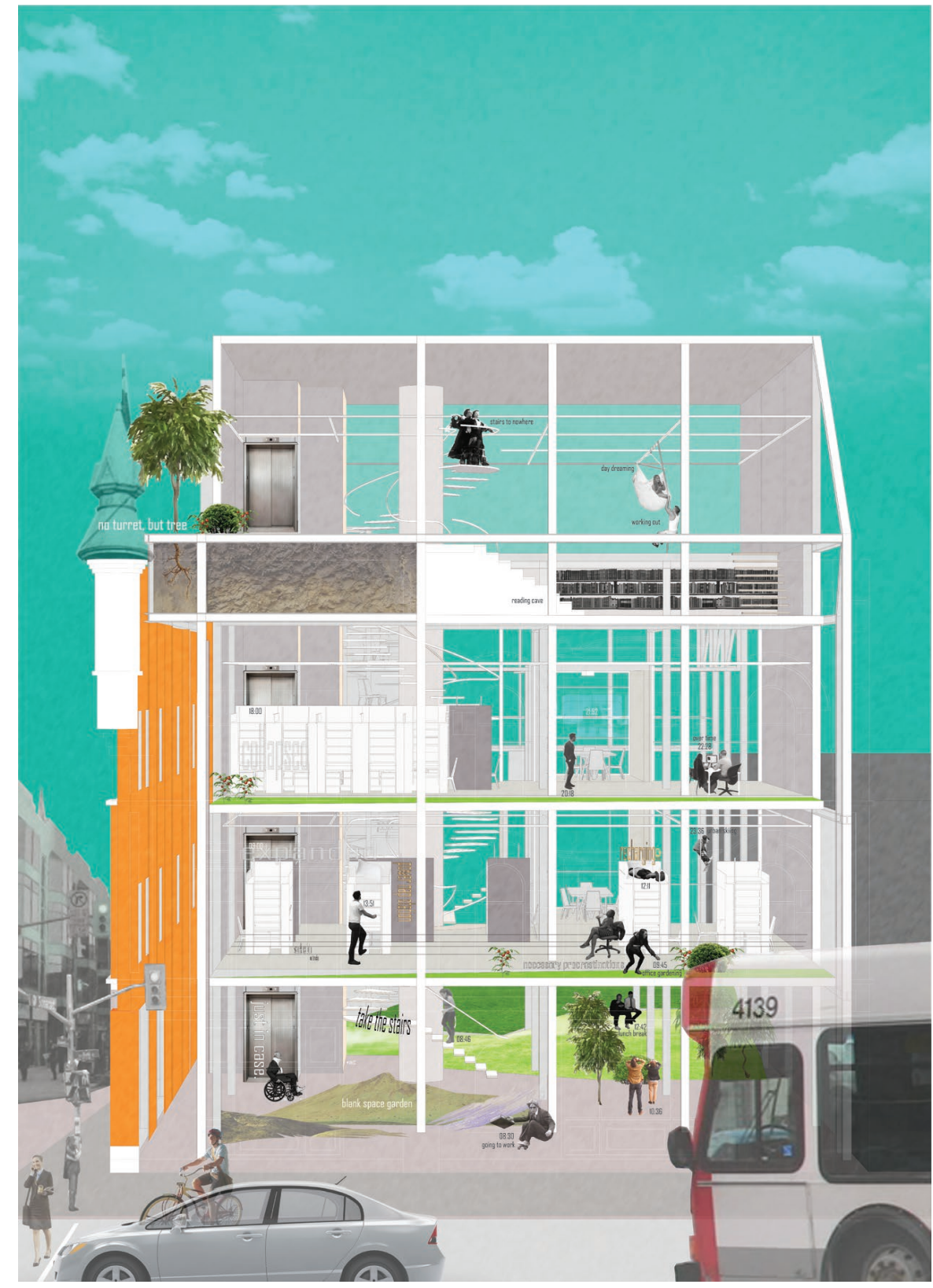




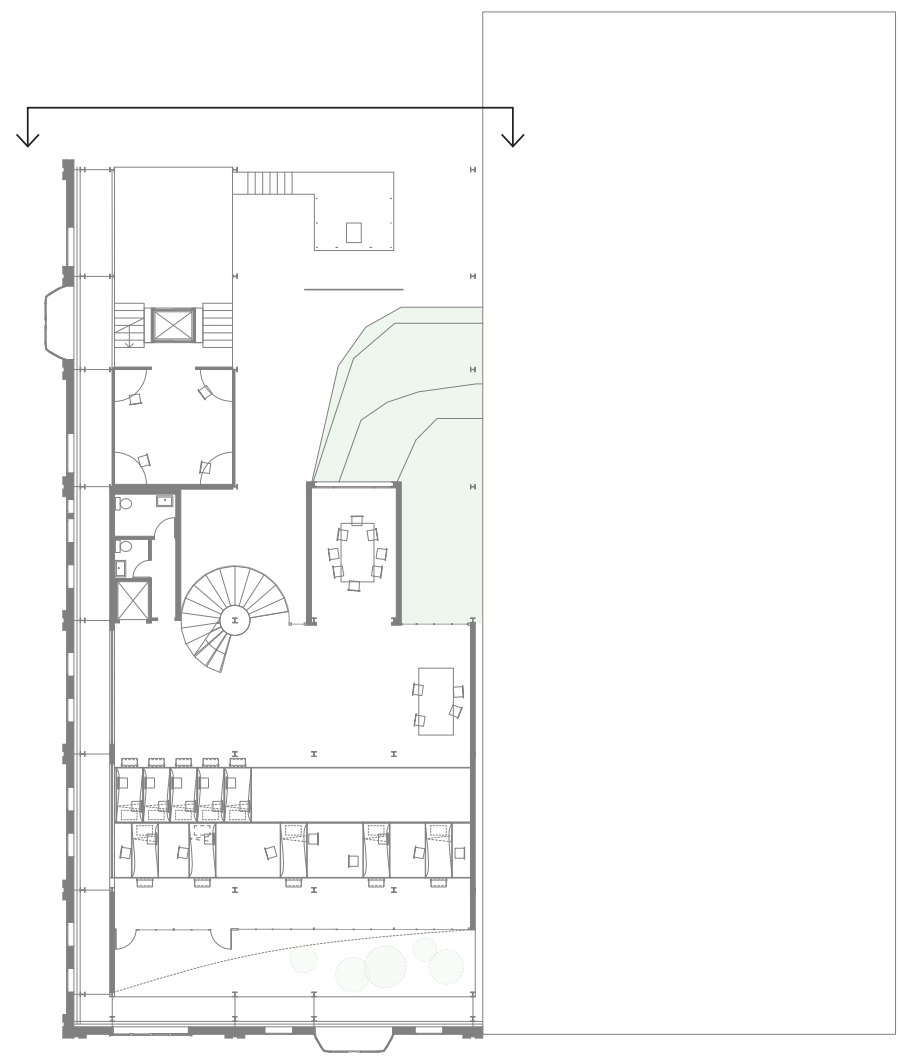

PERSPECTIVE

VIEW FRDM PARKING TOWARDS

BANK STREET

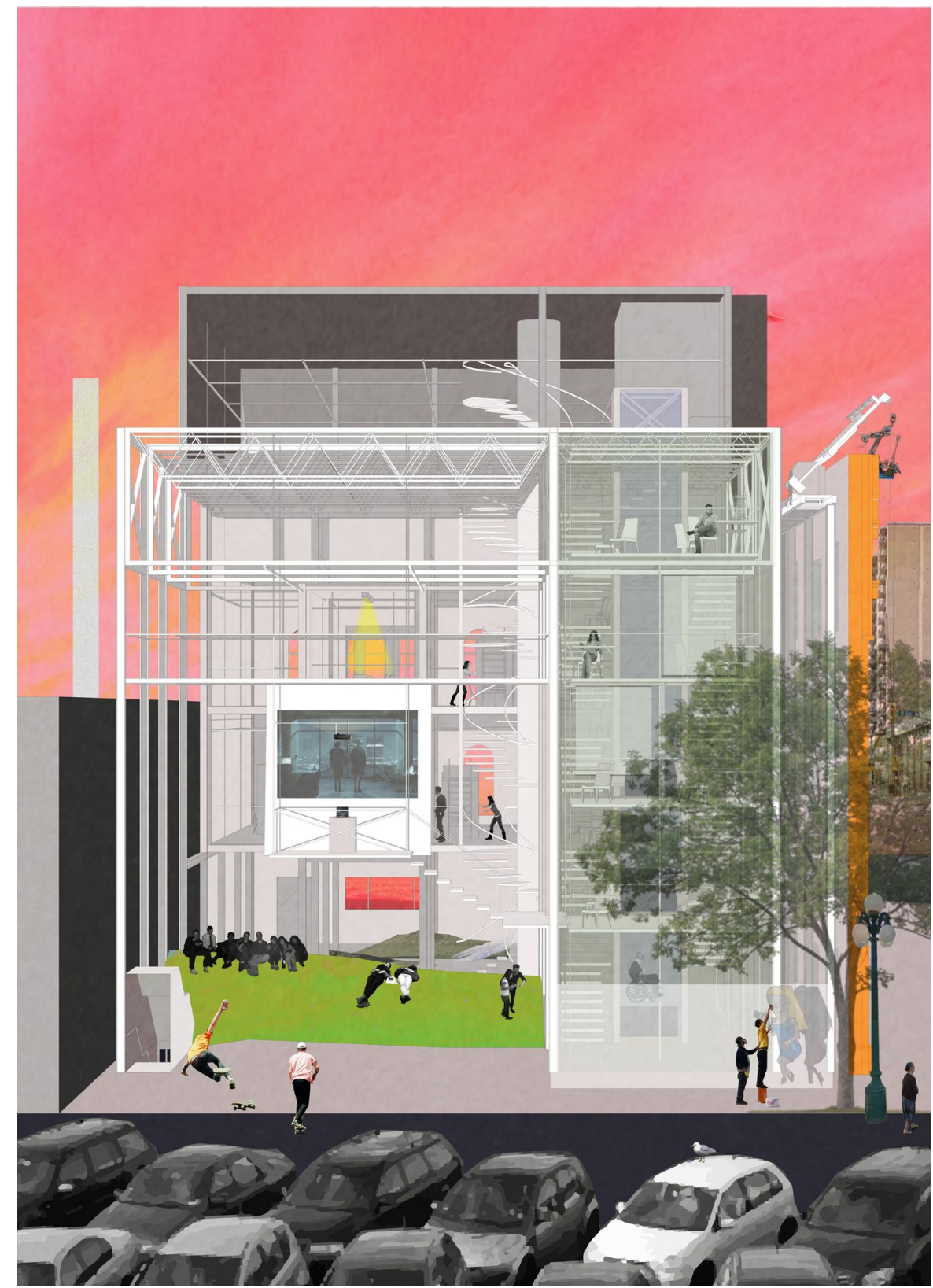




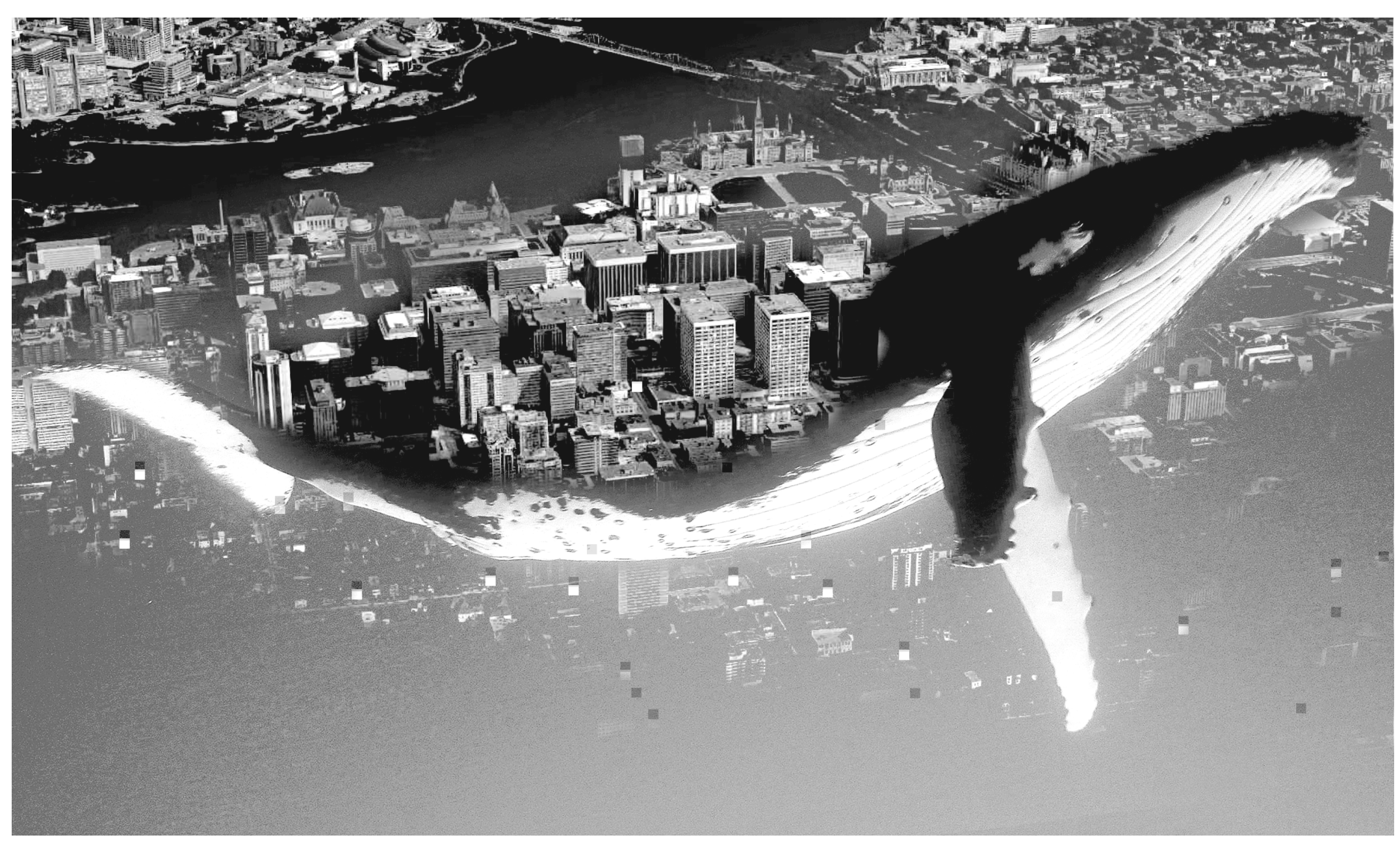

Keeping the City Afloat. 


\section{WORKS CITED}

Books

1. Deleuze, Gilles, and Felix Guattari. Thousand Plateaus: Capitalism and Schizophrenia. Univ Of Minnesota Press; 1 edition, 1987.

2. Easterling, Keller. Enduring Innocence. MIT, 2007.

3. - - Extrastatecraft: The Power of Infrastructure Space. Verso Books, 2014.

4. Hulshof, Michiel, and Daan Roggeveen. How the City Moved to Mr. Sun. SUN Publisher, 2010.

5. Prix, Wolf D. Get Off of My Cloud. Edited by Thomas Kramer and Martina Kandeler-Fritsch. Hatje Cantz Publishers, 2006.

6. Sadler, Simon. Archigram: Architecture without Architecture. MIT, 2005.

7. Zizek, Slavoj. The Year of Dreaming Dangerously. London: Verso Books, 2012.

Periodicals

1. Khan, Adella. "Somerset House seeks tenants." Centretown News, February 20, 2015: 1-2.

2. Prix, Wolf D. "On the Edge." Architectural Design Profile No.87, Deconstruction III, 1990: 60

Websites

1. Archdaily. Did the New World Trade Center Live Up to Its Expectations. October 4, 2014. http://www.archdaily. com/553708/did-the-new-world-trade-center-live-up-to-its-expectations/ (accessed October 4, 2014).

2. Architects, DUS. Bucky bar. 2012. http://www.dusarchitects.com/projects. php?categorieid=publicbuildings\&projectid=buckybar.

3. BBC News. Quick guide: China's economic reform. November 6, 2006. http://news.bbc.co.uk/2/hi/asiapacific/5237748.stm (accessed March 31, 2015).

4. BlouinArtinfo. David Chipperfield Deplores the "Impotence" of Contemporary Architecture at the London Design Festival. September 25, 2012. http://blogs.artinfo.com/objectlessons/2012/09/25/david-chipperfield-deploresthe-impotence-of-contemporary-architecture-at-the-Iondon-design-festival/ (accessed December 4, 2014)

5. Britannica Encyclepaedia. Special Economic Zone(SEZ). April 20, 2009. http://www.britannica.com/EBchecked/ topic/558530/special-economic-zone-SEZ (accessed October 27, 2015).

6. Bytown or Bust. A Digital History of Eastern Ontario and Western Quebec, Canada Including the Cities of Ottawa and Hull/Gatineau 1600 to 2014. http://www.bytown.net/ottawaname (accessed Janurary 17, 2015). 
7. Cairns, Stephen, and Jane M Jacobs. Buildings Must Die: A Perverse View of Architecture. MIT Press, 2014.

8. CNN. List of World Trade Center Tenants. http://edition.cnn.com/SPECIALS/2001/trade.center/tenants1.html. (accessed March 12, 2015).

9. Coop Himmelb(I)au. Architecture Must Blaze. http://www.coop-himmelblau.at/architecture/philosophy/ architecture-must-blaze (accessed September 21, 2014).

10. Designboom. Bernad Tschumi:advertisement for architecture. August 28, 2012. http://www.designboom.com/ architecture/bernard-tschumi-ads-for-architecture-2012-at-venice-biennale/ (accessed September 27, 2014).

11. Dezeen. 'Venice Architecture Biennale is exhausting bleak and boring' says Wolf D. Prix. August 30, 2012. http://www.dezeen.com/2012/08/30/venice-architecture-biennale-is-exhausting-bleak-and-boring-says-wolfd-prix (accessed November 17, 2014).

12. Eurasia Review. Kashgar: the next economic booming hub. June 28, 2014. http://www.eurasiareview. com/28062013-kashgar-the-next-economic-booming-hub-analysis/ (accessed November 30, 2014).

13. Foucault, Michel. "Des Espace Autres." Architecture/Movement/Continue, October 1984

14. La Biennale. 13th International Architecture Exhibition. http://www.labiennale.org/en/architecture/ archive/13th-exhibition/13iae/.

15. New York Times. To Protect an Ancient City, China Moves to Raze It. May 27, 2009. http://www.nytimes com/2009/05/28/world/asia/28kashgar.html?_r=0 (accessed March 12, 2015).

16. The Guardian. Chief Imam at Kashgar Mosque Stabbed to Death as Violence surges in Xinjiang. July 31, 2014 http://www.theguardian.com/world/2014/jul/31/china-jume-tahir-imam-kashgar-xinjiang-mosque-stabbeddeath-violence (accessed October 27, 2014).

17. - Chinese authorities tighten security in Xinjiang region after surge in violence. July 30, 2014. http://www. theguardian.com/world/2014/jul/30/chinese-tighten-security-xinjiang-violence-uighur-muslim-minority accessed October 27, 2014)

18. The Ottawa Citizen. The House They Called Home. December 7, 2009. http://www.canada.com/story print. html?id=6e3f7abf-0dd9-4239-be25-7d2338644070\&sponsor= (accessed Janurary 17, 2015).

19. TIME. 1 World Trade Center: TIME's View From The Top of NYC. 2014. http://time.com/world-trade-center/ (accessed November 17, 2014)

20. Tschumi, Bernard. Advertisement for Architecture. 1966-1967. http://www.tschumi.com/projects/19/.

21. Yahoo. Umbrella Revolution Ex/pained. http://news.yahoo.com/katie-couric-now-i-get-it-umbrellarevolution-175949877.html. 